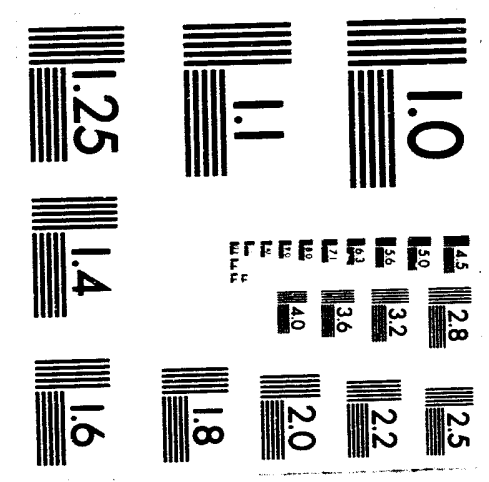



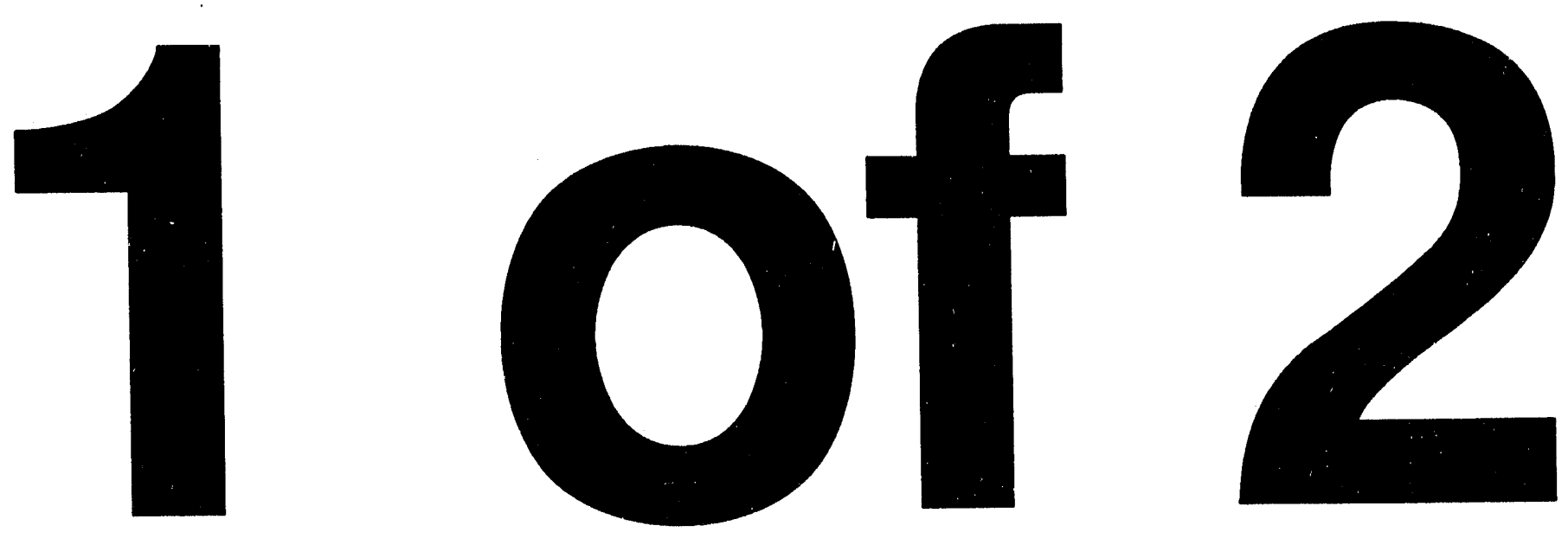
LBL 34909

\title{
Microstructural Development and Mechanical Behavior of Eutectic \\ Bismuth-Tin and Eutectic Indium-Tin in Response \\ to High Temperature Deformation
}

\author{
Julia L. Freer Goldstein
}

Ph.D. Thesis

\section{Department of Materials Science and Mineral Engineering \\ University of California}

and

\author{
Center for Advanced Materials \\ Materials Sciences Division \\ Lawrence Berkeley Laboratory \\ University of California \\ Berkeley, CA 94720
}

November 1993

This work was supported by the Director, Office of Energy Research, Office of Basic Energy Science, Materials Science Division of the U.S. Department of Energy under Contract No. DE-AC03-76F00098 
Microstructural Development and Mechanical Behavior of Eutectic Bismuth-Tin and Eutectic Indium-Tin in Response to High Temperature Deformation

\section{Copyright 1993}

by

\section{Julia Lauren Freer Goldstein}

The U. S. Department on Energy has the right to use this document for any purpose whatsoever, including the right to reproduce all or any part thereof 
Microstructural Development and Mechanical Behavior of Eutectic Bismuth-Tin and Eutectic Indium-Tin in Response to High Temperature Deformation

by

Julia Lauren Freer Goldstein

\begin{abstract}
The mechanical behavior and microstructure of eutectic $\mathrm{Bi}-\mathrm{Sn}$ and $\mathrm{In}-\mathrm{Sn}$ solders were studied in parallel in order to better understand high temperature deformation of these alloys. Bi-Sn solder joints were made with $\mathrm{Cu}$ substrates, and $\mathrm{In}-\mathrm{Sn}$ joints were made with either $\mathrm{Cu}$ or $\mathrm{Ni}$ substrates. The as-cast microstructure of $\mathrm{Bi}-\mathrm{Sn}$ is complex regular, with the two eutectic phases interconnected in complicated patterns. The as-cast microstructure of In-Sn depends on the substrate. In-Sn on $\mathrm{Cu}$ has a non-uniform microstructure caused by diffusion of $\mathrm{Cu}$ into the solder during sample preparation, with regions of the Sn-rich $\gamma$ phase imbedded in a matrix of the In-rich $\beta$ phase. The microstructure of In-Sn on $\mathrm{Ni}$ is uniform and lamellar and the two phases are strongly coupled.

The solders deform non-uniformly, with deformation concentrating in a band along the length of the sample for $\mathrm{Bi}-\mathrm{Sn}$ and $\mathrm{In}-\mathrm{Sn}$ on $\mathrm{Cu}$, though the deformation is more diffuse in In-Sn than in Bi-Sn. Deformation of In-Sn on Ni spreads throughout the width of the joint. The different deformation patterns affect the shape of the stress-strain curves. Stress-strain curves for $\mathrm{Bi}-\mathrm{Sn}$ and $\mathrm{In}-\mathrm{Sn}$ on $\mathrm{Cu}$ exhibit sharp decays in the engineering stress after reaching a peak. Most of this stress decay is removed for In-Sn on $\mathrm{Ni}$.

The creep behavior of In-Sn also depends on the substrate, with the creep deformation controlled by the soft $\beta$ phase of the eutectic for $\mathrm{In}-\mathrm{Sn}$ on $\mathrm{Cu}$ and controlled by the harder $\gamma$ phase for In-Sn on Ni. When In-Sn on Ni samples are aged, the microstructure coarsens and changes to an array of $\gamma$ phase regions in a matrix of the $\beta$ phase, and the creep
\end{abstract}


behavior changes to resemble that of $\mathrm{In}-\mathrm{Sn}$ on $\mathrm{Cu}$. The creep behavior of $\mathrm{Bi}-\mathrm{Sn}$ changes with temperature. Two independent mechanisms operate at lower temperatures, but there is still some question as to whether one or both of these, or a third mechanism, operates at higher temperatures. 


\section{ACKNOWLEDGMENTS}

There are many people who have been helpful to me during my graduate education and deserve recognition. However, I might not have even gotten started were it not for the support of my parents, Siephan and Sofia Freer. Their strong belief in the value of education and hard work has been a guiding force in my life. I grew up believing that I could do anything I wanted to, thanks to them. I would also like to thank Professor Joseph King of Harvey Mudd College for introducing me to materials science, a field I had never heard of when I entered college. I thank my husband, Martin Goldstein, for his support and encouragement and for not letting me give up.

The first person I must acknowledge for support during my education at UC Berkeley is my advisor, Professor J. W. Morris, Jr. Without his offer of a research assistantship in 1990 I probably would not have been able to continue on to the Ph.D. I would like to thank him for giving me the freedom to pursue a research project of my own choosing while also providing the guidance that enabled me to complete it. The members of Professor Morris' research group have been very helpful, as is the nature of the group. In particular, Zequn Mei has offered valuable advice and discussions numerous times throughout the past several years. Many Morris group members have offered suggestions, proofread my publications and/or this dissertation, and just been there to discuss research or anything else. Thank you all. For specific technical support I thank Choong-un Kim for performing DSC tests and Ferdinand Bartels for x-ray diffraction analysis of several samples. I must also thank Professors Robert O. Ritchie and David A. Dornfeld for serving on my dissertation committee and for their helpful comments. 
The alloys used in this research, Indalloy $1 \mathrm{E}$ and Indalloy 281 , were provided by the Indium Corporation of America. In particular, I thank John Ferriter at the Indium Corporation for his effort in obtaining the alloys. This research was supported by the Director, Office of Energy Research, Office of Basic Energy Science, Materials Science Division of the U.S. Department of Energy under Contract No. DE-AC03-76F00098 


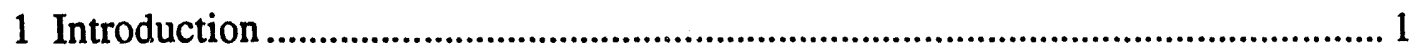

2 Background ............................................................................................... 3

2.1 Eutectic Microstructures ....................................................................... 3

2.1.1 Normal Eutectics ..................................................................... 3

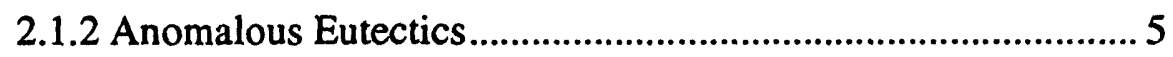

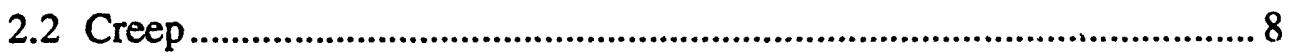

2.2.1 Stages of Creep Deformation .................................................. 8

2.2.2 Creep Mechanisms ................................................................ 9

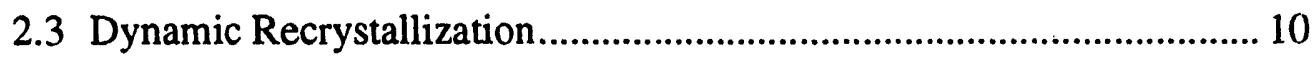

2.3.1 Nucleation Mechanisms ....................................................... 10

2.3.2 Methods of Measurement....................................................... 11

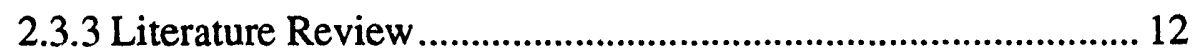

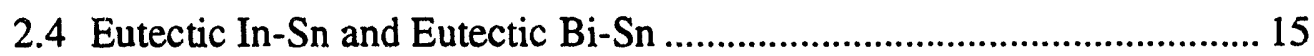

2.4.1 Phase Diagrams and Eutectic Phases ..................................... 15

2.4.2 Literature Review of Mechanical Properties............................. 16

3 Experimental Details ...................................................................................... 19

3.1 Sample Description ......................................................................... 19

3.2 Mechanical Testing ................................................................................ 21

3.3 Metallography and Microscopy .......................................................... 22

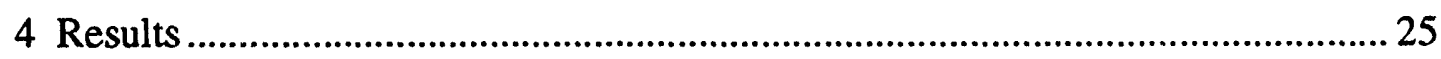

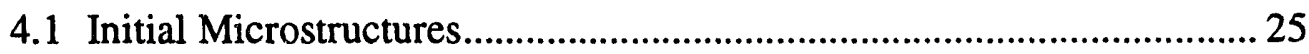

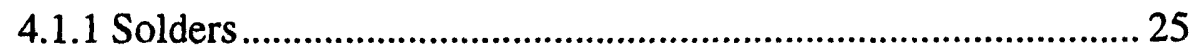

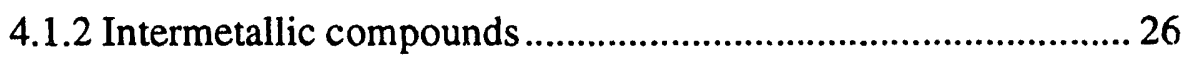

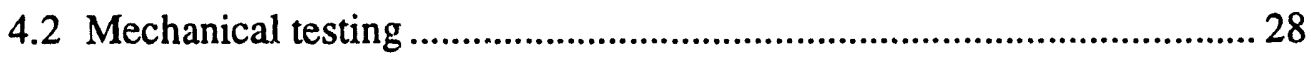

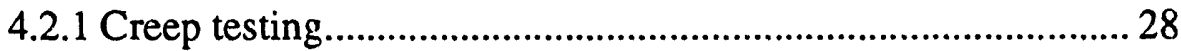

4.2.1.1 Shape of creep curves for Bi-Sn and In-Sn ............... 28

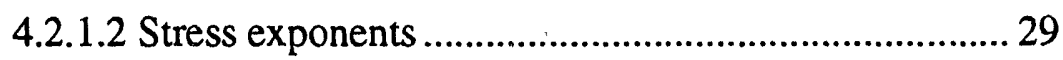

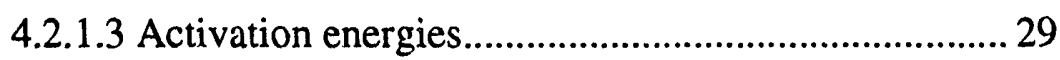

4.2.2 Constant Strain Rate Testing.................................................... 30 
4.2.2.1 Shape of Stress-Strain Curves .................................... 30

4.2.2.2 Relation to Creep Data ............................................. 30

4.2.3 Comparison to $\mathrm{Sn}-\mathrm{Pb}$............................................................ 31

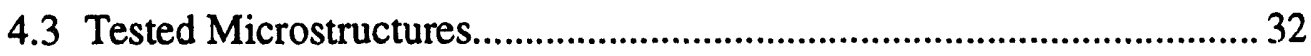

4.3.1 Eutectic Bi-Sn ................................................................... 32

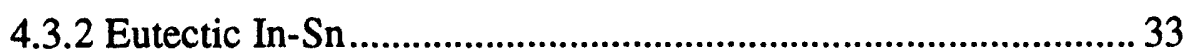

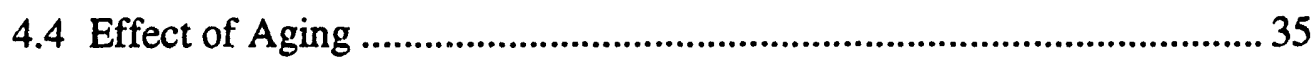

4.4.1 Aged Microstructures............................................................. 35

4.4.2 Mechanical Properties .............................................................. 36

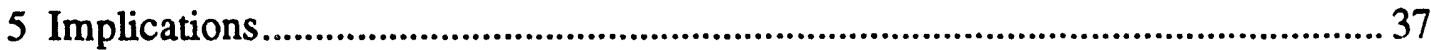

5.1 The Effect of Substrate on In-Sn ........................................................ 37

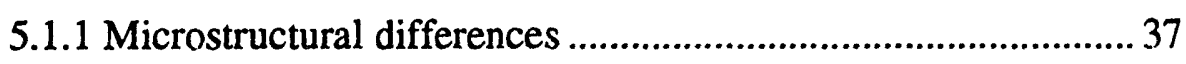

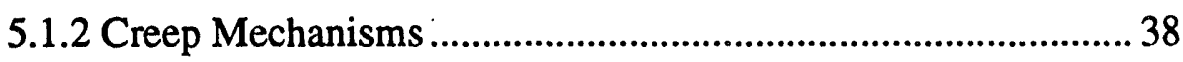

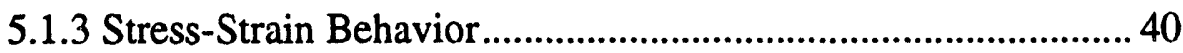

5.1.4 Aging of In-Sn......................................................................... 41

5.2 Microstructure and Deformation of Bi-Sn ............................................ 41

5.2.1 As-Cast Microstructure .............................................................. 41

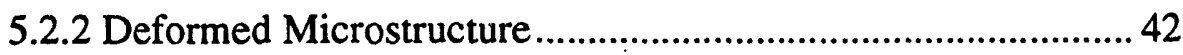

5.2.3 Creep Behavior......................................................................... 43

5.3 Deformation Patterns .......................................................................... 44

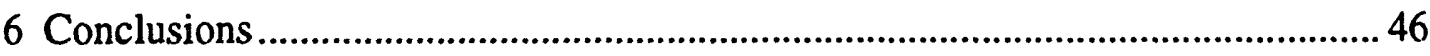

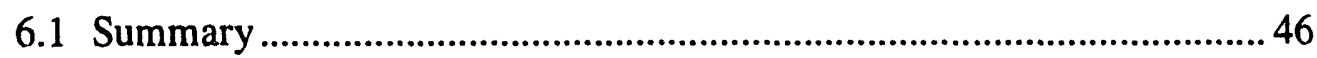

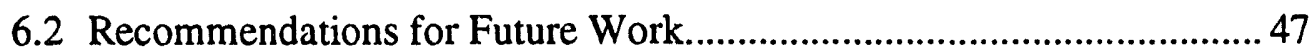

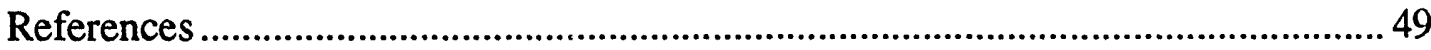




\section{INTRODUCTION}

In the past several years, interest in lead-free solder alloys has been heightened by threats of a congressional ban on lead in microelectronics. If such a ban were implemented, alternatives to the traditional tin-lead $(\mathrm{Sn}-\mathrm{Pb})$ solders would be needed. The usefulness of lead-free solders extends beyond the environmental concerns. There is also a need for lower melting solders, for applications such as step soldering, or for soldering electronic components that are particularly sensitive to temperature. Much of the research done on solder alloys has involved $\mathrm{Sn}-\mathrm{Pb}$ alloys, commonly of eutectic or near-eutectic composition. There is a need to understand the behavior of lead-free solders to aid engineers in solder selection.

The criterion for choosing solder alloys for this study was that they be binary eutectics with melting points below $200{ }^{\circ} \mathrm{C}$. Eutectic alloys with significant volume fractions of each phase were preferred, since ile standard $\mathrm{Sn}-\mathrm{Pb}$ eutectic consists of approximately equal volume fractions of each phase. Both the indium-tin (In-Sn) and bismuth-tin (Bi-Sn) systems fit these criteria. They are classified as low-temperature specialty solders, with melting points significantly below that of eutectic $\mathrm{Sn}-\mathrm{Pb}$.

Since solder alloys have low melting points, they are invariably used at high homologous temperatures, well over one-half of the absolute melting point. This has the consequence that creep deformation is important in any situation in which the alloy must support a load. The small solder joints used in electronic packaging are exposed to significant stresses, and therefore the mechanical integrity of the solder is crucial. Real solder joints experience complicated loading, in which creep and fatigue occur simultaneously. In order to obtain fundamental understanding of the way in which solders deform it is helpful to consider only one deformation mode at a time. The current 
study focuses on creep, with a goal of learning more about how In-Sn anci Bi-Sn solders respond to high temperature deformation.

Interesting microstructural changes have been observed in $\mathrm{Sn}-\mathrm{Pb}$ solder joints subjected to creep, $1,2,3$ isothermal fatigue, $3,4,5$ and thermal fatigue $3,6,7$ in shear. Under all types of deformation, the joints deformed inhomogeneously, and localized coarsening occurred in regions of concentrated shear deformation, in a band along the length of the joint. These coarsened bands had an equiaxed, recrystallizea microstructure which was softer than the as-cast lamellar microstructure in the rest of the joint. Once recrystallization was initiated in the highly deformed regions it could propagate easily along the length of the joint, further softening it and accelerating failure.

The primary goal of this research was to gain knowledge about the high temperature deformation behavior of $\mathrm{Bi}-\mathrm{Sn}$ and $\mathrm{In}-\mathrm{Sn}$ eutectics and relate it to the microstructure. This was accomplished by investigating the mechanical behavior and microstructure in parallel, with the objective that microstructural information could provide additional insight into deformation mechanisms.

The microstructures of the alloys were examined before and after testing, in order to compare the as-cast microstructures and then to observe how the microstructures responded to deformation. Of particular interest was whether the type of microstructural changes observed in $\mathrm{Sn}-\mathrm{Pb}$ could occur in $\mathrm{In}-\mathrm{Sn}$ or $\mathrm{Bi}-\mathrm{Sn}$, and if so what factors influenced such changes. The alloys were deformed and creep behavior determined as a function of stress and temperature, and these data were combined with microstructural information to propose possible mechanisms of deformation. 


\section{BACKGROUND}

\subsection{Eutectic Microstructures}

Eutectic alloys can form between two, three, or even more components. This discussion will focus on binary eutectics. The region in temperature-composition space on a binary phase diagram in which a eutectic structure is stable is called the coupled zone. Both phases grow together in a coupled fashion. Growth outside the coupled zone will result in the formation of pro-eutectic phases in addition to the eutectic structure. The two phases which make up the binary eutectic can be either faceted or non-faceted. Faceted phases grow by adding layers in steps, with the growth rate highly dependent on crystallographic orientation. This has the consequence that particles develop simple geometric shapes. ${ }^{8}$ Non-faceted phases exhibit dendritic growth, with the common treelike shape caused by instabilities along the dendrite sten that lead to subsequent branching.

Eutectic alloys can possess a wide variety of microstructures, depending on the alloy system and processing conditions. Eutectics are generally classified as either normal or anomalous. Normal eutectics solidify in either a lamellar microstructure, consisting of alternating plates of the two phases, or as rods of the minor phase in a matrix of the major phase. The microstructure of anomalous eutectics is much more varied and depends strongly on solidification conditions. Various possible microstructures will be described in section 2.1.2.

\subsubsection{Normal Eutectics}

The most extensively studied eutectic systems are those which solidify into normal eutectic structures. These are alloys in which both phases are non-faceting and have similar melting points. The coupled zone is symmetric about the eutectic composition, so that growth is within the coupled zone for any degree of undercooling. Also, pro-eutectic 
phases will only torm in alloys of off-eutectic composition. Often, specific crystallographic relationships exist between adjacent lamellae of the two phases. Several crystallographic relationships are usually possible between the phases, and any of these may occur in a given system. The $\mathrm{Sn}-\mathrm{Pb}$ system is an example of a normal eutectic.

Various models have been proposed to relate the inter-lamellar spacing of lamellar eutectics to the undercooling and growth velocity. The most commonly used model is an analysis by Jackson and Hunt. 9 They obtained an approximate solution to the diffusion and solute flow equations at the liquid-solid interface for the case of uniform lamellar spacing and a planar interface. They imposed periodic boundary conditions and assumed any fluctuations from the eutectic composition to be negligible. The resultant equation relating the undercooling $(\Delta T)$, growth velocity $(v)$ and inter-lamellar spacing $(\lambda)$ was of the form:

$$
\Delta \mathrm{T}=\mathrm{a}_{1} v \lambda+\mathrm{a}_{2} / \lambda
$$

where $a_{1}$ and $a_{2}$ are coefficients that depend on eutectic composition and the exact shape of the liquid-solid interface. This equation does not give a unique inter-lamellar spacing for given solidification conditions, but rather a range for which growth is stable. It has been suggested that growth will occur at the extrema of the v versus $\lambda$ or $\Delta T$ versus $\lambda$ plots, and that $\lambda$ can be adjusted to this value by the motion of lamellar faults, similar geometrically to the climb of an edge dislocation. Measurement of the parameter $\lambda^{2} v$ for various systems has shown that growth indeed does occur at the extrema. Lamellar fault motion has also been observed.

Regular eutectics with the volume fraction of the minor phase below a particular value will solidify in a rod morphology. The exact value at which this occurs depends on growth velocity and undercooling, as well as any anisotropy in interfacial free energies of the system. For the $\mathrm{Sn}-\mathrm{Pb}$ system, the transition to a rod morphology has been observed in off-eutectic alloys with the volume fraction of lead equal to $0.18,10$ which corresponds to a weight fraction of 0.25 . 


\subsubsection{Anomalous Eutectics}

Anomalous eutectics form in systems in which at least one of the phases is capable of faceting. In this case the coupled zone is asymmetric, such that growth is not necessarily coupled at the eutectic composition. Primary phases may grow in alloys of eutectic composition, depending on the amount of undercooling.

A thermodynamic analysis by Jackson for growth of pure components showed that faceting will occur when the entropy of fusion is greater than $16.8 \mathrm{~J} / \mathrm{mol}-\mathrm{K} .{ }^{11}$ High entropies are typical of metalloids such as gallium, antimony, bismuth, and arsenic. Most metals have much lower entropies of fusion. Jackson's analysis does not include factors such as undercooling and interface orientation, both of which affect a material's tendency to facet.

Cahn ${ }^{12}$ related faceting to undercooling in the following manner. The free energy of the liquid-solid interface is assumed to be periodic in position with a period related to the lattice spacing of the solid. There is therefore an energy barrier to be overcome in moving from one atomic position to the next. If the undercooling is low, there will not be sufficient driving force to overcome the barrier and continuous interface motion will not be possible, leading to a stepped, or faceted interface. Larger undercoolings allow for continuous interface movement and give a diffuse, non-faceted interface. This theory predicts that any material will facet given small enough undercooling. However, the critical undercooling for many metals is so low (much less than $1{ }^{\circ} \mathrm{C}$ ) that faceting will not be observed under real solidification conditions.

The above analyses have considered single components. For eutectic alloys the situation is similar, with the entropy of solution replacing the entropy of fusion as the condition for faceting. ${ }^{13}$ However, it is possible for an alloy of two non-faceting components to be capable of faceting. For example, neither pure aluminum nor pure tin facets, but at the eutectic composition of the Al-Sn system the Al-rich phase can facet. In general, phases with an entropy of solution greater the $23 \mathrm{~J} / \mathrm{mol}-\mathrm{K}$ will exhibit faceting. ${ }^{14}$ 
As mentioned earlier, a variety of microstructures can form in anomalous eutectics. According to Elliott, ${ }^{8}$ the type of structure that will form in a given situation can be predicted based on the volume fraction of the faceting phase and growth velocity, though anisotropy of the inter-phase boundary energy, thermal conductivity anisotropy, and variations in growth rate with crystallographic orientation are also important. Several possible microstructures will now be described.

When the volume fraction of the faceting phase $\left(v_{f}\right)$ is below about 10 percent, a broken lamellar structure forms. This is a regular array of plates which branch and split in the lamellar plane and thus appear "broken" in projection. For $v_{f}$ between 20 and 40 percent, a structure called complex regular exists for a certain range of the entropy of solution. Eutectic Bi-Sn often solidifies in a complex regular structure. The complex regular structure is cellular and is regular within cells but irregular between them. Cell boundaries are often well-defined spines, which in bismuth alloys is a right-angled pyramid with three bismuth $(100)$ plates joined at a $<111>$ axis. ${ }^{15}$ Lamellae of bismuth and tin grow out perpendicularly from these $(100)$ plates and then usually diverge. An example of this is shown in Figure 2.1. In general, the shape and size of complex regular cells varies with amount of constitutional undercooling, which increases as the temperature gradient in the liquid (and therefore the cooling rate) decreases. At higher volume fraction and high growth velocities, the quasi-regular structure forms in systems such as $\mathrm{Bi}-\mathrm{Sn}, \mathrm{Sb}-\mathrm{InSb}$, and $\mathrm{Sb}-\mathrm{ZnSb} .{ }^{15}$ It often consists of a combination of plates and rods.

Anomalous microstructures can be modified by solidifying at high growth rates or by adding impurities. When the complex regular structure becomes modified, the faceted cells disappear and dendrites of the non-faceting phase may form. The structure becomes lamellar or fibrous rather than cellular. One study on bismuth eutectics ${ }^{16}$ reported modified structures with additions of alkali metals, which chemisorb on the bismuth phase. This adsorption lowers the eutectic growth temperature, and cell formation is 
suppressed since growth of the eutectic at this temperature is coupled. Also, dendrites of the non-faceting phase (tin, in the case of $\mathrm{Bi}-\mathrm{Sn}$ ) grow faster than the eutectic at the lower temperature and therefore dendrites grow ahead of the eutectic front.

Sundquist, Bruscato and Mondolfo ${ }^{17}$ suggest that the presence or absence of impurities that can nucleate either of the eutectic phases is the determining factor for predicting whether an anomalous eutectic will form. For a binary eutectic with phases $\alpha$ (A-rich) and $\beta$ (B-rich), a normal eutectic will form when phase $\alpha$ nucleates phase $\beta$ (or vice-versa). An anomalous eutectic will form if both $\alpha$ and $\beta$ are nucleated by impurities in the melt. In the extreme case, all the liquid will solidify into a structure of primary $\beta$ crystals surrounded by haloes of the $\alpha$ phase, and the structure will be degenerate, with no coupling between the phases. This model is based on the fact that the phase with the lowest required undercooling will nucleate, and that the undercooling for nucleation of the eutectic may be greater or less than the undercooling for nucleation of $\alpha$ primary phase by impurities, depending on the system and the nature of the impurities.

The following example is based on the work of Mondolfo. ${ }^{18}$ Assume that primary $\alpha$ solidifies first, nucleated by impurity $\mathrm{X}$. The solidification raises the temperature of the liquid, which must now decrease before subsequent solidification. As the temperature drops, the composition of the liquid moves along the extension of the liquidus line, toward increasing concentration of $B$. If no impurities are present which can nucleate $\beta$, $\beta$ will eventually be nucleated by $\alpha$ and a normal eutectic will form. If an impurity $Y$ is present which nucleates $\beta$ at a lower undercooling than the nucleation of $\beta$ by $\alpha, \beta$ will be nucleated by $\mathrm{Y}$ and the eutectic will be anomalous. If the cooling rate of a eutectic is slow enough, solidification in the presence of impurities can result in a eutectic with both normal and anomalous regions. Assume an impurity is present which can form a ternary intermetallic compound with the eutectic components. During slow cooling the impurity can segregate and freeze into small crystals of the intermetallic compound within the melt which nucleate the $\alpha$ phase. Locally the concentration of $A$ is depleted and $\beta$ halos form 
around the primary $\alpha$. In regions far removed from the localized impurities, nucleation of $\beta$ by $\alpha$ can occur, resulting in a normal eutectic. In systems in which the $\alpha$ phase naturally grows faster than the $\beta$ phase, the segregation of impurities in the manner described can lead to the solidification of large dendrites of the $\alpha$ phase.

\subsection{Creep}

Creep is defined as "the time dependent component of plastic deformation"19 and therefore creep deformation can occur during testing under a variety of conditions. In practice, creep testirg is done at constant temperature and constant load or stress. While creep can occur at any temperature, the creep rate is only appreciable at relatively high temperatures, typically above one-half the melting point of the material.

\subsubsection{Stages of Creep Deformation}

At high temperatures, a creep curve (strain as a function of time) exhibits three regimes: primary, steady-state, and tertiary creep. These are shown schematically in Figure 2.2. Traditionally, the creep process is described as follows. ${ }^{20}$ During primary creep the strain rate decreases with time, within a transient period during which the material's substructure is formed. Increased dislocation density hardens the material. At low homologous temperatures this is the only creep regime experienced, and the creep rate eventually drops to zero. During steady-state creep a balance between hardening and softening processes is achieved, and the strain rate is constant. Tertiary creep is caused by mechanical instability of the material which produces a rapid increase in strain rate. Tertiary creep can occur as a result of either a change of stress (i.e. a reduction in crosssectional area during a constant load test) or microstructural changes. It can be seen from the above description that the steady-state strain rate is the minimum strain rate achieved during the creep test. If the applied stress is high enough, a material may not undergo a 
visible region of steady-state creep, but a minimum creep rate can still be measured at the start of tertiary creep.

\subsubsection{Creep Mechanisms}

The high temperature creep behavior of a material is generally defined by the steadystate creep rate, $d \gamma / d t$, and in particular how it depends on applied stress $(\tau)$ and test temperature $(T)$. A variety of mechanisms can be described by power law creep, in which the relation between stress and strain rate is determined by the stress exponent, $n$, in the equation below:

$$
\mathrm{d} \gamma / \mathrm{dt}=\mathrm{A} \tau^{\mathrm{n}} \exp (-\mathrm{Q} / \mathrm{kT})
$$

In this equation, $\mathbf{k}$ is Boltzman's constant. The temperature dependence follows an Arrhenius relationship, with $Q$ as an apparent activation energy for creep. The preexponential factor, $\mathrm{A}$, is a microstructural parameter which is fairly independent of stress and temperature. The grain size dependence on creep is contained within the parameter A.

High temperature creep at moderate stresses is usually controlled by climb of dislocations, which is, in turn, controlled by diffusion. When diffusion in the lattice dominates, as opposed to diffusion in dislocation cores or along grain boundaries, the stress exponent is generally between 3 and 7 . The activation energy is equal to the activation energy for bulk self-diffusion, in the case of a pure metal. For creep of twophase alloys, the activation energy is often equal to the activation energy for creep/selfdiffusion of the dominant phase, assuming that one phase dominates the creep deformation. In fine-grained materials, grain boundary sliding can dominate over bulk dislocation motion. In this case, the stress exponent drops to between 2 and 3 and the activation energy becomes equal to the activation energy for grain boundary diffusion.

In a given material, various creep mechanisms can operate depending on the test temperature, applied stress, grain size, and other factors. These mechanisms can operate 
either in series (sequentially) or in parallel (independently). For independent mechanisms, the mechanism producing the highest creep rate in a given range of conditions will dominate the creep behavior. An example of independent mechanisms is diffusional creep versus dislocation creep. For creep mechanisms in series, the creep rate will be limited by the slowest mechanism and therefore the mechanism with the lowest creep rate will dominate. An example of sequential mechanisms is dislocation climb-and dislocation glide-controlled creep. For generic mechanisms with different stress dependences, the difference in steady-state strain rate as a function of applied stress for independent versus sequential mechanisms is illustrated in Figure 2.3.

\subsection{Dynamic Recrystallization}

Recrystallization of metals and alloys is usually achieved by deforming the material at ambient temperature (cold working the material) and then annealing at an elevated temperature. A minimum temperature is required to cause recrystallization for a given material and deformation history. Raising the annealing temperature above this minimum increases the rate of recrystallization. However, if a material is deformed above its recrystallization temperature it may dynamically recrystallize during deformation. Dynamic recrystallization has been observed and studied in various steel, copper, nickel and aluminum alloys.

\subsubsection{Nucleation Mechanisms}

Four models have been suggested to describe nucleation during dynamic recrystallization, and are described by Haessner. ${ }^{21}$ The classical nucleation model, used to explain solidification, assumes that a nucleus of critical size must be formed by thermal fluctuations, and that such a nucleus will grow. This is not a good model to describe recrystallization, since observed nuclei sizes in recrystallized materials are much smaller than those predicted by homogeneous nucleation using the classical model. Even 
if heterogeneous nucleation is assumed with dislocations acting as nucleation sites, an extremely high dislocation density, several orders of magnitude larger than that observed in highly deformed materials, would need to exist in order to predict accurate nuclei sizes. The second model is the martensitic model. This mechanism assumes that two adjacent grains of specific crystallographic orientations can generate a nucleus of material of a third related orientation between them by a martensitic-like process. The martensitic model has been used to explain the formation of nuclei of cube orientation formed in face centered cubic metals, but has limited general utility since it can only properly describe nuclei that form in particular crystallographic orientations.

The most promising models for describing nucleation in recrystallization processes are the subgrain coarsening model and the bulging mechanism, bcth of which rely on grain boundaries as nucleation sites. The concept behind subgrain coarsening is that small-angle grain boundaries can transform into large-angle grain boundaries. This can occur either by subgrain boundaries migrating and increasing the grain boundary angle gradually, or by subgrain boundaries disintegrating so that subgrains coalesce into grains with larger grain boundary angles. By the bulging mechanism, recrystallized regions are formed when large-angle grain boundaries bulge or bow out, leaving behind dislocationfree regions.

\subsubsection{Methods of Measurement}

Various experimental methods can be employed to investigate the phenomenon of dynamic recrystallization. In general, both recovery and recrystallization can occur when a material is subjected to high temperature deformation. The amount of recovery increases with increasing strain and dislocation density until it balances work hardening processes, at which point the flow stress reaches a plateau. The onset of recrystallization causes softening of the material and therefore a drop in the flow stress. In general, materials which exhibit dynamic recrystallization will show a peak in the stress-strain 
curve whereas those which merely undergo dynamic recovery will not. This behavior is illustrated in Figure 2.4 and can be investigated by testing materials in tension, compression, shear or torsion. In addition, microstructural observation and grain size measurements are useful for determining the onset of dynamic recrystallization. A dramatic decrease in grain size should be observed upon recrystallization. Other morphological changes in the arrangement of grains and/or phases are often apparent. Drops in electrical resistivity and hardness which occur upon recrystallization can also be measured. Detailed observation of the effect of deformation on the dislocation structure is often done using Transmission Electron Microscopy (TEM). Knowledge about dislocation structure can help distinguish between dynamic and static recrystallization.

\subsubsection{Literature Review}

Often it is difficult to prove whether recrystallization observed in a test is dynamic or static. When samples are subjected to a rapid quench immediately after deformation it is unlikely that recrystallization could have occurred after the sample was unloaded. For slowly cooled samples or samples that may recrystallize at room temperature, this is not the case. In a study of boron-doped $\mathrm{Ni}_{3} \mathrm{Al}$ which was slow-cooled after deformation in compression, Gottstein, Chang and Yung 22 addressed this issue. Observations of recrystallized grains using TEM showed that some grains contained dislocations. These grains must have dynamically recrystallized and then undergone further deformation. However, the interiors of other recrystallized grains were dislocation-free. The authors proposed several possible explanations for this observation: the grains could have dynamically recrystallized near the end of the test and had insufficient time to develop a subsequent dislocation structure, they could have statically recrystallized during cooldown, or they could have dynamically recrystallized and then deformed superplastically rather than by dislocation glide. Thus, it appears that no definitive answer is available. This question is even more difficult to answer for low melting-point materials, such as 
solder alloys, since it is not feasible to quench them to a sufficiently low temperature after deformation.

Gottstein has published a number of articles on dynamic recrystallization, primarily studying copper. One of his earlier studies ${ }^{23}$ investigated tensile creep of copper single crystals. The samples underwent dynamic recrystallization during creep deformation, indicated on creep curves by a sudden increase in the strain that occurred during steadystate creep. After this sulden increase, the creep behavior would return to primary creep. Plots of strain rate versus strain showed cusps where dynamic recrystallization had occurred. This type of creep curve is peculiar to single crystals that dynamically recrystallize. Recrystallization in polycrystalline samples will not occur simultaneously throughout the sample, since some grains will recrystallize before others. Thus, the creep behavior will be affected gradually rather than suddenly and sharp peaks should not appear. Gottstein produced log-log plots of applied stress versus strain rate at recrystallization and found they were linear for fixed deformation temperature. The data followed the same lines as log-log plots of stress at recrystallization versus applied strain rate for dynamic (constant strain rate) tests. This indicated that for a given test temperature there is a critical combination of stress and strain rate required for recrystallization, regardless of the mode of tensile deformation. An interesting observation from this study was that for temperatures above $0.8 \mathrm{~T}_{\mathrm{m}}$ recrystallization initiated when steady state had been reached, and for temperatures between $0.5 \mathrm{~T}_{\mathrm{m}}$ and $0.8 \mathrm{~T}_{\mathrm{m}}$ recrystallization initiated prior to achieving steady state. Gottstein also reported the results of a study by Hirst on lead single crystals, which showed that dynamic recrystallization initiated before steady state creep in lead as well.

While dynamic recrystallization studies are sparse for solder alloys, experiments on static recrystallization of bismuth alloys have been done by Ali, et al. ${ }^{24}$ They deformed pure bismuth and bismuth alloys containing small amounts of antimony, tin, or lead in compression at room temperature. Annealing was done between room temperature and 
$227{ }^{\circ} \mathrm{C}$. Electrical resistivity $(\rho)$ and hardness were measured to determine the recrystallization temperature, which was defined as the peak of the $d \rho / d T$ versus $T$ curve, although recrystallization initiated before this point. The authors found the recrystallization temperature of pure bismuth to be about $877^{\circ} \mathrm{C}$, and that of the alloys to be higher. However, the temperature range over which resistivity and hardness dropped also increased with alloying, so the alloys exhibited initiation of recrystallization at a lower temperature than did pure bismuth.

Solorzano, Cohn and Andrade ${ }^{25}$ have done research on a $\mathrm{Cl}$-In and a $\mathrm{Ni}-\mathrm{Sn}$ alloy, investigating recrystallization that occurs not during deformation, but as a result of phase transformations. The two processes studied are discontinuous precipitation, in which a supersaturated phase transforms into a two-phase lamellar structure, and continuous dissolution, in which the two phases dissolve back into a single phase. The discontinuous precipitation reaction occurs at grain boundaries, whereas continuous dissolution involves bulk diffusion. The two alloys were initially solution treated to cause discontinuous precipitation, then heated at a higher temperature to cause continuous dissolution. If the initial heat treatment was long enough to allow the lamellar colonies to grow sufficiently to cover the entire original grains, then the dissolution heat treatment resulted in a fully recrystallized microstructure. Otherwise, the dissolution reaction occurred only in the regions of the material that formed lamellar colonies. Thus, by combination of discontinuous precipitation and continuous dissolution, a fully or partially recrystallized microstructure could be achieved without plastic deformation. 


\subsection{Eutectic In-Sn and Eutectic Bi-Sn}

\subsubsection{Phase Diagrams and Eutectic Phases}

According to the $\mathrm{In}-\mathrm{Sn}^{26}$ and $\mathrm{Bi}-\mathrm{Sn}^{27}$ phase diagrams, which are shown in Figures 2.5 and 2.6, the eutectic temperatures are $120^{\circ} \mathrm{C}$ and $138^{\circ} \mathrm{C}$, respectively. The eutectic phases of In-Sn are both intermediate solid solutions with crystal structures different from those of In and $\mathrm{Sn}$. The $\beta$ phase has an approximate composition of $\mathrm{In}_{3} \mathrm{Sn}$ and is bodycentered tetragonal. The $\gamma$ phase is nominally $\mathrm{InSn}_{4}$ and has a simple hexagonal crystal structure. Neither phase can be truly called an int rrmetallic compound, since both phases can exist within a wide range of compositions and are not perfectly ordered compounds. The $\gamma$ phase is a random solid solution, but there is some question as to the atomic arrangement in the $\beta$ phase, which has been reported to exhibit partial ordering. ${ }^{28}$ Both the $\gamma$ and $\beta$ phases are relatively soft and ductile and have wide solubility ranges, in contrast to the behavior expected for ordered intermetallics. The composition of the $\gamma$ phase of the eutectic does not change much as the alloy is cooled. The composition of the $\beta$ phase, however, varies from 44 atomic percent at the eutectic temperature to 30 atomic percent at $25^{\circ} \mathrm{C}$.

The $\mathrm{Bi}-\mathrm{Sn}$ is a simple eutectic, consisting of tin and bismuth terminal solid solutions. Bismuth is one of the few elements with a rhombohedral crystal structure. The arrangement of the atoms is similar to the face centered cubic (fcc) structure, since one possible unit cell for the fcc structure is a rhombohedral cell with an angle of 60 ". For $\mathrm{Bi}$, the rhombohedral angle is $57^{\circ}$. The bonding in this element is different from that of fcc metals. The structure of bismuth is usually modeled as corrugated sheets consisting of two $\{111\}$ planes. ${ }^{29}$ A top view of this arrangement is drawn in Figure 2.7. Within the sheets, each atom is covalently bonded to its three nearest neighbors. The $\{111\}$ sheets are stacked in layers to produce the bismuth structure, with weak metallic bonding between the sheets. Molten bismuth is nearly close-packed, with the consequence that it 
has a higher density than the solid. ${ }^{29}$ This expansion upon solidification can be useful, in that shrinkage voids are usually not a problem with bismuth alloys.

Tin is face-centered tetragonal in its $\beta$ form, which is stable above $13{ }^{\circ} \mathrm{C}$. Decomposition into the low-temperature diamond cubic phase, $\alpha$-Sn, is detrimental since the large volume change associated with the transformation causes severe cracking of the material. However, the transformation is extremely slow and does not occur unless the tin is inoculated. A small amount of $\alpha$-Sn can act as an inoculant, as can the presence of other diamond cubic crystals, such as silicon. This is only a problem with extremely high purity tin. Experiments in which inoculated $\beta-\mathrm{Sn}$ was held at $-40^{\circ} \mathrm{C}$, the temperature at which the transformation is fastest, showed that 0.3 percent bismuth was sufficient to prevent transformation within a reasonable time period. 30 Since the tin-rich phase of eutectic $\mathrm{Bi}-\mathrm{Sn}$ has a much higher bismuth content than this, decomposition into $\alpha$-Sn should not be a concern. The solubility of bismuth in $\beta$-Sn ranges from 13 atomic percent at the eutectic temperature to about 2 atomic percent at $25^{\circ} \mathrm{C}$. This has the consequence that bismuth precipitates out of the tin-rich phase as the solidified eutectic is cooled to room temperature.

\subsubsection{Literature Review of Mechanical Properties}

There has generally been more interest in $\mathrm{Bi}-\mathrm{Sn}$ than in $\mathrm{In}-\mathrm{Sn}$ and consequently there is more published research on Bi-Sn. Several articles present data on mechanical properties of various solder alloys and show Bi-Sn to have a similar shear strength to $\mathrm{Sn}$ $\mathrm{Pb}$, but to be much less ductile and have a lower fatigue life. ${ }^{31,32,33}$ Shear strengths of $\mathrm{Bi}-\mathrm{Sn}$ have been reported to be near $35 \mathrm{MPa}$ for applied strain rates between $3 \times 10^{-3}$ and $1 \times 10^{-1} / \mathrm{sec}$ and about $26 \mathrm{MPa}$ for strain rates between $6 \times 10^{-4}$ and $1 \times 10^{-3} / \mathrm{sec}^{34,35,36}$ The shear strength of In-Sn is much lower, $6 \mathrm{MPa}$ at $1 \times 10^{-3} / \mathrm{sec}^{37}$ and $14 \mathrm{MPa}$ at $8 \times 10^{-2} / \mathrm{sec}^{36}$ It might be expected that the low strength and high ductility of In-Sn would produce a 
high fatigue resistance, but $\mathrm{In}-\mathrm{Sn}$ exhibits a lower fatigue resistance than either $\mathrm{Bi}-\mathrm{Sn}$ or $\mathrm{Sn}-\mathrm{Pb} .{ }^{38,39}$

Caulfield, et al.40 studied the effect of aging on the microstructure and low temperature mechanical properties of eutectic In-Sn. Their samples were quenched and had an initially fine microstructure which coarsened significantly after 2 days at room temperature. The tin-rich phase of the eutectic was also observed to precipitate from the In-rich phase. The effect on the tensile properties was to lower the tensile strength and increase the elor gation to failure in samples tested at $77 \mathrm{~K}$ and $4.2 \mathrm{~K}$.

Tomlinson and Collier ${ }^{31}$ calculated an activation energy for creep of eutectic $\mathrm{Bi}-\mathrm{Sn}$. The value was much closer to the activation energy for creep of bismuth than of tin, leading the authors to postulate that deformation was concentrated in the bismuth phase of the eutectic. However, the activation energy for creep of $\mathrm{Bi}-\mathrm{Sn}$ determined by Tomlinson and Collier was $0.3 \mathrm{eV}$, which is surprisingly low. It was below the values the authors quoted for both individual phases, $0.73 \mathrm{eV}$ for tin ${ }^{41}$ and $0.49 \mathrm{eV}$ for bismuth. ${ }^{42}$ Another source of information on Bi-Sn is from Pattanaik and Raman. ${ }^{43}$ They studied room temperature tensile properties of rolled $\mathrm{Bi}-\mathrm{Sn}$ and found that the strain rate sensitivity $(\mathrm{m})$ changed with strain rate. For strain rates below $2 \times 10^{-3} / \mathrm{sec}, \mathrm{m}$ was 0.5 and for higher strain rates, $m$ was 0.1 . This corresponds to stress exponents of 2 for the low strain rate region and 10 for the high strain rate region. The authors found that the fracture mode varied as well. At high strain rates fracture was through the bismuth phases of the eutectic and had a faceted morphology, indicating brittle fracture. At low strain rates the fracture was ductile, with microvoids and cavities at interphase boundaries.

Frenkel ${ }^{44}$ studied creep of pure metals and found activation energies of $0.91 \mathrm{eV}$ for polycrystalline tin and $0.72 \mathrm{eV}$ for polycrystalline indium. Another study by Darveaux, et al. ${ }^{45}$ on pure indium gave an activation energy of $0.51 \mathrm{eV}$ and a stress exponent of 7. The reason for the difference in activation energy between these two sources cannot be 
determined without additional information about the processing of the samples, which was not given. Mohamed, Murty and Morris ${ }^{46}$ reported an activation energy for creep of $1.0 \mathrm{eV}$ and a stress exponent of 7 for pure tin.

Shear moduli of indium alloys at room temperature were determined by Magomedev. 47 Values given for 50In-50Sn, pure tin and pure bismuth are 8.8, 22.2 and 10.3 GPa, respectively. An approximate shear modulus for eutectic Bi-Sn can be calculated by assuming the rule of mixtures applies. Since eutectic Bi-Sn contains 49.6 percent bismuth by volume, the modulus is approximated as $16.3 \mathrm{GPa}$. 


\section{EXPERIMENTAL DETAILS}

The alloys used for this study were provided in bulk ingot form by the Indium Corporation of America. Results of chemical analyses (by weight) done by the Indium Corporation showed the In-Sn alloy to contain $51.4 \%$.In and $48.6 \%$ Sn with $130 \mathrm{ppm}$ impurities, and the Bi-Sn alloy to contain 58.1\% Bi and $41.9 \%$ Sn with less than 217 ppm impurities.

\subsection{Sample Description}

A method developed by previous researchers at Lawrence Berkeley Laboratory ${ }^{7}$ was used, with minor modifications, to make samples for mechanical testing. Three solder/substrate combinations were manufactured: $\mathrm{Bi}-\mathrm{Sn}$ on $\mathrm{Cu}, \mathrm{In}-\mathrm{Sn}$ on $\mathrm{Cu}$, and $\mathrm{In}-\mathrm{Sn}$ on Ni. Sample blocks were prepared by heating the solder ingots in Teflon crucibles to about $50^{\circ} \mathrm{C}$ above their melting points, bolting three $\mathrm{Cu}$ plates together with $0.5-\mathrm{mm}$ diameter wires between them as spacers, and immersing the plate assembly into the molten solder. For samples on $\mathrm{Cu}$ substrates, the $\mathrm{Cu}$ plates were rough polished and etched with a $50 \% \mathrm{HNO}_{3}$ solution before assembly with $\mathrm{Cu}$ wires. To produce $\mathrm{In}-\mathrm{Sn}$ on $\mathrm{Ni}$, polished $\mathrm{Cu}$ was plated with about $8 \mu \mathrm{m}$ of electroless $\mathrm{Ni}$, and $\mathrm{Ni}$ wires were used for assembly. The plating procedure produced a smooth, relatively oxide-free surface, so that subsequent etching was not required. All blocks were soaked in a $\mathrm{ZnCl}_{2}$ flux for 30 seconds prior to immersing in the molten solder. The blocks were solidified by removing the crucibles from the furnace and placing them in ice water. After solidification, each block was removed from the crucible and machined into 12 to 15 individual double-lap shear samples. An illustration of the sample preparation procedure appears in Figure 3.1, and a drawing of the sample is shown in Figure 3.2. The design of the notches in the sample is such that the central region of the joint is deformed in nearly simple shear when 
tensile deformation is applied to the sample. Regions of the alloy outside the central gage region remain undeformed during testing.

Shear stresses $(\tau)$ on these samples are calculated by the equation

$$
\tau=\mathrm{P} /\left(\mathrm{x}^{*} \mathrm{~h}\right),
$$

where $P$ is the load, $x$ is the length of the joint (central gage section length), and $h$ is the sample thickness. Shear strains $(\gamma)$ are calculated as

$$
\gamma=\Delta x / w,
$$

where $\Delta \mathrm{x}$ is the displacement along the joint length and $\mathrm{w}$ is the width of the joint. For all samples, $w=0.51 \mathrm{~mm}$ (0.020 inches). The quantities in equations (3.1) and (3.2) are engineering stress and engineering strain, respectively. However, since the samples are deformed in shear, the difference between engineering stress and strain and true stress and strain is slight. As will be discussed in chapter 4, concentrations of stress and strain during deformation affect the true stress and strain in the samples, but the magnitude of this effect cannot be quantified.

One difference between the current sample preparation method and previous ones is the crucible material. Originally, graphite crucibles were used. The crucibles are cylindrical in shape and slightly tapered with the bore diameter widest at the top. Sn and $\mathrm{Pb}$, like most metals, contract upon solidification, and could easily be removed from the crucibles. The expansion of $\mathrm{Bi}$ upon solidification caused problems. The first attempt to produce a Bi-Sn block using a graphite crucible resulted in a cracked crucible. Therefore, a material was needed which was chemically inert, could withstand temperatures up to $250^{\circ} \mathrm{C}$, and would be able to elastically deform. Teflon was chosen for this purpose, and it was used for the In-Sn blocks as well in order to give the same conditions for both alloys. Thermocouple wires of the same diameter as the spacers were inserted into some of the $\mathrm{Cu}$ plate assemblies in order to monitor the temperature as the block was immersed and then cooled. A temperature profile for $\mathrm{In}-\mathrm{Sn}$ on $\mathrm{Cu}$ is shown in Figure 3.3. Other profiles are similar, except that the starting temperature and eutectic temperature are 
higher for Bi-Sn. It takes several minutes for the alloys to solidify, and then another few minutes to cool to room temperature.

\subsection{Mechanical Testing}

The $\mathrm{Bi}-\mathrm{Sn}$ and In-Sn alloys were tested both at constant load (creep) and at constant strain rate. Drawings of the machines used for creep and constant strain rate testing are shown in Figures 3.4 and 3.5. The creep machine contains a linear variable differential transformer (LVDT) that registers the displacement of the sample. In the constant strain rate testing machine, displacement of the sample is measured by a strain gage. Both machines are computer-controlled, allowing displacement and time (creep) or load and displacement (constant strain rate) data to be read at a user-specified interval.

Tests were done at temperatures between 0 and $75^{\circ} \mathrm{C}$, which correspond to homologous temperatures of over 0.66 and are thus considered high temperature tests. Elevated temperature tests were run by submerging the sample into a heated silicone oil bath, and $0{ }^{\circ} \mathrm{C}$ tests were run in an ice water bath. The temperature was allowed to stabilize for about one hour before starting each test. Room temperature was controlled to within $2{ }^{\circ} \mathrm{C}$ and all other temperatures to within $1^{\circ} \mathrm{C}$. Creep tests were run until the samples were in the tertiary creep region. Applied stresses ranged from 1 to $20 \mathrm{MPa}$ for In-Sn samples and 7 to $42 \mathrm{MPa}$ for $\mathrm{Bi}-\mathrm{Sn}$ samples. Constant strain rate tests were run until an arbitrary total strain was reached, at strain rates ranging from $2 \times 10^{-4}$ to $8 \times 10^{-4} / \mathrm{sec}$ for both alloys. For both test types, tests were usually stopped before complete fracture of the samples. For the constant strain rate tests, the change in effective area during the test was accounted for in calculating the shear stress from load data. This change in area is shown in Figure 3.6, in which the effective gage length changes from $a_{0}$ to $a_{1}$ as a result of testing. The area drops by about 6 percent for a test taken to 100 percent shear strain. This was not taken into effect in the creep samples, 
which were subjected to constant load rather than constant stress. However, since these are shear tests, the difference is very slight.

Most of the samples were subjected to creep tests. Constant strain rate tests were added to compare to reports in the literature of the effect of recrystallization on the shape of stress-strain curves. The strain rate during steady-state creep was discussed in section 2.2.2. Equation (2.2) is repeated here for convenience:

$$
\mathrm{d} \gamma / \mathrm{dt}=\mathrm{A} \tau^{\mathrm{n}} \exp (-\mathrm{Q} / \mathrm{kT}) .
$$

For constant strain rate tests, a similar equation exists relating strain rate, flow stress and temperature:

$$
\tau=B(d \gamma / d t)^{(1 / n)} \exp (Q / n k T)
$$

These are really the same equation in different forms, and a log-log plot of strain rate versus stress which combines data from both types of tests usually results in a single straight line at a given test temperature. If creep and stress-strain data do not fall on the same line, that means that the deformation mechanisms are not identical during the two types of tests.

\subsection{Metallography and Microscopy}

Before testing the Bi-Sn samples, each sample was mechanically polished, starting with 180 through 600 grit $\mathrm{SiC}$ papers. Fine polishing was done with $1 \mu \mathrm{m}$ alumina powder followed by a colloidal silica suspension. Etching with a solution of $5 \% \mathrm{HNO}_{3}-$ $2 \% \mathrm{HCl}-93 \%$ methanol for several seconds preferentially attacked the Sn-rich phase and resulted in excellent contrast between the $\mathrm{Sn}$ and $\mathrm{Bi}$ phases.

This method was not possible with the In-Sn samples, since the alloy is extremely soft. Samples must be cold-mounted before polishing to avoid smearing or working the In-Sn into a depression between the $\mathrm{Cu}$ plates. If samples are rough-polished without mounting, the soft In-Sn is pressed down between the $\mathrm{Cu}$ plates, so that it is well below the plane of the $\mathrm{Cu}$ and cannot be polished further. The mounting material provides 
sufficient restriction of the $\mathrm{In}-\mathrm{Sn}$ in the direction normal to the surface that a good polish can be achieved. The method chosen for metallographic preparation involved first mounting the samples in an acrylic mount, using a silicon mold release on the mounting holder and the sample. Acrylic was chosen because it cures relatively quickly (in 30 to 40 minutes) without significant temperature increase and can be separated from the sample after polishing. Separation requires machining the acrylic from the sides of the mounted sample and then prying the sample away from the remaining acrylic.

The polishing procedure for the mounted samples was similar to that used for unmounted Bi-Sn samples. However, a polishing step using $6 \mu \mathrm{m}$ diamond paste was added and final polishing was done using a cerium oxide polishing compound $(0.05 \mu \mathrm{m})$ instead of silica. During all stages of polishing, the soft In-rich phase was preferentially polished, but this was especially true for the final step. The final polish brought out the contrast between the In-rich and Sn-rich phases and gave good definition at the phase boundaries, eliminating the need for etching.

The above described procedures allowed for examination of the same sample before and after testing. Examination of the samples by optical microscopy immediately after testing revealed the surface relief developed during testing, which showed where deformation was concentrated. A final polish (and re-etch, for $\mathrm{Bi}-\mathrm{Sn}$ ) starting at the $1 \mu \mathrm{m}$ alumina stage was used to eliminate the surface relief for microstructural examination of the tested samples. This light polishing could be done on both $\mathrm{In}-\mathrm{Sn}$ and $\mathrm{Bi}-\mathrm{Sn}$ with good results, and the In-Sn samples did not have to be remounted after testing.

Both optical microscopy and scanning electron microscopy (SEM) were used to examine the samples. Optical microscopy was sufficient for examining the microstructure of the solders, and was in fact superior to SEM since contrast between phases is better. SEM was used to see cracks in heavily deformed samples and for chemical analysis. Energy dispersive $x$-ray spectroscopy (EDS) was used to determine composition of phases, while wavelength dispersive x-ray spectroscopy (WDS) was 
useful for producing $x$-ray images, or maps, showing the spatial distribution of the elements. Some sections of samples were fractured in liquid nitrogen to observe the intermetallic layers, and these were examined by SEM as well. 


\section{RESULTS}

\subsection{Initial Microstructures}

\subsubsection{Solders}

In general, the solder microstructure depends of the rate of cooling from the melt and the geometry of the sample. The faster the cooling rate, the finer the microstructure. The morphology of the eutectic microstructure can also change with cooling rate. Therefore the micrographs shown are representative of the cooling conditions used, which were described in section 3.1. Also, the microstructure at the solder/substrate interface can be important. The samples used in this study were sufficiently thick that the interfacial layer comprises a small fraction of the overall joint thickness, but for extremely thin joints the intermetallic layer becomes appreciable.

The untested as-cast microstructures of the two alloys differ considerably. Bi-Sn (Figure 4.1) has what is generally called a complex regular microstructure. The two phases are apparently arranged in alternating plates, but the plates are not flat, resulting in a microstructure with complicated patterns. Occasionally isolated islands of $\mathrm{Sn}$ dendrites or faceted $\mathrm{Bi}$ particles are observed. The decrease in solid solubility of $\mathrm{Bi}$ in $\mathrm{Sn}$ as the alloy is cooled causes $\mathrm{Bi}$ to precipitate out within the Sn-rich regions. The precipitates appear in the form of very fine plates, about one-fourth the thickness of the eutectic lamellae. An example of this is shown in Figure 4.2.

The microstructure of eutectic In-Sn depends strongly on the substrate. As mentioned earlier, some blocks were manufactured using bare copper and others used copper plated with $\mathrm{Ni}$. In-Sn on $\mathrm{Cu}$ has an irregular microstructure, the scale and morphology of which varies throughout the joint (see Figure 4.3a). No well-developed lamellar structure exists, although lamellae form in isolated regions. Many large dendrites of the Sn-rich $\gamma$ phase are also observed. The $\gamma$ phase is discontinuous, suggesting that the $\gamma$ phase regions are imbedded in a matrix of the $\beta$ phase. The microstructure of $\mathrm{In}-\mathrm{Sn}$ on $\mathrm{Ni}$ is quite different, 
as can be seen in Figure 4.3b. The eutectic phases are arranged in lamellar colonies, in a microstructure which is much more uniform. No large regions of either phase are present and neither phase clearly forms a continuous matrix.

\subsubsection{Intermetallic compounds}

The bond between the solder and substrate is formed by intermetallic compounds at the interface. For the In-Sn samples, there are significant differences in the appearance of the alloy/substrate interface between joints made on $\mathrm{Ni}$ and those on $\mathrm{Cu}$. Significant diffusion of $\mathrm{Cu}$ through the $5(00-\mu \mathrm{m}$ wide joint is apparent in joints on bare $\mathrm{Cu}$. The layer of $\mathrm{Ni}$ on Ni-plated samples serves as an effective barrier to diffusion of $\mathrm{Cu}$. No $\mathrm{Cu}$ or $\mathrm{Ni}$ can be seen within as-cast samples of the In-Sn alloy in the samples on Ni substrates.

A ternary intermetallic layer forms in the In-Sn joints on $\mathrm{Cu}$. Figure 4.4 shows an SEM micrograph and $\mathrm{x}$-ray image of $\mathrm{Cu}, \mathrm{In}$ and $\mathrm{Sn}$ distribution for a typical sample. The intermetallic layer appears to be composed of two compounds of different compositions. The compound on the $\mathrm{Cu}$ side of the interface contains primarily $\mathrm{Cu}$, while the compound on the solder side of the interface is particularly rich in In and poor in $\mathrm{Sn}$. These findings support previous research on this system by Romig, Yost and Hlava. ${ }^{48}$ They found layers of $\mathrm{Cu}_{2}(\mathrm{Sn}, \mathrm{In})$ and $\mathrm{Cu}_{2} \mathrm{In}_{3} \mathrm{Sn}$ at the $\mathrm{Cu} /$ solder interface, with the In-rich $\mathrm{Cu}_{2} \mathrm{In} 3 \mathrm{Sn}$ on the solder side of the interface.

No intermetallic layers were observed in the as-cast samples on $\mathrm{Ni}$. Theoretically $\mathrm{Ni}$ can form several intermetallic compounds with both In and $\mathrm{Sn} .{ }^{49} \mathrm{Also}$, if the interface were not strongly bonded, i.e. no continuous intermetallic layer were present, the sample would fracture at the interface rather than within the joint as observed. Therefore, it is likely that the intermetallic layer is present but merely too thin to be seen at the magnifications used (2000 $\mathrm{x}$ or less). This hypothesis is supported by the observation that a thin intermetallic layer, about $0.5 \mu \mathrm{m}$ thick, was detected after aging samples for two months at room temperature. This layer was too thin to be examined by $x$-ray 
mapping with the SEM, since good focus could not be obtained at high enough magnification.

Aging for two months at $81{ }^{\circ} \mathrm{C}$ caused sufficient intermetallic growth so that the layer could be analyzed. The $x$-ray images in Figure 4.5 show an intermetallic layer consisting of $\mathrm{In}, \mathrm{Sn}, \mathrm{Ni}$ and $\mathrm{Cu}$. The $\mathrm{Cu}$ seems to have diffused through the $\mathrm{Ni}$ layer to the intermetallic. EDS analysis showed approximately equal quantities of each element within the intermetallic layer. It is expected that no $\mathrm{Cu}$ was present in the intermetallic layers of the unaged samples and that the $\mathrm{Cu}$ diffusion was a result of high temperature aging. The short amount of time at elevated temperature during solidification of the sample blocks is not likely to be sufficient to allow diffusion of $\mathrm{Cu}$ through the $8 \mu \mathrm{m}$ layer of $\mathrm{Ni}$. This is supported by the observation that no $\mathrm{Cu}$ was found within the joints in unaged In-Sn on Ni samples. Also, a sample aged at room temperature and fractured in liquid nitrogen showed the presence of In-Sn-Ni intermetallics on the fracture surface, which contained virtually no $\mathrm{Cu}$. An SEM micrograph is shown in Figure 4.6. The intermetallic appears in pockets which are particularly poor in In. The overall fracture surface looks fairly ductile despite the low temperature at which fracture occurred.

The intermetallic layer formed between $\mathrm{Bi}-\mathrm{Sn}$ and $\mathrm{Cu}$ is about $1 \mu \mathrm{m}$ thick in as-cast samples and contains $\mathrm{Cu}$ and $\mathrm{Sn}$. It is too thin to be seen in the optical micrographs shown, but is visible by $\mathrm{SEM}$. In the $\mathrm{Sn}-\mathrm{Pb} / \mathrm{Cu}$ system, $\mathrm{Cu}_{3} \mathrm{Sn}$ and $\mathrm{Cu}_{6} \mathrm{Sn}_{5}$ intermetallics form. 50 Intermetallic particles exist within the $\mathrm{Bi}$ - $\mathrm{Sn}$ solder in the form of hexagonal rods, a known morphology for $\mathrm{Cu}_{6} \mathrm{Sn}_{5}$. These particles probably broke off from the growing intermetallic layer at the $\mathrm{Cu}$-solder interface and remained in the molten solder during sample preparation. The hexagonal shape of one such intermetallic can be seen in cross-section in Figure 4.7a. Figure 4.7b shows intermetallics sectioned lengthwise. Formation of a $\mathrm{Cu}_{6} \mathrm{Sn}_{5}$ intermetallic layer in the $\mathrm{Bi}-\mathrm{Sn} / \mathrm{Cu}$ system has been previously observed. 31 


\subsection{Mechanical testing}

\subsubsection{Creep testing}

\subsubsection{Shape of creep curves for $\mathrm{Bi}-\mathrm{Sn}$ and $\mathrm{In}-\mathrm{Sn}$}

The shape of the Bi-Sn creep curves in the primary and steady-state regions depends on the testing temperature. At temperatures of 0 and $20^{\circ} \mathrm{C}$, the creep curves have the appearance of the one shown in Figure 4.8a. There is a distinct primary creep region and then a smooth transition into steady-state creep. The steady-state creep region is welldefined, with a constant slope. In contrast, the creep curves at temperatures of 65 and 75 ${ }^{\circ} \mathrm{C}$ are very rough. The example of a $65^{\circ} \mathrm{C}$ test in Figure $4.8 \mathrm{~b}$ shows that there is no prolonged region of constant strain rate. The strain rate oscillates, and so the steady-state creep region is defined by a period during which the average creep rate is constant, before it begins to rise rapidly during tertiary creep. There may be a primary creep region for this sample, but it is obscured by the roughness of the data. In general, the roughness of Bi-Sn creep curves increases with increasing test temperature.

The In-Sn samples showed relatively smooth creep curves for all test parameters, an example of which appears in Figure 4.9. The primary creep region was slight or absent in all cases.

For both alloys, the steady-state strain rate and the extent of steady-state creep were highly dependent on applied stress and temperature. These relationships will be described in more detail in the next two sections. While the time duration of steady-state creep varied, strain during steady-state creep was between 3 and 7 percent for $\mathrm{Bi}$-Sn and between 10 and 16 percent for In-Sn, independent of temperature or applied stress. A plot of the strain to tertiary creep (i.e., creep strain during primary and steady-state creep) as a function of steady-state strain rate and as a function of temperature for both alloys is shown in Figure 4.10. The bulk of shear strain occurs during tertiary creep, with very large strains to failure. 


\subsubsection{Stress exponents}

Log-log plots of steady-state strain rate versus applied stress for each test temperature were constructed to determine the stress exponent in equation 2.2. Such plots are shown in Figure 4.11 for $\mathrm{In}-\mathrm{Sn}$ on $\mathrm{Cu}$ and $\mathrm{In}-\mathrm{Sn}$ on $\mathrm{Ni}$. The data fit very well to straight lines for all temperatures tested. Stress exponents are near 3 for samples on $\mathrm{Cu}$ and close to 5 for samples on $\mathrm{Ni}$ and are relatively constant with temperature. Owing to the difference in stress exponents, the $\mathrm{Cu}$ and $\mathrm{Ni}$ data lines at a given temperature will cross. Therefore, at high stresses the creep rate of $\mathrm{Ni}$ samples is generally higher than for $\mathrm{Cu}$ samples at the same stress, whereas at lower stresses the opposite is true.

The creep behavior of $\mathrm{Bi}-\mathrm{Sn}$ is more complicated. Creep data for $\mathrm{Bi}-\mathrm{Sn}$ are plotted in Figure 4.12. At temperatures of 0 and $20^{\circ} \mathrm{C}$, the data split into two regions, a low stress region with a stress exponent near 3 and a high stress region with a stress exponent greater than 6. The stress at which the break occurs decireases with increasing temperature. Data at temperatures of 65 and $75^{\circ} \mathrm{C}$ fit a single stress exponent, between 4 and 5 , for the entire range of stresses tested. At $40{ }^{\circ} \mathrm{C}$ there is a low stress region with a stress exponent near 4, but the scatter at higher stresses makes it unclear whether there is an increase in stress exponent for stresses above about $28 \mathrm{MPa}$.

\subsubsection{Activation energies}

The activation energy for creep of each type of sample was determined by using multivariable linear regression to fit all stress, temperature and strain rate data to a single equation of the form:

$$
Y=m_{1} x_{1}+m_{2} x_{2}+b
$$

In this case, $Y=\ln (d \gamma / d t), x_{1}=\ln (\tau), x_{2}=1 / T, m_{1}=n, m_{2}=-Q / k$, and $b=\ln (A)$. This calculation also gives an overall stress exponent, which is effectively an average over the range of test temperatures. The type of analysis described above was done for data from tests on both alloys. An attempt to fit all the Bi-Sn to a single equation resulted in a poor 
correlation coefficient. Instead, the data were divided into a high temperature region $(\mathrm{T}>$ $40^{\circ} \mathrm{C}$ ) and a low temperature region $\left(\mathrm{T}<40^{\circ} \mathrm{C}\right)$. In addition, the low temperature data were further divided into low and high stress regions, as indicated by the change in stress exponents seen in Figure 4.12. The low stress data at $40{ }^{\circ} \mathrm{C}$ were combined with the high temperature data. The higher stress data at $40{ }^{\circ} \mathrm{C}$ were ignored for this calculation because of the large scatter. For In-Sn, one equation gave a good fit for all the data on each substrate. The calculated activation energies and stress exponents are given in Table 4.1. Values for eutectic $\mathrm{Sn}-\mathrm{Pb}$ are given for comparison.

\subsubsection{Constant Strain Rate Testing}

\subsubsection{Shape of Stress-Strain Curves}

The difference in the shape of stress-strain curves between alloys which dynamically recrystallized and those which merely experienced dynamic recovery was discussed in section 2.3.2. The stress strain curves observed for constant strain rate tests of $\mathrm{Bi}-\mathrm{Sn}$ and In-Sn on $\mathrm{Cu}$ differed considerably from the expected shape. As can be seen in Figures 4.13 and 4.14 , a plateau in the flow stress is never reached. Instead, stress decays approximately logarithmically after an initial peak. While the stress-strain curves are qualitatively similar for the two alloys, Bi-Sn experiences much higher peak stresses and slower decay rates (longer time to fall to a given fraction of the peak stress) than In-Sn. In-Sn on $\mathrm{Ni}$ samples exhibited completely different stress-strain curves than did the samples on $\mathrm{Cu}$ (see Figure 4.14). No rapid decay of the flow stress was observed. Instead, the stress remains fairly constant even at strains up to 100 percent.

\subsubsection{Relation to Creep Data}

There is a definite correlation between creep and constant strain rate tests for $\mathrm{In}-\mathrm{Sn}$, as shown by the data presented in Figures 4.15 and 4.16. The creep data are steady-state strain rate versus applied stress, as before, and the stress-strain data are presented as 
applied strain rate versus peak stress. Data from both types of tests lie on the same line for $\mathrm{In}-\mathrm{Sn}$ on $\mathrm{Cu}$ and $\mathrm{In}-\mathrm{Sn}$ on $\mathrm{Ni}$ tested at $40^{\circ} \mathrm{C}$ and $\mathrm{Bi}-\mathrm{Sn}$ tested at $20^{\circ} \mathrm{C}$.

\subsubsection{Comparison to $\mathrm{Sn}-\mathrm{Ph}$}

Since the concept of this study developed out of research on eutectic $\mathrm{Sn}-\mathrm{Pb}$, it is useful to compare the creep behavior of $\mathrm{In}-\mathrm{Sn}, \mathrm{Bi}-\mathrm{Sn}$ and $\mathrm{Sn}-\mathrm{Pb}$. In order to compare creep data from materials with various melting points and elastic properties, it is useful to normalize the strain rate and stress in some manner. The stress is normalized by dividing by the shear modulus of each material. One source of error is that the shear modulus changes with temperature. While this change can be taken into account, it is not done here since the temperature range used is relatively narrow. The moduli used are those mentioned in section 2.4.2, which are room temperature values. The shear modulus used for $\mathrm{Sn}-\mathrm{Pb}$ is $14.4 \mathrm{GPa} .{ }^{51}$ The strain rate can be normalized by factoring in the activation energy for creep of each material, i.e. by multiplying the strain rate by $\exp (\mathrm{Q} / \mathrm{kT})$. However, when the activation energies of different systems differ widely, as they do here (see Table 4.1), this type of plot can be misleading.

Another way to compare creep data from alloys with different melting points is to examine data taken at a fixed homologous temperature. The plot in Figure 4.17 shows the differences in creep resistance between the three alloys for data at a homologous temperature of $0.75 \pm 0.01$. This corresponds to about $20{ }^{\circ} \mathrm{C}$ for $\mathrm{In}-\mathrm{Sn}, 40{ }^{\circ} \mathrm{C}$ for $\mathrm{Bi}-\mathrm{Sn}$ and $75^{\circ} \mathrm{C}$ for $\mathrm{Sn}-\mathrm{Pb}$. The In-Sn data is for $\mathrm{In}-\mathrm{Sn}$ on $\mathrm{Cu}$. In-Sn on Ni has a similar creep resistance at $20^{\circ} \mathrm{C}$, and was omitted to simplify the plot. The data on $\mathrm{Sn}-\mathrm{Pb}$ are taken from research by Tribula, ${ }^{1}$ who used the same sample geometry and similar cooling rates to those used in the current study. The data show that $\mathrm{Bi}-\mathrm{Sn}$ is more creep resistant than $\mathrm{Sn}-\mathrm{Pb}$, as expected. However, the creep resistance of $\mathrm{In}-\mathrm{Sn}$ and $\mathrm{Sn}-\mathrm{Pb}$ appear similar when measured at the same homologous temperature. This shows that the low creep 
resistance of $\mathrm{In}-\mathrm{Sn}$ is partly a result of the comparatively high homologous temperatures at which it is usually measured.

\subsection{Tested Microstructures}

\subsubsection{Eutectic Bi-Sn}

Bi-Sn samples can exhibit definite microstructural changes due to deformation. The deformation is concentrated in a band which begins at opposite corners and propagates toward the center of the joint. An example of this can be seen in Figure 4.18, which also shows the microstructure revealed after re-polishing the tested sample. This sample was tested in creep at $20^{\circ} \mathrm{C}$ at a series of applied loads to a total strain of 44 percent. A distinctly different microstructure exists where the deformation was concentrated, whereas outside this region the original as-cast microstructure remains. This can be seen more clearly in the high magnification micrographs in Figure 4.19. The microstructure in the highly deformed region appears to be slightly coarser than the as-cast microstructure, and the interphase boundaries between $\mathrm{Bi}$ and $\mathrm{Sn}$ are more irregular. This new microstructure always formed in the same geometrical location in the samples, which was also where recrystallization had been observed in $\mathrm{Sn}-\mathrm{Pb}$ samples. While the example in Figures 4.18 and 4.19 is for a creep-tested sample, the same type of behavior was observed in samples tested at constant strain rate (see Figure 4.20).

Another experiment was conducted in order to examine better the deformed microstructure in $\mathrm{Bi}-\mathrm{Sn}$. Bulk ingots of the alloy were compressed in a hydraulic press until they were reduced to less than one-half their original thickness. In extensive regions of the pressed samples a morphology similar to that seen in the highly deformed regions of the Bi-Sn joints was observed. A typical micrograph of this structure appears in Figure 4.21. The pressed microstructure seemed elongated in one direction, designated the vertical direction. This morphology is not expected, since the alloy was pressed and 
not rolled (a rolled alloy should have elongated phases in the rolling direction). Nevertheless, this is the microstructure observed.

Measurements of the phase size were made by the line intercept method on several micrographs of unpressed and pressed ingots to determine quantitatively whether the deformed microstructure had coarsened. Results of phase size measurements in three directions are shown in Figure 4.22, which is a plot of mean phase size. The deformed microstructure is coarser, except in the horizontal direction, in which the standard deviation of the phase size was greater that the difference between the mean phase sizes, indicating that there is no difference in phase size in the horizontal direction.

An attempt was made to determine whether the deformed microstructure of $\mathrm{Bi}-\mathrm{Sn}$ was softer than the as-cast microstructure by doing microhardness measurements on both creep samples and ingots. However, the scatter in the data was greater than differences in hardness between deformed and undeformed microstructures.

Another interesting feature was observed in a $\mathrm{Bi}-\mathrm{Sn}$ sample within an unusually large Bi particle. Examination of the surface relief in the as-tested sample, Figure 4.23 , revealed slip lines in the $\mathrm{Bi}$. This particular sample had been deformed to 18 percent shear strain, at which point visible microstructural changes had not occurred. Much of the lamellar microstructure surrounding the $\mathrm{Bi}$ particle remained undisturbed. Therefore, deformation of the $\mathrm{Bi}$ phase is apparently occurring at relatively low strains with the eutectic microstructure still intact.

\subsubsection{Eutectic In-Sn}

The deformation pattern in In-Sn on $\mathrm{Cu}$ is similar to that of $\mathrm{Bi}-\mathrm{Sn}$, with the deformation concentrated in a band along the length of the joint. The deformation is somewhat more spread out than in $\mathrm{Bi}-\mathrm{Sn}$, as can be seen in Figure 4.24. In- $\mathrm{Sn}$ on $\mathrm{Ni}$ samples show surface relief throughout the width and length of the sample, though the most severe deformation is often within particular colonies (see Figure 4.25). 
No obvious morphological changes were observed in tested In-Sn samples, even though concentrations of deformation were observed. Examples of tested In-Sn microstructures appear in Figure 4.26. When these are compared to the micrographs of untested In-Sn samples in Figure 4.3, the microstructures appear to be similar. It is possible that microstructural coarsening has occurred in isolated regions of tested In-Sn on Ni samples, but the evidence is not conclusive. Measurements of phase size were done on a In-Sn on Ni sample before and after creep testing. The results show no change in phase size: the untested sample had a mean phase size of $7.1 \pm 2.0 \mu \mathrm{m}$ and the tested sample had a mean phase size of $6.8 \pm 1.2 \mu \mathrm{m}$. The estimated errors represent one standard deviation. Similar measurements were not done on the $\mathrm{In}-\mathrm{Sn}$ on $\mathrm{Cu}$ owing to the large variation in phase size within a single sample, but the optical micrographs show no apparent change in overall phase size as a result of testing. This lack of coarsening or microstructural changes during high temperature deformation has been confirmed by thermal fatigue studies on In-Sn by Marshall and Walter ${ }^{52}$ and Seyyedi, 39 in which no microstructural changes were observed.

While the overall morphology of the In-Sn eutectic does not appear to be affected by deformation, changes within the $\gamma$ phase were observed. The micrograph in Figure 4.27 shows the presence of what appear to be individual grains within a large $\gamma$ dendrite. Although these grains were not visible in the untested sample, they may have existed within the $\gamma$ phase prior to testing, in which case grain rotation as a result of deformation could cause them to become visible in the optical microscope. Another possibility is that recrystallization within the $\gamma$ phase occurred during deformation, producing new grains. 


\subsection{Effect of Aging}

\subsubsection{Aged Microstructures}

Various samples were aged at $0.9 \mathrm{~T}_{\mathrm{m}}$, which is $100{ }^{\circ} \mathrm{C}$ for $\mathrm{Bi}-\mathrm{Sn}$ and $81{ }^{\circ} \mathrm{C}$ for $\mathrm{In}-\mathrm{Sn}$. Since the diffusional processes that occur during aging are thermally activated, increasing the aging temperature should merely accelerate the rate at which observed changes occur.

After one month aging at $100{ }^{\circ} \mathrm{C}$, several changes in the $\mathrm{Bi}-\mathrm{Sn}$ samples were observed. The fine $\mathrm{Bi}$ lamellae present within the $\mathrm{Sn}$-rich regions of unaged samples coarsened into individual particles, similar in width to $\mathrm{Bi}$ lamellae within the larger eutectic structure. Analysis using EDS on the SEM showed significant diffusion of $\mathrm{Cu}$ through the $\mathrm{Bi}-\mathrm{Sn}$. Up to 15 weight percent $\mathrm{Cu}$ was measured in the center of the joint, compared to less than one percent for unaged samples. Unfortunately, a $\mathrm{Bi}-\mathrm{Sn}$ - $\mathrm{Cu}$ phase diagram is not available. The $\mathrm{Sn}-\mathrm{Cu}$ intermetallic layer at the solder-Cu interface had grown to a thickness of about $7 \mu \mathrm{m}$. The x-ray images for an aged $\mathrm{Bi}$-Sn sample in Figure 4.28 show that the intermetallic is composed of $\mathrm{Cu}$ and $\mathrm{Sn}$.

In order to better observe the intermetallic layer, an aged Bi-Sn sample was fractured in liquid nitrogen $(77 \mathrm{~K})$. Figure 4.29 shows both sides of the fracture surface. The faceted regions on both fracture surfaces are the Bi phase immediately adjacent to the intermetallic layer. Intermetallic particles remain intact and attached to surface 1 (Figure $4.29 a$ ), where they appear fairly round and arrayed in a grain-like structure. The morphology of these intermetallics matches those of $\mathrm{Cu}_{6} \mathrm{Sn}_{5}$ appearing on fracture surfaces of eutectic $\mathrm{Sn}-\mathrm{Pb}$ samples fractured at $77 \mathrm{~K} .{ }^{50}$ Analysis of the sample by $\mathrm{x}$-ray diffraction confirmed the presence of both $\mathrm{Bi}$ and $\mathrm{Cu}_{6} \mathrm{Sn}_{5}$. No $\mathrm{Cu}_{3} \mathrm{Sn}$ was detected, even though the depth analyzed was about $20 \mu \mathrm{m}$, well into the $\mathrm{Cu}$ substrate. Dimples are left behind on surface 2 (Figure 4.29 b) where the intermetallic particles have separated from the surface. The bulk of the solder remains attached to surface 2 .

No obvious change in the arrangement of eutectic phases was observed after aging $\mathrm{Bi}-\mathrm{Sn}$ samples. Figure 4.30 shows the same region of a sample before aging, and after 1 
and 2 months at $100^{\circ} \mathrm{C}$. It appears that slight lamellar fault movement has occurred in a few regions, but overall the structure in the three micrographs appears identical. This result is surprising, since $\mathrm{Bi}-\mathrm{Sn}$ has a relatively fine eutectic microstructure and significant coarsening would be expected after such a severe aging treatment.

Aging has no visible effect on the microstructure of In-Sn on $\mathrm{Cu}$. In contrast, In-Sn on $\mathrm{Ni}$ samples aged for two months at $81{ }^{\circ} \mathrm{C}$ show remarkable microstructural changes. No trace of the as-cast colony microstructure remains. Instead, the microstructure throughout the joint has evolved into what appear to be islands of $\gamma$ phase in a matrix of the $\beta$ phase, similar to the situation in $\mathrm{In}-\mathrm{Sn}$ on $\mathrm{Cu}$. The micrograph in Figure 4.31 is of an In-Sn on Ni sample after aging, which illustrates the dramatic effect of aging on the microstructure (for comparison, see Figure 4.3b). This is similar to the type of microstructural coarsening observed by Caulfield et al. 40 Since evolution of the microstructure with time was not measured, the kinetics of the microstructural changes are not known.

\subsubsection{Mechanical Properties}

Creep testing of an aged In-Sn on Ni sample at $65^{\circ} \mathrm{C}$ gave a stress exponent of 3.4 . The strain rate versus stress data follows the data for $\mathrm{In}-\mathrm{Sn}$ on $\mathrm{Cu}$ samples at the same temperature, as illustrated in Figure 4.32. The creep behavior of In-Sn on Cu does not appear to change with aging.

Aging of Bi-Sn also has no noticeable effect on the creep behavior. Aged samples follow the same curves as unaged samples tested at the same temperature. In a related experiment, a single unaged $\mathrm{Bi}-\mathrm{Sn}$ sample was creep-tested at 75 "C, cooled to room temperature and reloaded at $20^{\circ} \mathrm{C}$. Another sample was tested first at 20 "C followed by additional testing at $75^{\circ} \mathrm{C}$. In both cases, the $20^{\circ} \mathrm{C}$ data matched that of samples tested only at $20^{\circ} \mathrm{C}$ and the $75^{\circ} \mathrm{C}$ data matched that of samples tested only at $75^{\circ} \mathrm{C}$, as seen in Figure 4.33 . 


\section{IMPLICATIONS}

\subsection{The Effect of Substrate on In-Sn}

Among the experimental results mentioned in the previous chapter are the many ways in which In-Sn on $\mathrm{Cu}$ differs from In-Sn on Ni. It is important to synthesize these results and explain why the differences occur and what they mean.

\subsubsection{Microstructural differences}

The microstructure of In-Sn is severely affected by the substrate, as seen in the previous chapter. The most likely explanation is that the diffusion of $\mathrm{Cu}$ into the samples without a Ni diffusion barrier is significant enough to disturb the formation of the eutectic structure. Cu diffuses into the In-Sn while it is still liquid. Because of the relatively slow cooling rate used, the alloy remains in the liquid state for several minutes. If the solder is now an off-eutectic ternary alloy, that would explain the observed microstructure. Unfortunately, no ternary phase diagrams are available for $\mathrm{In}-\mathrm{Sn}-\mathrm{Cu}$ in the low-Cu region. Therefore, DSC tests were run on $\mathrm{In}-\mathrm{Sn}$ pieces taken from both $\mathrm{In}-\mathrm{Sn}$ on $\mathrm{Cu}$ and In-Sn on Ni samples to determine the effect of the substrate on solidification. Results showed a large peak at the eutectic temperature for both samples, with an additional smaller peak at higher temperature for the $\mathrm{In}-\mathrm{Sn}$ on $\mathrm{Cu}$. This confirms the hypothesis that the In-Sn on $\mathrm{Cu}$ is off-eutectic. Dendrites of the $\mathrm{Sn}$-rich $\gamma$ phase solidify first, and subsequent nucleation of the eutectic near the $\gamma$ dendrites is coarse and irregular. Regions of the In-Sn far removed from $\gamma$ dendrites solidify in a fairly normal manner, thus producing some lamellar regions in the joint. This microstructure is predicted based on the theories of Mondolfo, ${ }^{18}$ which were described in section 2.1.2. The regions of very fine eutectic structure are large $\beta$ phase regions in which lamellae of the $\gamma$ phase have precipitated during cooling. This is a result of the variation in composition of the $\beta$ phase with temperature as the alloy is cooled. The slow rate of cooling allowed the 
precipitation to occur. Precipitation would not be expected in rapidly cooled samples. In fact, rapid cooling of eutectic In-Sn gives an entirely different microstructure than either microstructure observed here. Experiments by Mei and Morris ${ }^{53}$ showed that the microstructure of rapidly cooled In-Sn on bare $\mathrm{Cu}$ was uniform and equiaxed, and much finer than the microstructures observed in the slowly cooled samples.

The $8 \mu \mathrm{m}$ layer of $\mathrm{Ni}$ in the Ni-plated samples is sufficient to prevent diffusion of $\mathrm{Cu}$ into the joint. This is expected, since a previous study showed that a $2 \mu \mathrm{m}$ layer of $\mathrm{Ni}$ deposited on a $\mathrm{Cu}$ substrate underneath a coating of a Sn-bearing alloy was sufficient to prevent formation of $\mathrm{Cu}-\mathrm{Sn}$ intermetallics. ${ }^{54} \mathrm{Ni}$ diffuses much more slowly than does $\mathrm{Cu}$ into liquid In-Sn, so only trace quantities of $\mathrm{Ni}$ reach the In-Sn. Therefore, no obstacles exist to prevent the formation of a normal, colony-based eutectic microstructure.

\section{1 .2 Creep Mechanisms}

The creep data can be interpreted in terms of possible mechanisms for creep deformation in the two systems. The data obtained in this study point strongly to diffusion-controlled dislocation creep as a likely creep mechanism. The stress exponents for $\mathrm{In}-\mathrm{Sn}$ on $\mathrm{Ni}$ have a mean value near 5 and those for $\mathrm{In}-\mathrm{Sn}$ on $\mathrm{Cu}$ are all near 3, as mentioned previously. Previous studies on creep of the pure elements gave stress exponents near 7 for both $\mathrm{Sn}^{46}$ and In. ${ }^{45}$ While the stress exponent for In-Sn on $\mathrm{Ni}$ is below these values, it is still within the expected range for dislocation climb-controlled creep. A possible explanation for the lower stress exponent of $\mathrm{In}-\mathrm{Sn}$ on $\mathrm{Cu}$ can be found by examining research on aluminum. Bradley 55 tested $\mathrm{Al}$ alloys at constant strain rate and found the strain rate sensitivity to be near 0.15 for pure $\mathrm{Al}$ and near 0.3 for $\mathrm{Al}-2.9 \mathrm{Mg}$. The strain rate sensitivity is the inverse of the stress exponent, so the corresponding stress exponents would be near 7 for $\mathrm{Al}$ and 3 for $\mathrm{Al}-\mathrm{Mg}$. The $\mathrm{Al}-\mathrm{Mg}$ alloy is a solid solution, similar to the $\beta$ and $\gamma$ phases in eutectic In-Sn. Reasons for the difference in behavior 
between $\mathrm{In}-\mathrm{Sn}$ on $\mathrm{Cu}$ and on $\mathrm{Ni}$ will be made clearer in the discussion of activation energies which follows.

Literature values for bulk self-diffusion activation energies of In and $\mathrm{Sn}$ are $0.78^{56}$ and $1.08 \mathrm{eV}, 57,58$ respectively. The value of $0.73 \mathrm{eV}$ obtained for creep of $\mathrm{In}-\mathrm{Sn}$ on $\mathrm{Cu}$ compares favorably to the value for pure In, and the value of $1.04 \mathrm{eV}$ for creep of In-Sn on $\mathrm{Ni}$ is similar to that for self-diffusion of pure $\mathrm{Sn}$. Kaur, et al. ${ }^{59}$ have surveyed the available data on grain-boundary diffusion in $\mathrm{Sn}$ and found reliable activation energies ranging from 0.41 to $0.464 \mathrm{eV}$. These values are significantly helow the activation energies calculated for creep of In-Sn, implying that grain boundary sliding is not dominant in either system. One factor complicating the determination of creep mechanisms for eutectic In-Sn is that the allo. is composed of intermediate phases rather than terminal solid solutions, as mentioned earlier. Therefore, it is likely that the diffusivity within these phases will not be equal to the diffusivities of either of the pure elements. Diffusion data for $\mathrm{In}-\mathrm{Sn}$ alloys are scarce. One reference reports an activation energy for diffusion of In in $\mathrm{Sn}$ of $0.51 \mathrm{eV},{ }^{60}$ which does not match the activation energy for creep of $\mathrm{In}-\mathrm{Sn}$ on $\mathrm{Cu}$ determined in the current study.

Since the microstructure of $\mathrm{In}-\mathrm{Sn}$ on $\mathrm{Cu}$ appears to consist of $\gamma$ phase regions in a $\beta$ phase matrix, it is reasonable to presume that the $\beta$ phase dominates the creep deformation. The islands of $\gamma$ phase are discontinuous and do not control the deformation but are swept along in the flow of the $\beta$ phase. For In-Sn on $\mathrm{Ni}$ the data strongly suggest that the Sn-rich $\gamma$ phase is controlling the creep behavior. In the lamellar eutectic microstructure the two phases are strongly coupled, and the deformation is dominated by the harder phase. Creep controlled by the Sn-rich phase is also supported by creep data on pure $\mathrm{Sn}$ mentioned earlier, ${ }^{46}$ in which the authors found an acuvation energy for creep of $1.0 \mathrm{eV}$, similar to the activation energy for creep of In-Sn on $\mathrm{Ni}$. 


\subsubsection{Stress-Strain Behavior}

The rapid decay in flow stress of the In-Sn on $\mathrm{Cu}$ can be explained in two different ways. The non-uniform deformation mentioned earlier has the consequence that the entire sample is not experiencing the strain measured by the strain gage, which registers overall displacement. Therefore, the local strain rate is actually higher than that measured by differentiating "bulk" strain with respect to time. The stress is also distributed over a smaller area than assumed, so that the stress calculated using equation (3.1) is too low. This implies that the stress drop is not really as steep as the plots in Figures 4.13 and 4.14 indicate. However, this probably does not account for all of the stress drop. A second reason for a decrease in flow stress is microstructural softening, since recovery is expected to be significant at the testing temperatures used. Since the concentration of deformation cannot be quantified, it is difficult to tell how much of the apparent stress drop is due to this concentration and how much is due to microstructural softening.

The In-Sn on Ni samples exhibit neither severe deformation concentrations nor dramatic drops in the flow stress during stress-strain tests. It appears that with more uniform deformation, the slight decrease in stress during testing is a result of microstructural softening alone. This supports the hypothesis that stress and strain concentrations are responsible for much of the stress decay observed in $\mathrm{In}-\mathrm{Sn}$ on $\mathrm{Cu}$.

The observation that In-Sn on Ni appears to have a lower shear strength than In-Sn on $\mathrm{Cu}$ is unexpected. Presumably, the In-Sn on Ni system should be more creep resistant, since the microstructure is finer and deformation is presumably controlled by the $\gamma$ phase, which should be harder to deform than the $\beta$ phase. At present, there is no obvious explanation for the observed differences in shear strength.

The correlation between creep and constant strain rate data is important, but not surprising. The In-Sn alloy is at a high homologous temperature and will naturally creep under any type of testing conditions above $200 \mathrm{~K}$. The continuity between the data from 
the two types of tests indicates that the same deformation mechanisms are operating regardless of whether stress or strain rate is the independent variable. It also shows that the shear strength at a given applied strain rate can be inferred from creep data.

\subsubsection{Aging of In-Sn}

The effect of aging on microstructure can be explained by simple coarsening theory. The fine lamellar eutectic of the In-Sn on Ni samples is inherently unstable, because of the high interfacial energy of the many interphase boundaries between the lamellae. When exposed to high temperature the phases will rearrange to lower their interfacial energy by reducing the number of interphase boundaries. This is done not merely by coarsening the lamellar structure but by spheroidization of the $\gamma$ phase regions, toward a geometry with the lowest possible surface-to-volume ratio. The microstructure of the In$\mathrm{Sn}$ on $\mathrm{Cu}$ does not coarsen in this manner because it is fairly coarse in the as-cast condition and therefore has a much lower interfacial energy and thus insufficient driving force to cause noticeable rearrangement of the phases under the aging conditions of this study.

Since the microstructure of $\mathrm{In}-\mathrm{Sn}$ on $\mathrm{Cu}$ does not coarsen with aging, it follows that the creep behavior does not change either. However, when In-Sn on Ni samples are aged they coarsen into a microstructure that is qualitatively similar to the $\mathrm{In}-\mathrm{Sn}$ on $\mathrm{Cu}$ microstructure, in that the soft $\beta$ phase forms a matrix. The creep deformation is now dominated by the $\beta$ phase and therefore the behavior matches that of the In-Sn on $\mathrm{Cu}$.

\subsection{Microstructure and Deformation of Bi-Sn}

\subsubsection{As-Cast Microstructure}

The complex regular microstructure can be affected by both cooling rate and impurities, as mentioned in section 2.1.2. The slow cooling rate used to make the samples in this study allows significant time for diffusion. This includes both diffusion 
of $\mathrm{Cu}$ into the melt and diffusion of $\mathrm{Bi}$ and $\mathrm{Sn}$ during solidification. The result is a modified complex regular eutectic. In the example of alkali metal impurities in $\mathrm{Bi}$ containing eutectics discussed in section 2.1.2, chemisorption of the impurities lowered the growth temperature, which caused dendrites of the non-faceting phase to grow ahead of the eutectic front ${ }^{16}$. This explains the existence of occasional $\mathrm{Sn}$ dendrites observed in the Bi-Sn eutectic. This rapid growth of the Sn-rich phase also inhibits development of a cellular structure. Though some cells have been observed in the $\mathrm{Bi}-\mathrm{Sn}$ samples, the cellular structure does not encompass the entire joint.

\subsubsection{L. formed Microstructure}

The que ion of whether it is appropriate to label the microstructural changes observed in de rmed $\mathrm{Bi}-\mathrm{Sn}$ as recrystallization is complicated. In order to address this question it is us. ful to consider two of the mechanisms for dynamic recrystallization described in section 2.3.1. The nucleation and growth mechanism can be used to describe the microstructural changes in $\mathrm{Sn}-\mathrm{Pb}$. The as-cast lamellar microstructure was replaced with an equiaxed recrystallized microstructure. Another mechanism used to explain dynamic recrystallization is grain boundary migration and/or bulging. The net effect of grain boundary migration is a rearrangement of grains, with the size remaining relatively constant. The new structure is not equiaxed, but has a morphology similar to the original structure. This model better fits the observed behavior of $\mathrm{Bi}-\mathrm{Sn}$. However, instead of grain boundaries it is interphase boundaries which migrate. In this context, it seems appropriate to label the microstructural changes observed in $\mathrm{Bi}-\mathrm{Sn}$ as dynamic recrystallization. The changes are presumably caused by a build-up of dislocation density at the interphase boundaries which provides sufricient driving force to promote rearrangement of the phases into a more energetically favorable arrangement.

The recrystallized bands observed in $\mathrm{Bi}-\mathrm{Sn}$ samples were seen in samples subjected to a wide variety of applied stress and strain rate conditions but did not develop in all tested 
Bi-Sn samples. In general, recrystallization has been found to depend on stress, strain rate, strain, or a combination of these parameters, depending on the material and the type of deformation (see section 2.3). The fact that recrystallization was observed in some but not all samples tested under both creep (minimum strain rate $=10-6 / \mathrm{sec}$ ) and constant strain rate (strain rate $\approx 10^{-4} / \mathrm{sec}$ ) conditions indicated that strain rate is probably not a factor. However, an analysis of 11 tested Bi-Sn samples showed a definite correlation between recrystallization and total shear strain during a test. This strain represents the strain at which a given test was stopped and the microstructure examined, and not the strain to failure. Table 5.1 gives total strain, minimum or applied strain rate, and peak or applied stress for the 11 samples and indicates which samples recrystallized. Samples are listed in order of increasing total strain. A minimum shear strain of between 20 and 30 percent was required to cause well-developed recrystallized bands.

\subsubsection{Creep Behavior}

The creep behavior of Bi-Sn was described in section 4.2.1. An attempt will be made to explain why the behavior varies with both temperature and stress and to propose creep mechanisms.

The variation of stress exponent with stress seen at 0 and 20 " $\mathrm{C}$ is fairly straightforward, and typical of a situation in which two independent mechanisms operate, each with a different stress exponent. The mechanism with the lower stress exponent will dominate at low stresses, and vice versa. In order to identify these mechanisms, it is useful to look at the activation energies.

The calculated values for activation energy for creep of Bi-Sn (see Table 4.1) vary widely from region to region. The values do noi match the activation energies of either bulk or grain boundary diffusion for pure $\mathrm{Sn}$. Two sources quote the activation energy for self-diffusion of $\mathrm{Sn}$ to be about $1.1 \mathrm{eV}, 57.58$ and that for grain boundary diffusion of $\mathrm{Sn}$ is reported to be between 0.41 and $0.464 \mathrm{eV} .{ }^{59}$ However, since the $\mathrm{Sn}$ phase in the Bi- 
Sn eutectic is decorated with Bi precipitates, the diffusion within this phase is likely to be different from diffusion in pure $\mathrm{Sn}$. The self-diffusion activation energy for $\mathrm{Bi}-\mathrm{Sn}$ was calculated by Otake, et al. ${ }^{61}$ and was found to be $0.66 \mathrm{eV}$, matching the activation energy for creep of $\mathrm{Bi}-\mathrm{Sn}$ in the low temperature, low stress region. This suggests that the $\mathrm{Bi}$ phase may be controlling the creep deformation in this region.

The activation energy for creep in both the low temperature, high stress region and the high temperature region is the same, suggesting that the same mechanism may be responsible for the deformation. The stress exponents in the two temperature ranges are different, but they are both within the expected range for dislocation creep. One possibility is that the Sn-rich phase is controlling the deformation in these regions. The reason the activation energy does not match that of self-diffusion of $\mathrm{Sn}$ is that the $\mathrm{Sn-rich}$ phase contains $\mathrm{Bi}$, both in solid solution and as precipitates. The change in solid solubility of $\mathrm{Bi}$ in $\mathrm{Sn}$ with temperature may be responsible for the change in the shape of creep curves, and perhaps also the change in stress exponent, as test temperature is raised. The roughness of the creep curves increases gradually with increasing temperature. Creep curves at $40^{\circ} \mathrm{C}$ are only slightly rough, while those at $75^{\circ} \mathrm{C}$ are so rough that determination of an appropriate steady-state creep rate is difficult. However, the connection between amount of $\mathrm{Bi}$ precipitates in the Sn phase and the shape of creep curves remains unclear.

\subsection{Deformation Patterns}

It is useful to look at the relationship between deformation patterns and microstructural changes in solder alloys by comparing the current results to previous research on $\mathrm{Sn}-\mathrm{Pb}$. The research on $\mathrm{Sn}-\mathrm{Pb}^{3}$ proposed the following sequence of events. Inhomogeneous shear strain develops during high temperature deformation (creep or fatigue), with concentrations of stress and strain at free surfaces (the corners of the notches in creep samples). The lamellar eutectic microstructure of $\mathrm{Sn}-\mathrm{Pb}$ is inherently 
unstable and recrystallizes locally to relieve deformation in the most highly strained regions. Since the recrystallized material is softer than the as-cast material, recrystallization progresses along the length of the solder joint, similar to the propagation of a crack. This recrystallized band is always located near the solder/substrate interface but entirely within the solder. One assumption in this theory is that if the microstructure were not unstable, then concentrated shear along the length of the joint would not develop.

The deformation patterns observed for $\mathrm{Bi}-\mathrm{Sn}$ and for In-Sn on $\mathrm{Cu}$ in this study are qualitatively similar to those seen in $\mathrm{Sn}-\mathrm{Pb}$, with concentrated deformation along the length of the joint slightly displaced from the solder/substrate interface. In Bi-Sn distinct microstructural changes were observed, but that was not the case in In-Sn. Therefore, it seems as though microstructural instability is not necessary to induce this deformation pattern. The deformation pattern was more diffuse in the In-Sn, though, suggesting that microstructural changes can intensify the concentration of shear deformation. In-Sn on Ni samples were the only ones that exhibited a different deformation pattern, with deformation spread throughout the joint width and concentrated in particular colonies. Deformation still started at the corners where concentrations of stress and strain exist. It appears that deformation begins to concentrate at these corners because of the sample geometry, but that the manner in which it spreads is microstructure-dependent. The current results do not contradict the previous results on $\mathrm{Sn}-\mathrm{Pb}$. The theory used to describe $\mathrm{Sn}-\mathrm{Pb}$ behavior probably applies, though it is not known whether the deformed microstructure in $\mathrm{Bi}-\mathrm{Sn}$ is softer than the as-cast microstructure. However, in alloys such as In-Sn in which obvious morphological changes do not occur, the connection between deformation patterns and microstructure is still not understood. 


\section{Conclusions}

\subsection{Summary}

This research has revealed much information about how $\mathrm{In}-\mathrm{Sn}$ and $\mathrm{Bi}-\mathrm{Sn}$ eutectics respond to high temperature deformation. To begin with, the as-cast microstructures of the three alloy systems studied vary considerably. The Bi-Sn samples have the complex regular microstructure expected for this alloy. Diffusion of $\mathrm{Cu}$ through the In-Sn solder in In-Sn on $\mathrm{Cu}$ samples creates an off-eutectic ternary alloy that solidifies into a nonuniform and irregular microstructure. The Ni diffusion barrier in In-Sn on Ni samples is effective, giving a lamellar nicrostructure with eutectic colonies. : 'hese differences in microstructure affect the creep behavior.

The non-uniform microstructure of $\mathrm{In}-\mathrm{Sn}$ on $\mathrm{Cu}$ gives creep deformation that is presumably controlled by dislocation creep in the In-rich $\beta$ phase. The addition of a $\mathrm{Ni}$ diffusion barrier leads to a much more uniform microstructure with creep controlled by the harder $\mathrm{Sn}$-rich $\gamma$ phase. When the In-Sn on $\mathrm{Ni}$ is aged the microstructure coarsens and the creep behavior changes to resemble that of $\mathrm{In}-\mathrm{Sn}$ on $\mathrm{Cu}$.

There are also differences in the deformation patterns of In-Sn that depend on substrate, and these affect the stress-strain curves. Deformation is concentrated in a band along the length of $\mathrm{In}-\mathrm{Sn}$ on $\mathrm{Cu}$ samples, and rapid decay in the engineering stress is observed. With the more uniform deformation of $\mathrm{In}-\mathrm{Sn}$ on $\mathrm{Ni}$, much of the stress drop is eliminated, showing that most of the decay in stress is due to concentrations of deformation rather than microstructural softening.

The assumption in the microelectronics industry and by alloy manufacturers has been that the presence of $\mathrm{Cu}$ in $\mathrm{In}-\mathrm{Sn}$ joints is detrimental. ${ }^{62}$ However, current research shows that while a Ni diffusion barrier certainly changes the behavior of $\mathrm{In}-\mathrm{Sn}$, it is not clear whether it leads to an improvement. 
Additional information has also been gained regarding the creep behavior of $\mathrm{Bi}-\mathrm{Sn}$. More than one creep mechanism operates in the Bi-Sn system, which suggests that accelerated testing at a higher temperature and/or a higher strain rate than expected in service will not accurately predict behavior under realistic conditions. While two independent mechanisms operate at temperatures of 0 and $20^{\circ} \mathrm{C}$ (a low stress and a high stress mechanism), it is not clear whether one of these, both of these, or a completely separate mechanism operates at higher temperatures.

The deformation of $\mathrm{Bi}-\mathrm{Sn}$ is concentrated in a band along the length of the sample, similar to In-Sn. Bi-Sn exhibits localized microstructural changes in the same geometrical pattern as did $\mathrm{Sn}-\mathrm{Pb}$, but the nature of these changes is quite different. While both can be called dynamic recrystallization, the morphology of the recrystallized regions is definitely not the same. In-Sn exhibits no obvious microstructural changes as a result of high temperature deformation, presumably because the alloy cannot build up sufficient density of dislocations to drive microstructural rearrangement.

\subsection{Recommendations for Future Work}

Various additional experimental work could lead to a greater understanding of the behavior of $\mathrm{In}-\mathrm{Sn}$ and $\mathrm{Bi}-\mathrm{Sn}$.

From a fundamental viewpoint, the reason why $\mathrm{Sn}-\mathrm{Pb}$ and $\mathrm{Bi}-\mathrm{Sn}$ undergo microstructural changes and In-Sn does not is not completely understood. Without knowing the dislocation structure in these alloys and how it changes during deformation, understanding is necessarily limited. An in situ TEM study of the three alloys could yield important insights into the ways in which the alloys deform. Sample preparation would be difficult, particularly with the In-Sn. If the alloy recovers as rapidly as expected, it might not be possible to observe dislocations within a thin foil. A TEM study is more feasible with the other two alloys. 
The proposed mechanisms for creep behavior of $\mathrm{In}-\mathrm{Sn}$ on $\mathrm{Cu}$ versus $\mathrm{In}-\mathrm{Sn}$ on $\mathrm{Ni}$ have not been proven. One difficulty in interpreting results on the In-Sn eutectic is that the behavior of the $\beta$ and $\gamma$ phases of the eutectic is unknown. This makes it difficult to accurately determine which phase is controlling the creep deformation in a given situation. Studies of the creep behavior of the individual phases could confirm the hypotheses presented here and enhance understanding of how the In-Sn eutectic deforms.

The changes observed upon aging of $\mathrm{In}-\mathrm{Sn}$ and $\mathrm{Bi}-\mathrm{Sn}$ have not been investigated in depth. Additional studies to investigate the kinetics of aging processes, such as the coarsening of the fine lamellar eutectic in the In-Sn on $\mathrm{Ni}$, would be worthwhile. Also, very little is known about the ternary intermetallics in the $\mathrm{In}-\mathrm{Sn}-\mathrm{Cu}$ and $\mathrm{In}-\mathrm{Sn}-\mathrm{Ni}$ systems and research on the crystallography and growth of these compounds is recommended.

Examination of the fatigue behavior of both $\mathrm{In}-\mathrm{Sn}$ and $\mathrm{Bi}-\mathrm{Sn}$ would be useful, both for fundamental research and because fatigue of solder joints is a primary concern to the microelectronics industry. For $\mathrm{Sn}-\mathrm{Pb}$, the same failure mechanisms operate in creep, isothermal fatigue and thermal fatigue, but that might not be the case for In-Sn and Bi-Sn. Because of the hypothesis that the solubility of $\mathrm{Bi}$ in $\mathrm{Sn}$ as a function of temperature may influence the deformation characteristics of the $\mathrm{Bi}-\mathrm{Sn}$ eutectic, thermal fatigue studies on this alloy would be particularly interesting. Although current results showed that prior creep testing at one temperature does not affect creep behavior at a different temperature, that experiment involved only one thermal cycle. Extensive thermal cycling that would change the distribution and size of $\mathrm{Bi}$ precipitates within the $\mathrm{Sn}$ phase could have important consequences. 


\section{REFERENCES}

1. D. Tribula, J. Electronic Packaging, 112, 87, 1990.

2. D. Tribula, Ph. D. Dissertation, University of California, Berkeley, CA, 1990.

3. D. Tribula, D. Grivas, D. R. Frear and J. W. Morris, Jr., J. Electron. Packaging, 111, 83 (1989).

4. M. McCormack, M. S. Thesis, University of California, Berkeley, CA, 1988.

5. T. S. E. Summers, Ph. D. Dissertation, University of California, Berkeley, CA, 1991.

6. D. Frear, D. Grivas and J.W. Morris, Jr., J. Metals, 40, 18 (1988).

7. D. Frear, D. Grivas, M. McCormack, D. Tribula, and J. W. Morris, Jr., Proc. 3rd Ann ASM Electron. Packaging and Corrosion in Microelectronics Conf., 3, 269 (1987).

8. R. Elliott, Eutectic Solidification Processing: Crystalline and Glassy Alloys, p. 120, Butterworths \& Co., Ltd., London, U. K., 1983.

9. K. A. Jackson and J. D. Hunt, Trans. Metall. Soc. AIME, 236, 1129 (1966).

10. F. R. Mollard and M. C. Flemings, Trans. Metall. Soc. AIME, 239, 1534 (1967).

11. K. A. Jackson, Liquid Metals and Solidification, p. 174, ASM Intl., Cleveland, OH, 1958.

12. J. W. Cahn, Acta Metall., 8, 554 (1960).

13. M. R. Taylor, R. S. Fidler, and R. W. Smith, J. Crystal Growth, 3-4, 666 (1968).

14. R. S. Fidler, M. N. Croker and R. W. Smith, J. Crystal Growth, 13-14, 739 (1972).

15. R. Elliott, Eutectic Solidification Processing: Crystalline and Glassy Alloys, pp. 150-51, Butterworths \& Co., Ltd., London, U. K., 1983.

16. D. L. Baragar, M. Sahoo, and R. W. Smith, J. Crystal Growth, 41, 278 (1977).

17. B. E. Sundquist, R. Bruscato, and L. F. Mondolfo, J. Inst. Metals, 91, $2(1) 4$ (1962).

18. L. F. Mondolfo, J. Australian Inst. Metals, 10, 169 (1965).

19. J. Cadek, Creep in Metallic Materials, p. 14, Elsevier Science Publ. Co., New York, NY, 1988. 
20. R. W. Hertzberg, Deformation and Fracture Mechanics of Engineering Materials, 3rd ed., pp. 145-46, John Wiley and Sons, Inc., New York, NY, 1989.

21. F. Haessner, in Recrystallization of Metallic Materials, F. Haessner, editor, pp. 1-10, Dr. Riederer Verlag GmbH, Stuttgart, Germany, 1978.

22. G. Gottstein, L. Chang and H. F. Yung, Materials Science and Technology, 7, 158 (1991).

23. G. Gottstein, Metal Science, 17, 497 (1983).

24. El Saied M. I. Ali, M. W. Barsoum, M. H. Ishaq, and H. D. Merchant, J. LessCommon Metals, 58, 133 (1978).

25. I. G. Solorzano, J. A. C. Cohn, and R. M. A. de Andrade, Materials Science and Technology, 7, 565 (1991).

26. C. E. T. White and H. Okamoto, Phase Diagrams of Indium Alloys and Their Engineering Applications, p. 255, Indium Corporation of America, Utica, NY and ASM Intl., Materials Park, OH, 1992.

27. T. B. Massalski, editor-in-chief, Binary Alloy Phase Diagrams, p. 540, ASM Intl., Materials Park, OH, 1986.

28. R. Kubiak, M. Wolcyrz and W. Zacharko, J. Less-Common Metals, 65, 263 (1979).

29. R. C. Evans, An Introduction to Crystal Chemistry, pp. 126-27, Cambridge University Press, New York, NY, 1964.

30. E. S. Hedges, editor, Tin and Its Alloys, pp. 56-59, Edward Arnold, Ltd., London, U. K., 1960.

31. W. J. Tomlinson and I. Collier, J. Mater. Sci., 22, 1835 (1987).

32. K. S. Dogra, Brazing and Soldering, 9, 28 (1985).

33. R. N. Wild, "Some Fatigue Properties of Solders and Solder Joints," IBM Report no. 74Z00481, Owego, NY, 1975.

34. Z. Guo, A. F. Sprecher, Jr., H. Conrad and M. Kim, Proc. Mater. Development in Microelectronics Packaging Conf., 155 (1991).

35. L. E. Felton, C. H. Raeder, C. K. Havasy, and D. B. Knorr, Proc. IEEE/CHMT Int. Electon. Manufacturing Technol. Symp., 300 (1992). 
36. R. N. Wild, "Properties of Some Low Melt Fusible Solder Alloys," IBM Report no. 71Z00408, Owego, NY, 1971.

37. M. Plötner, B. Donat and A Benke, Cryogenics, 31, 159 (1991).

38. Z. Mei and J. W. Morris, Jr., J. Electon. Mater., 21, 599 (1992).

39. J. Seyyedi, Soldering and Surface Mount Technology, 13, 26 (1993).

40. T. Caulfield, S. Purushothaman and D. P. Waldman, Adv. Cryogenic Eng. Mater., 30, 311 (1984).

41. A. G. Atkins, et al., J. Inst. Metals, 94, 369 (1966).

42. U. P. Singh and H. D. Merchant, Met. Trans., 4, 2621 (1973).

43. Pattanaik and V. Raman, Proc. Mater. Development in Microelectronics Packaging Conf., 251 (1991).

44. R. E. Frenkel, M. S. Thesis, University of California, Berkeley, CA, 1954.

45. R. Darveaux, E. Yung, I. Turlik, and K. L. Murty, Mater. Res. Soc. Symp. Proc., 203, 443 (1991).

46. F. A. Mohamed, K. L. Murty and J. W. Morris, Jr., Metall. Trans, 4, 935 (1973).

47. A. M. Magomedev, Russian Metallurgy, no. 2, 135 (1986).

48. A. D. Romig, Jr., F. G. Yost, and P. F. Hlava, in Microbeam Analysis - 1984, A. D. Romig, Jr. and J. I. Goldstein, editors, p. 87, San Francisco Press, San Francisco, CA, 1984.

49. D Villars and L. D. Calvert, Pearson's Handbook of Crystallographic Data for Intermetallic Phases, vol. 3, pp. 2552-53 and 2897-98, ASM Intl., Metals Park, $\mathrm{OH}$, 1985.

50. L. Quan, D. Frear, D. Grivas, and J. W. Morris, Jr., J. Electron. Mater., 16, $2(13$ (1987).

51. T. J. Kilinski, J. R. Lesniak, and B. I. Sandor, in Solder Joint Reliability: Theory and Applications, pp. 385-86, J. H. Lau, editor, Van Nostrand Reinhold, New York, NY, 1991.

52. J. L. Marshall and S. R. Walter, Int. J. Hybrid Microelectronics, 10, 11 (1987).

53. Z. Mei and J. W. Morris, Jr., J. Electron. Mater., 21, 401 (1992). 
54. V. V. Slepushkin and G. S. Mukovnina, Zashchita Metallov, 21, 280 (1985).

55. E.L. Bradley, III, Ph. D. Dissertation, University of California, Berkeley, CA, 1993.

56. R. E. Eckert and H. J. Drickamer, J. Chem. Phys., 20, 13 (1952).

57. J. D. Meakin and E. Klokholm, Trans. Met. Soc. AIME, 218, 463 (1960).

58. C. Coston and N. H. Nachtreib, J. Phys. Chem., 68, 2219 (1964).

59. I. Kaur, W. Gust, and L. Kozma, Handbook of Grain and Interface Boundary Diffusion, pp. 1277-85, Ziegler Press, Stuttgart, Germany, 1989.

60. B. B. Straumal, L. M. Klinger and L. S. Shvindlerman, Acta Metall., 32, 1355 (1984).

61. S. Otake, Y. Ishii, and N. Matsuno, Jap. J. Appl. Phys., 20, 1037 (1981).

62. C. E. T. White and G. P. Evans, Research and Development, 28, 88 (1986). 


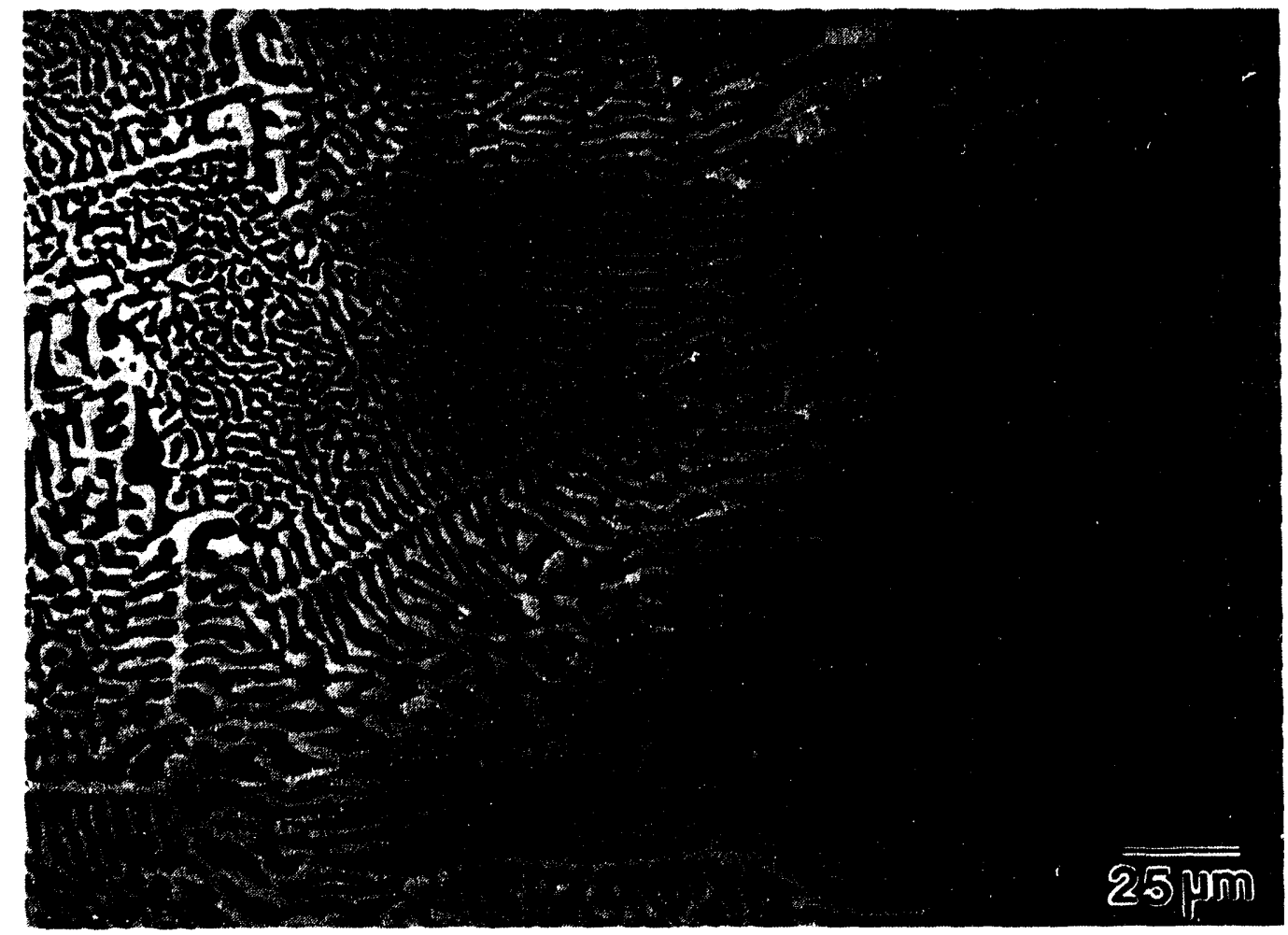

Figure 2.1 Optical micrograph showing cell boundaries in eutectic Bi-Sn. The Bi phase appears light and the Sn phase appears dark. [XBB 9311-7271] 


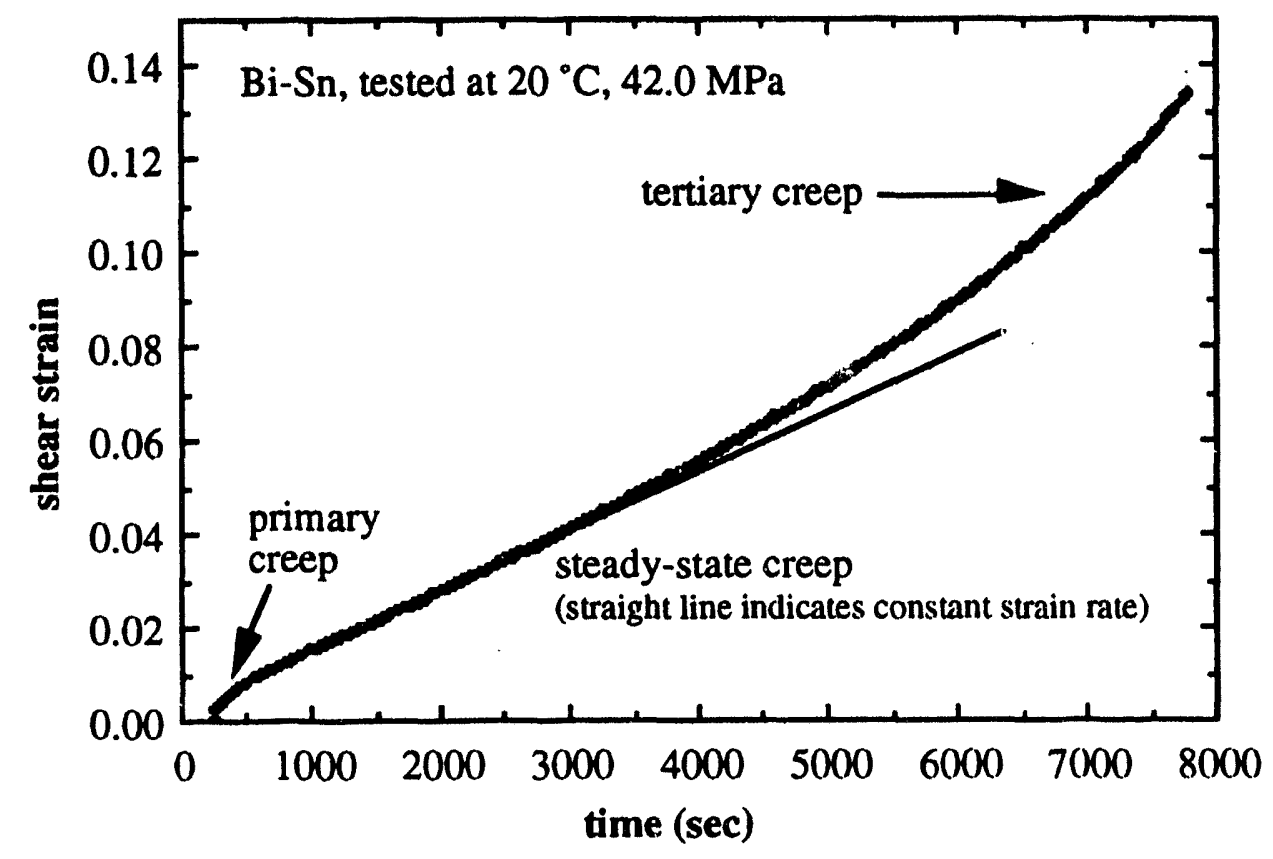

Figure 2.2 Typical creep curve showing regions of primary, steady-state and tertiary creep. 

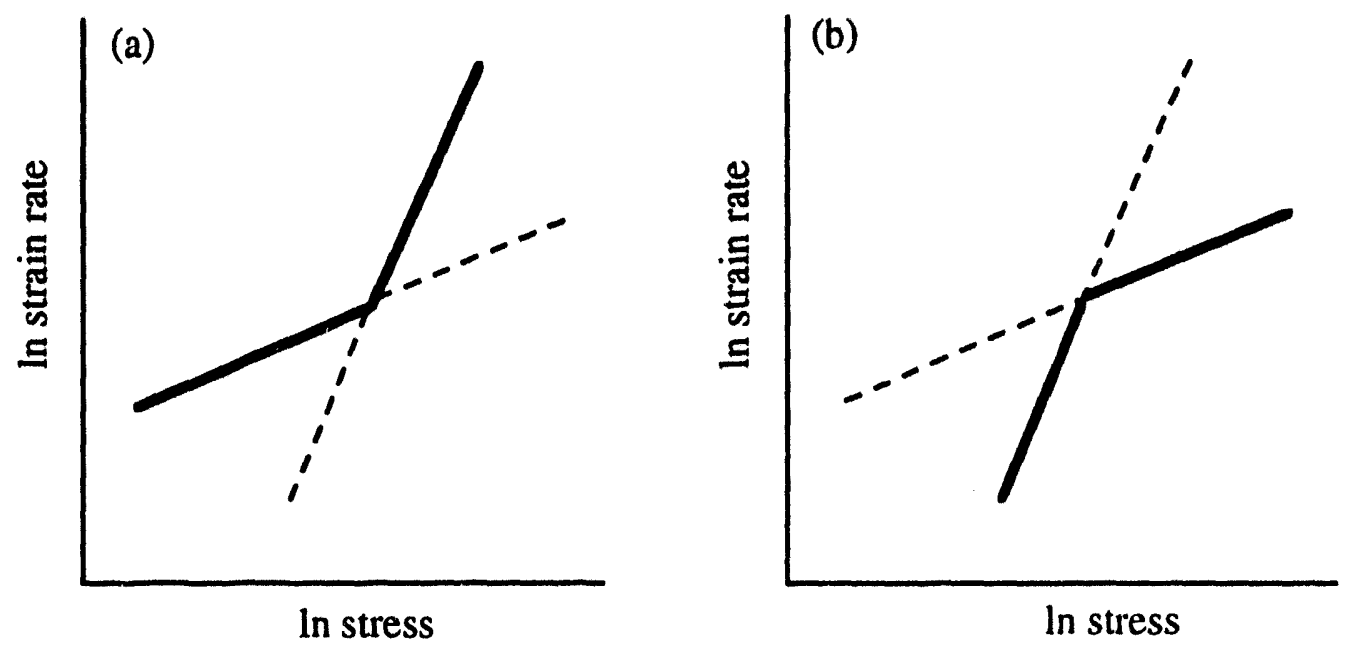

Figure 2.3 Illustrations of creep behavior for two mechanisms with different stress dependences when the mechanisms are (a) independent and (b) sequential. The observed creep rate will follow the solid lines. 

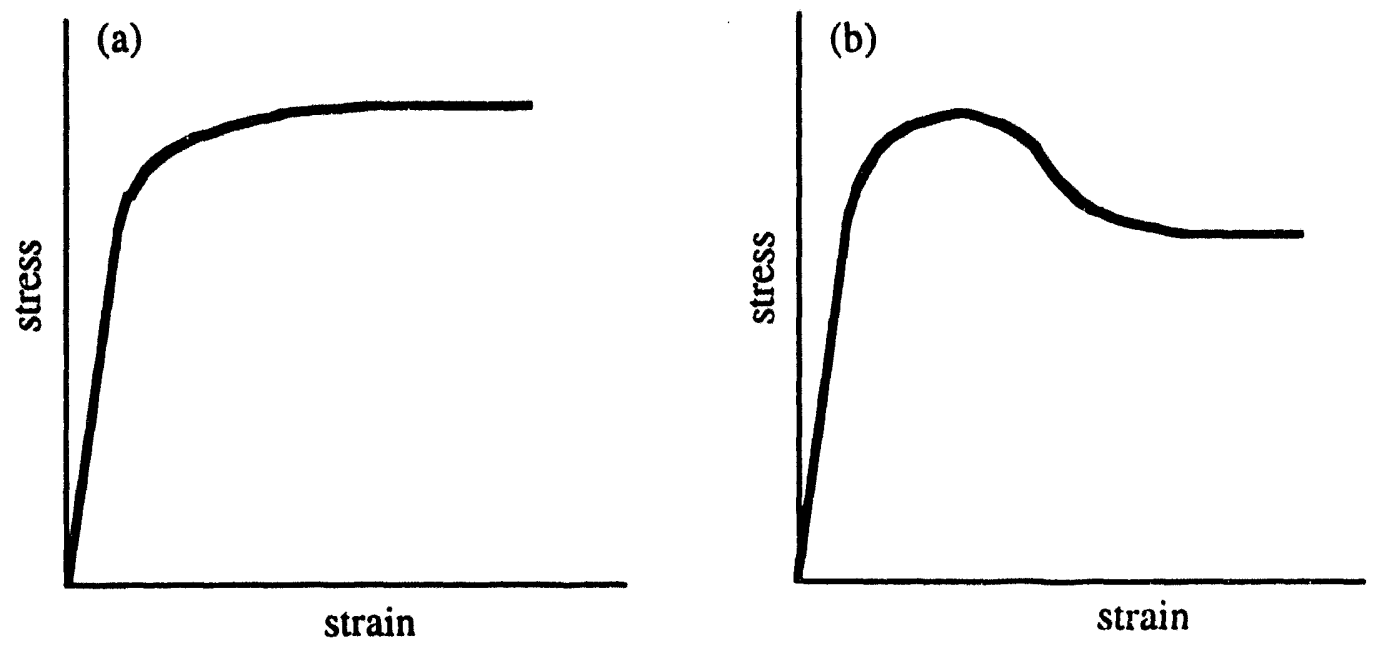

Figure 2.4 Generic stress-strain curves for a material deformed at high temperature and undergoing (a) recovery only and (b) recrystallization. 


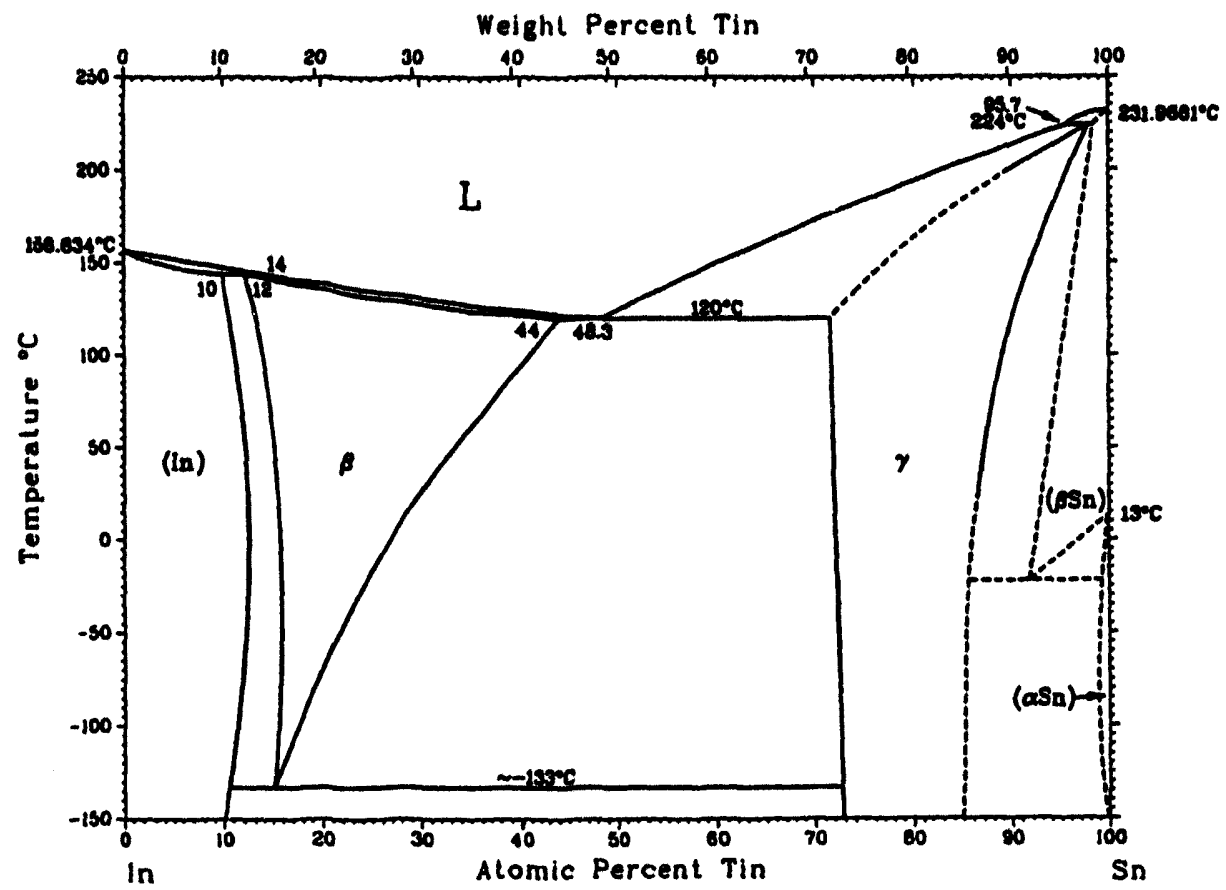

Figure 2.5 - In-Sn phase diagram. Taken with permission from Phase Diagrams of Indium Alloys and Their Engineering Applications, p. 255, C. E. T. White and H. Okamoto, editors, Indium Corporation of America, Utica, NY and ASM International, Materials Park, OH, 1992. 


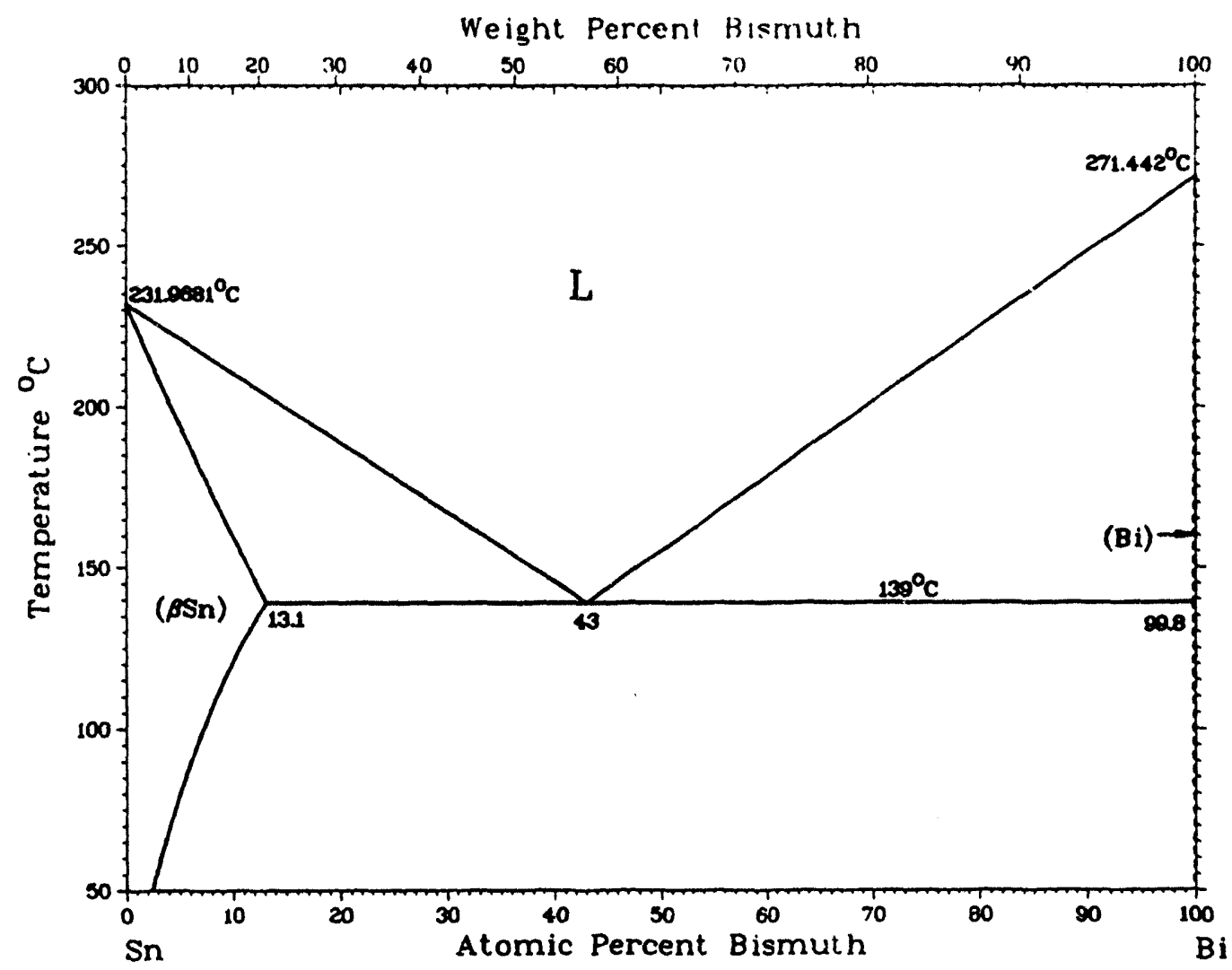

Figure 2.6 - Bi-Sn phase diagram. Taken with permission from Binary Alloy Phase

Diagrams, p. 540, T. B. Massalski, editor-in-chief, ASM International, Materials Park, OH, 1986. 


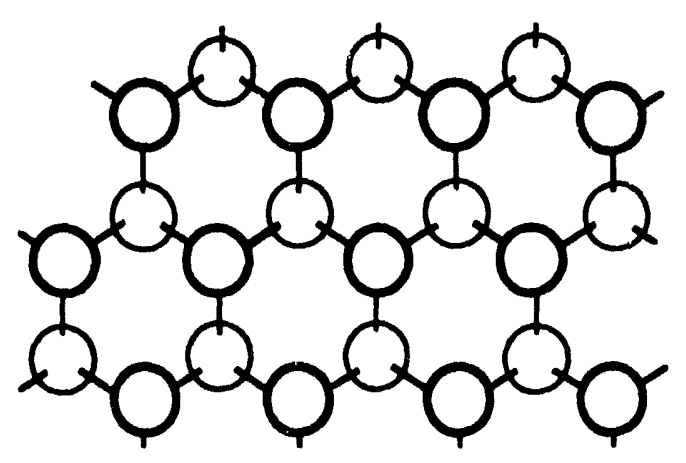

Figure 2.7 - Corrugated sheet of covalently bonded $\mathrm{Bi}$ atoms. Two planes of atoms are represented, and each atom is bonded to its three nearest neighbors as shown. One-half of the atoms in the adjacent sheets will fall into the "holes" in this sheet, forming an fcctype stacking sequence. Drawing adapted from R. C. Evans, An Introduction to Crystal Chemistry, p. 126, Cambridge University Press, New York, NY, 1964. 


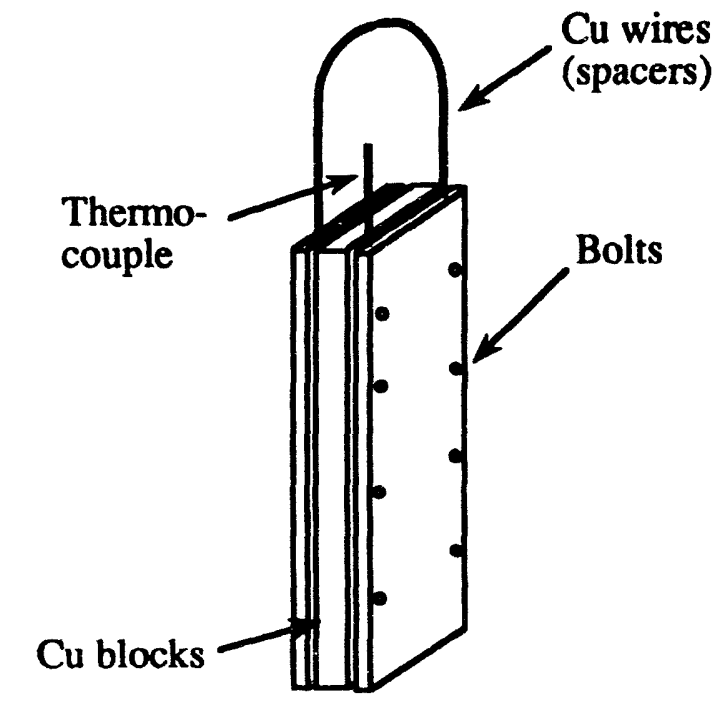

(a)

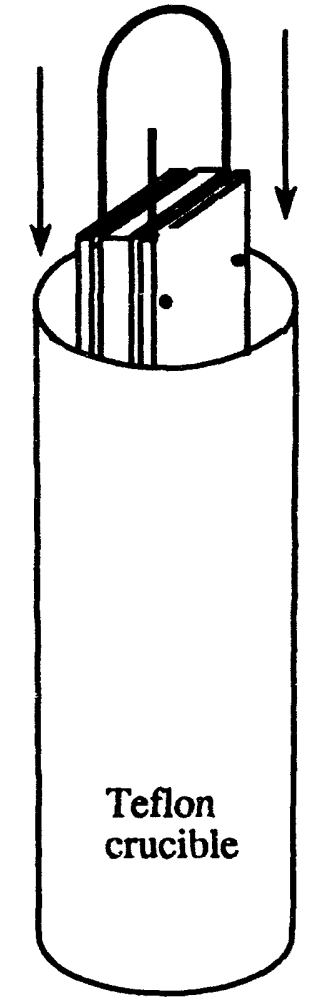

(b)

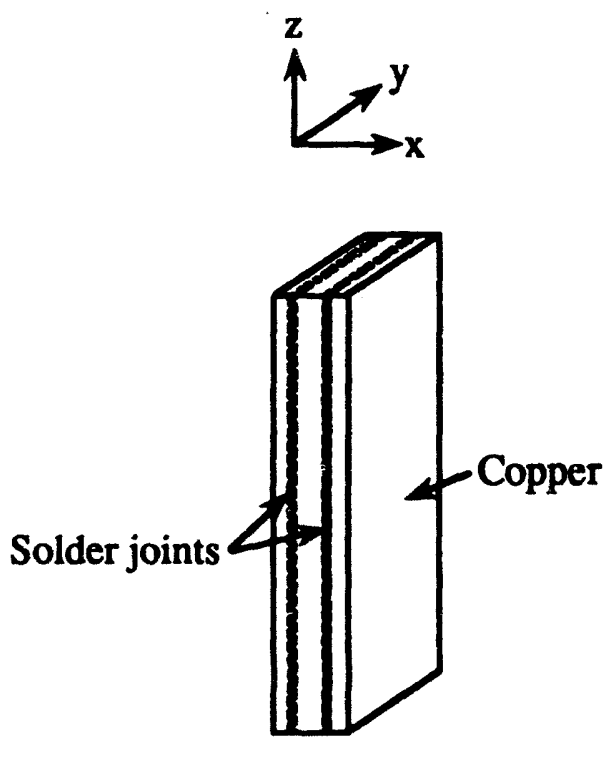

(c)

Figure 3.1 - Procedure used to make modified double-lap shear samples. (a) Plate assembly before immersion, (b) assembly being immersed in crucible, and (c) solidified block after machining away excess solder. Individual samples are made by slicing in the $x-z$ plane. 


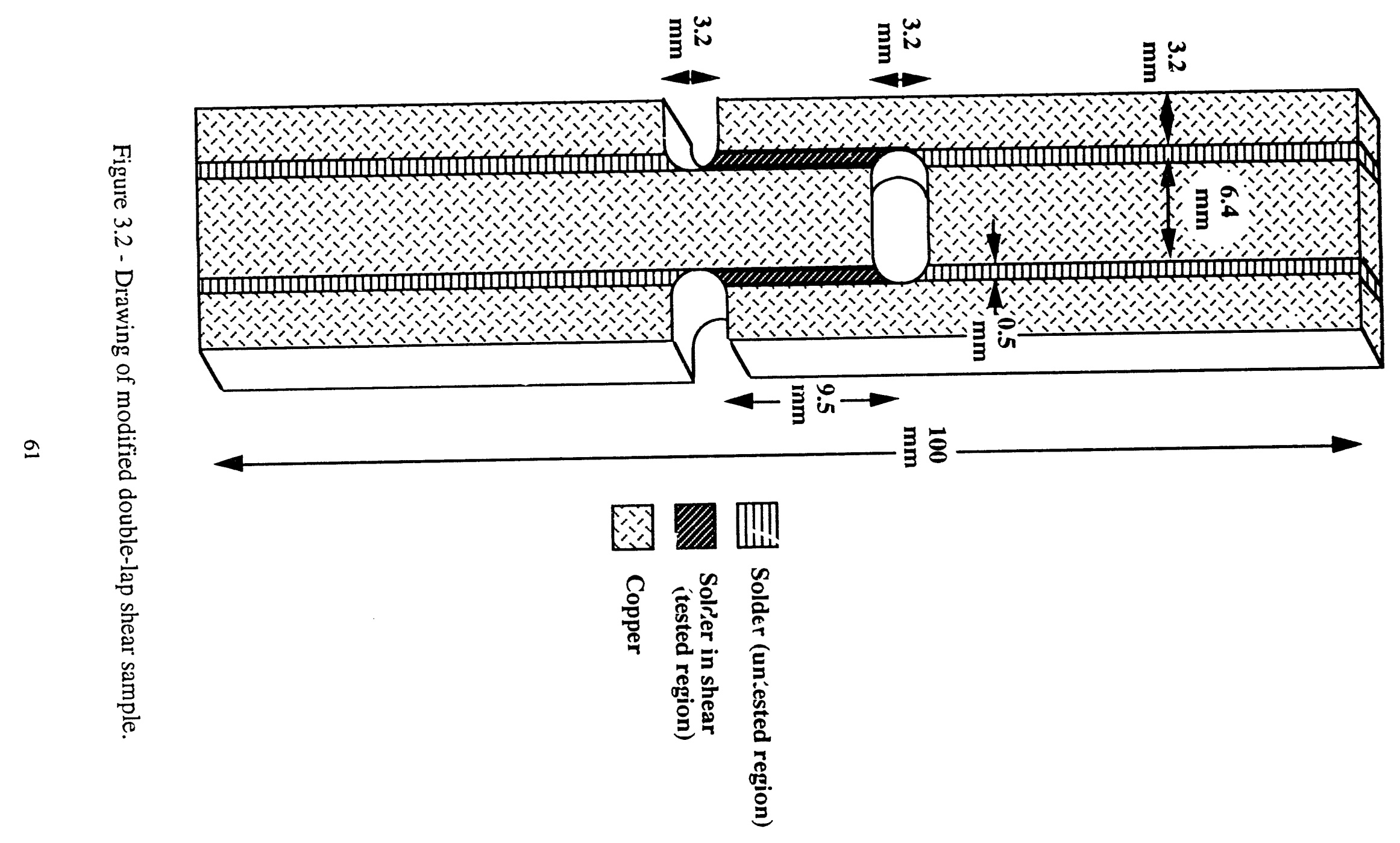




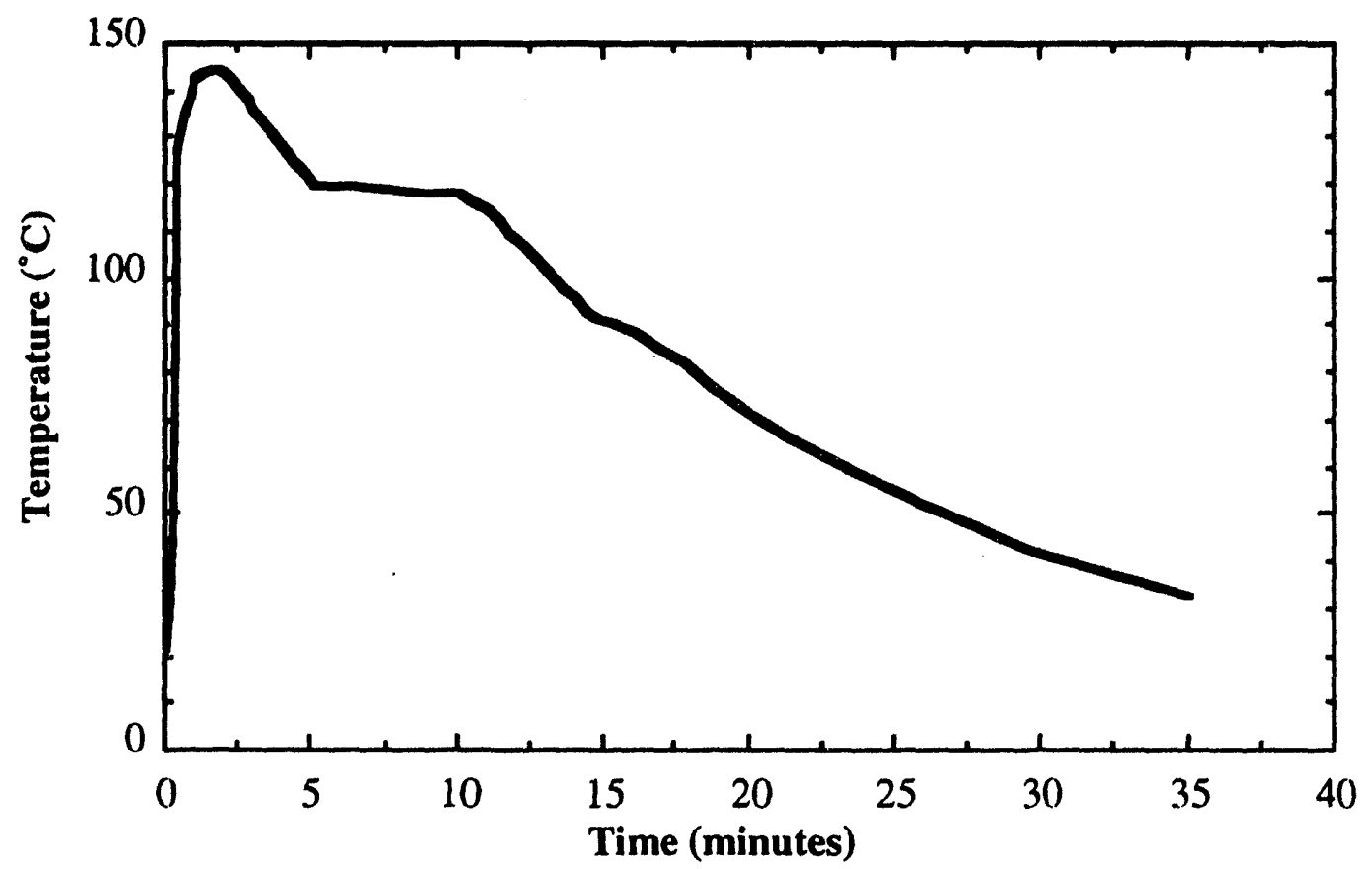

Figure 3.3 - Cooling curve for solidification of In-Sn on Cu block. Initial rise in temperature occurred when the block was immersed into the molten solder, and subsequent cooling began when the entire assembly was immersed into ice water. 


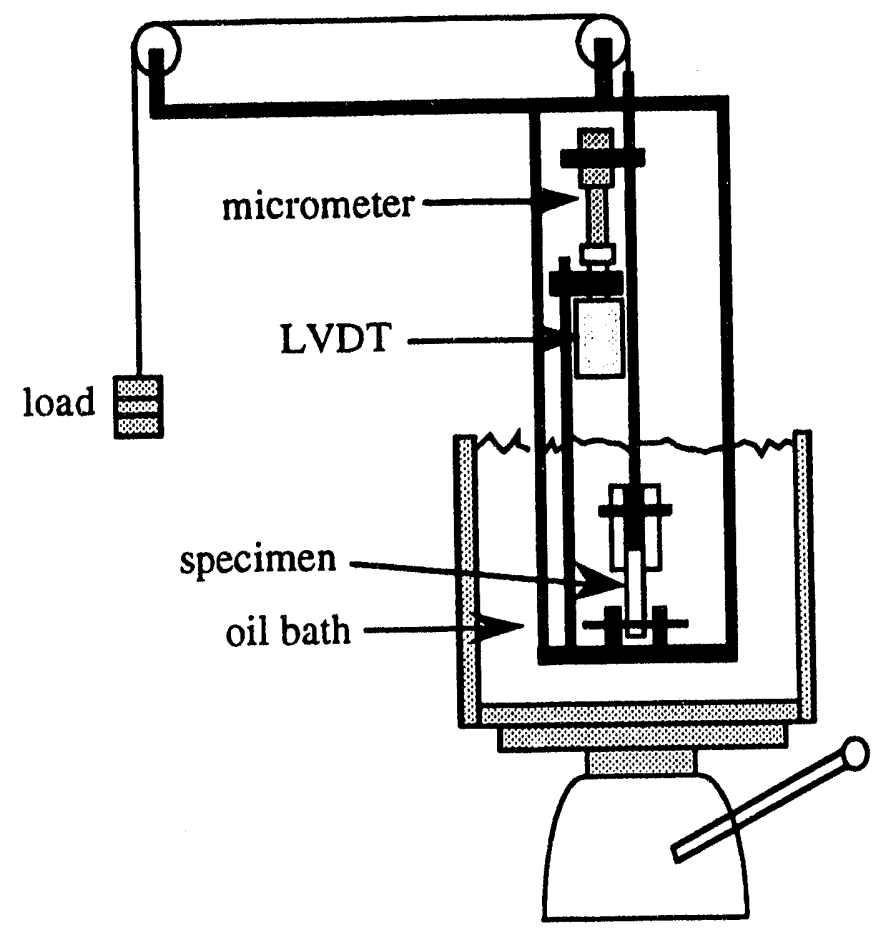

Figure 3.4 - Drawing of machine used for creep testing (not to scale). 


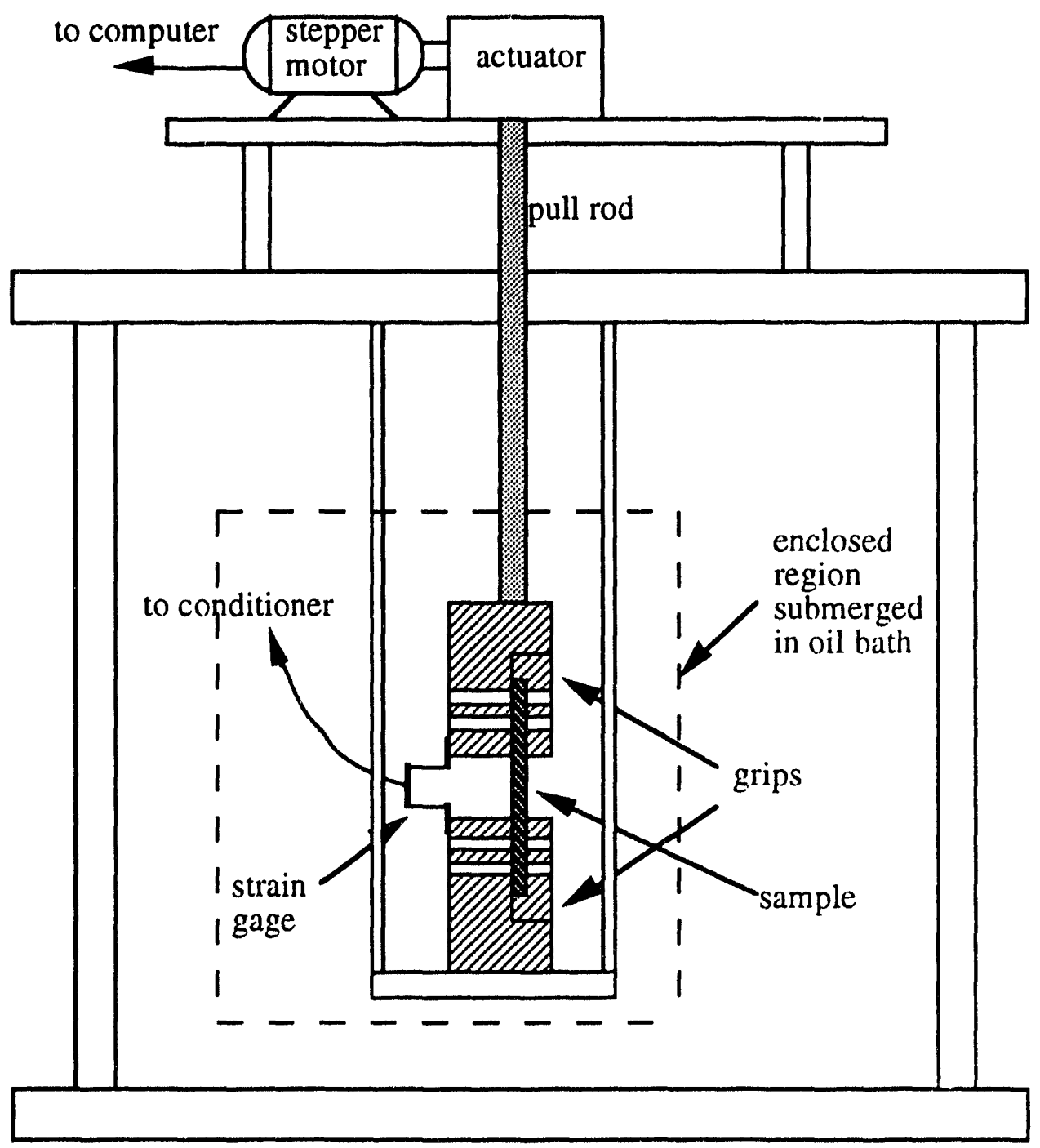

Figure 3.5 - Drawing of machine used for constant strain rate testing (not to scale) 


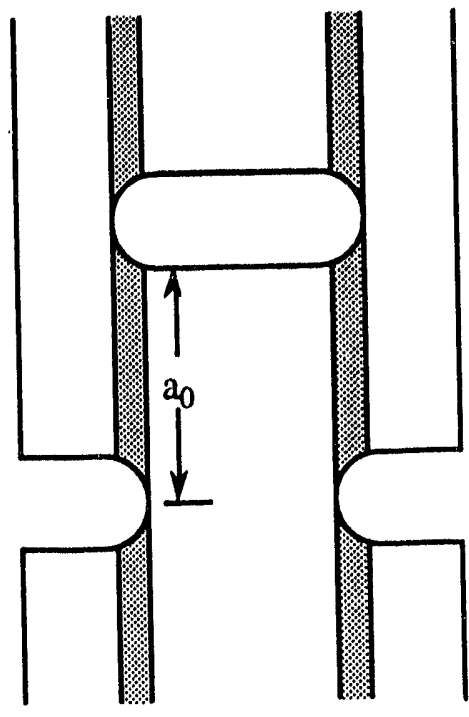

(a)

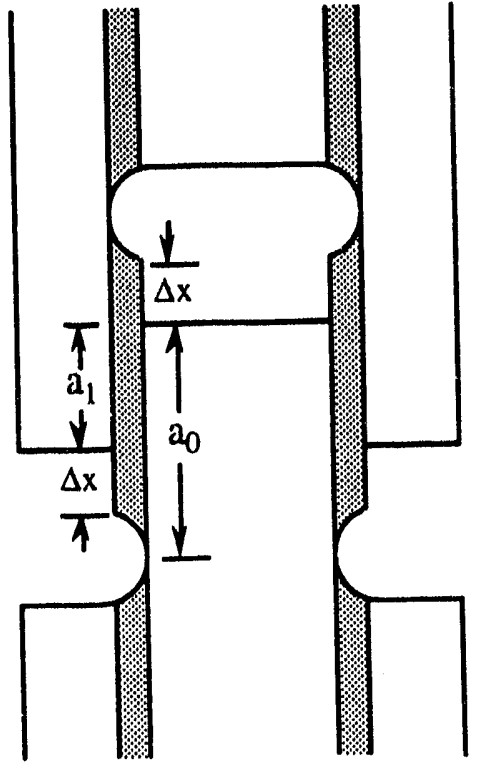

(b)

Figure 3.6 - Drawing of central gage region of modified double-lap shear sample (a) untested and (b) after testing (amount of displacement is exaggerated). 


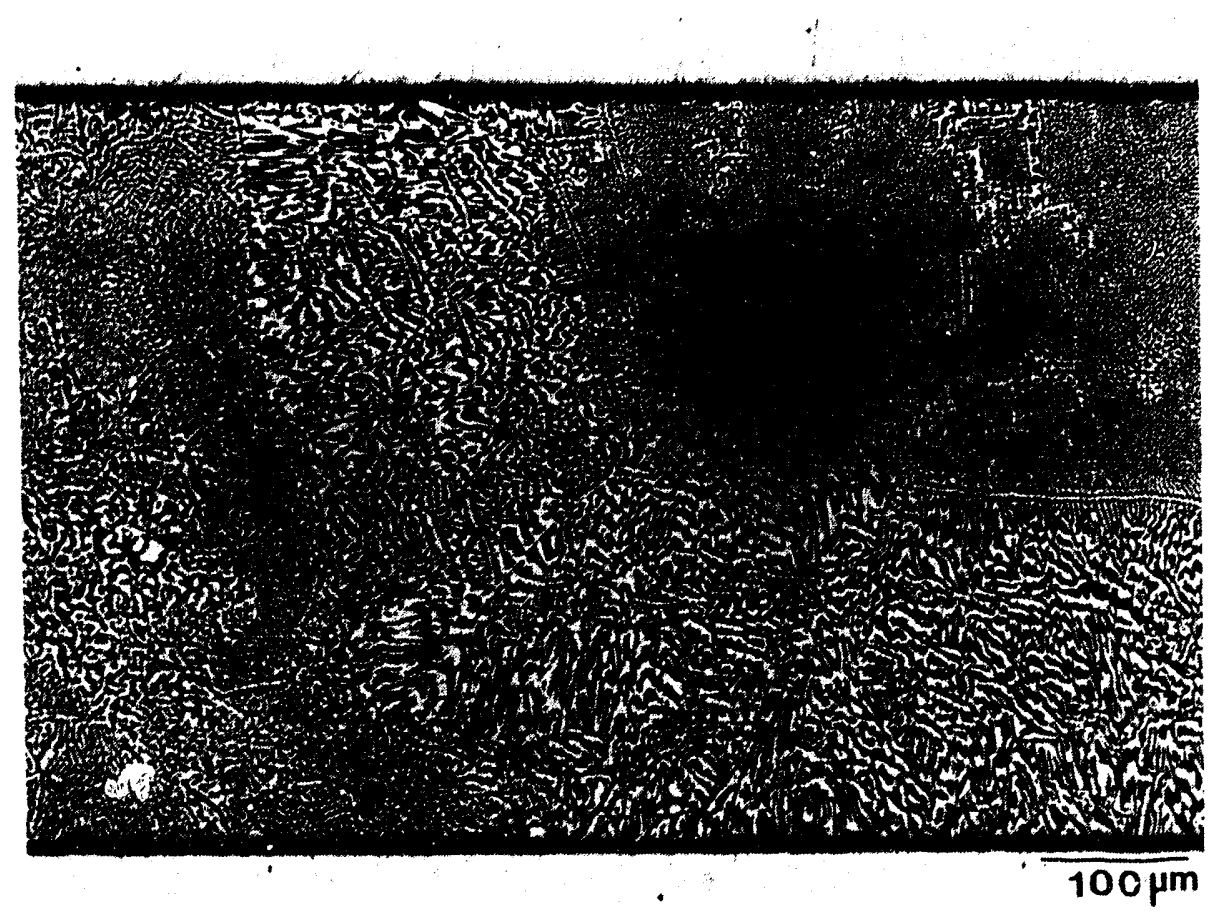

Figure 4.1 - Optical micrograph of untested Bi-Sn sample. In this and all optical micrographs of Bi-Sn, the Bi phase appears light and the Sn-rich phase appears dark. [XBB 939-5984 (Top)] 


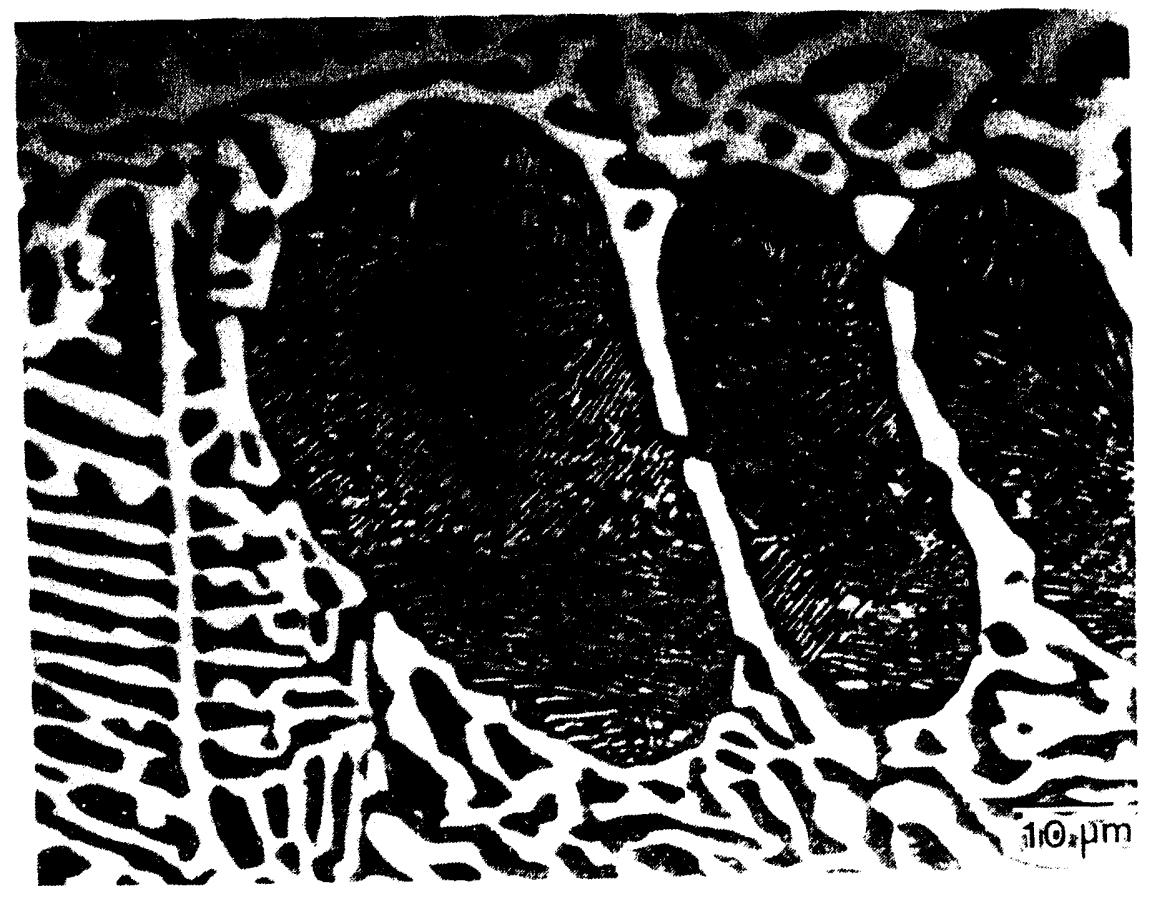

Figure 4.2 - Optical micrograph of $\mathrm{Bi}-\mathrm{Sn}$ sample showing $\mathrm{Bi}$ precipitates within $\mathrm{Sn}$ dendrites. [XBB 939-5984 (Bottom)] 

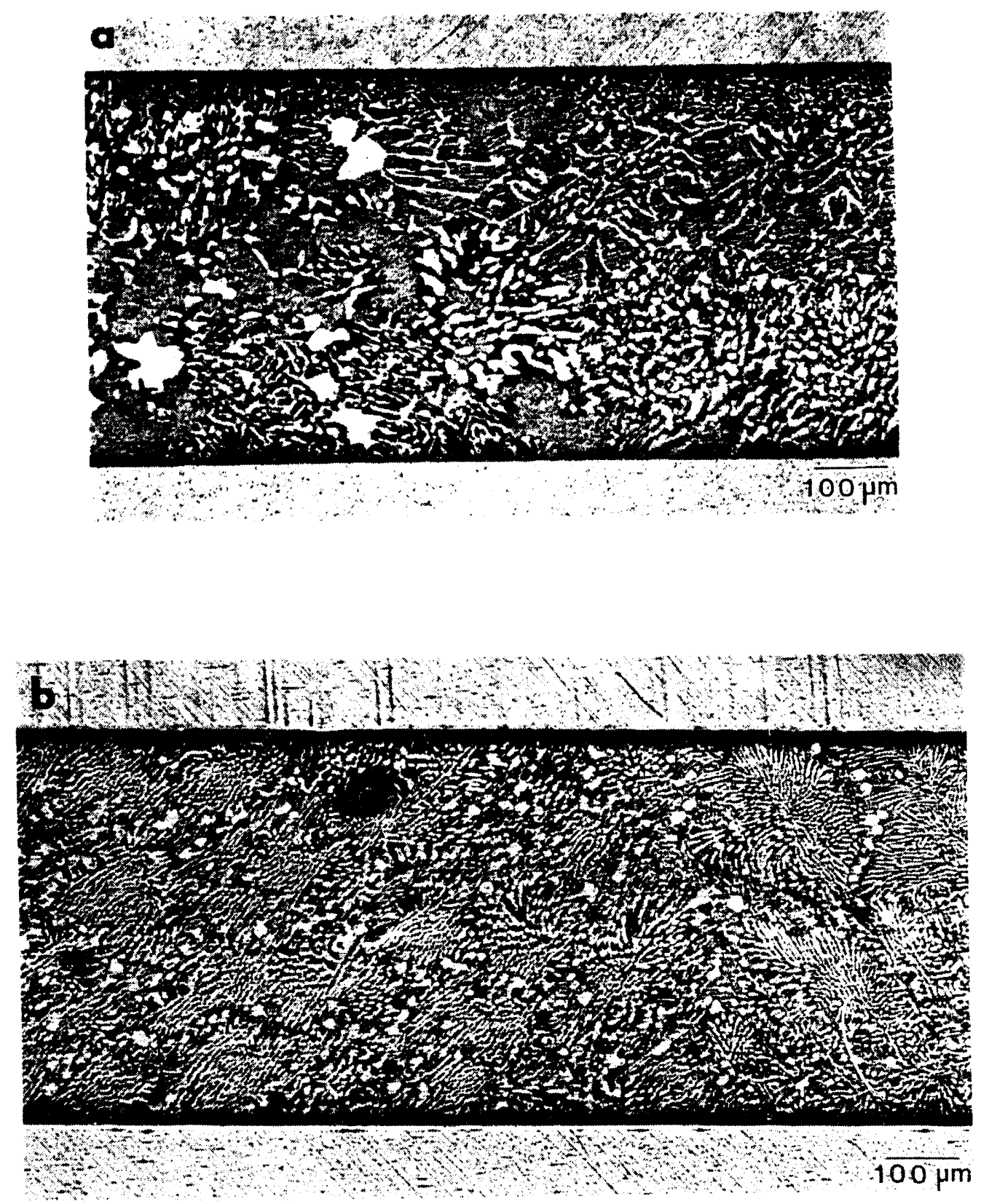

Figure 4.3 - Optical micrographs of untested In-Sn samples on (a) $\mathrm{Cu}$ and (b) $\mathrm{Ni}$

substrates. In this and all optical micrographs of $\mathrm{In}-\mathrm{Sn}$, the Sn-rich $\gamma$ phase appears light and the In-rich $\beta$ phase appears dark. [XBB 934-24()1 A] 

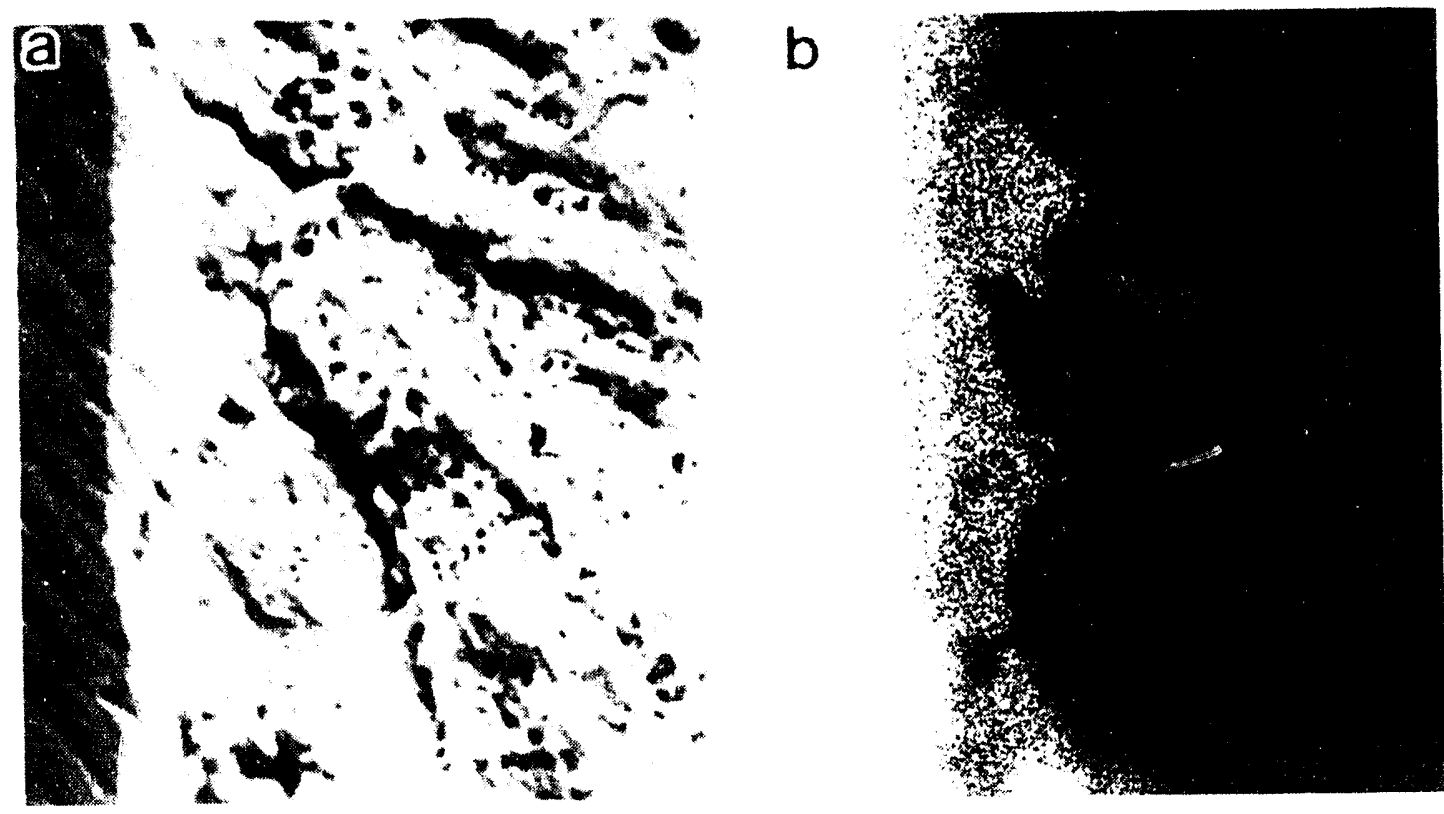

\section{$\overline{5 \mu m}$}
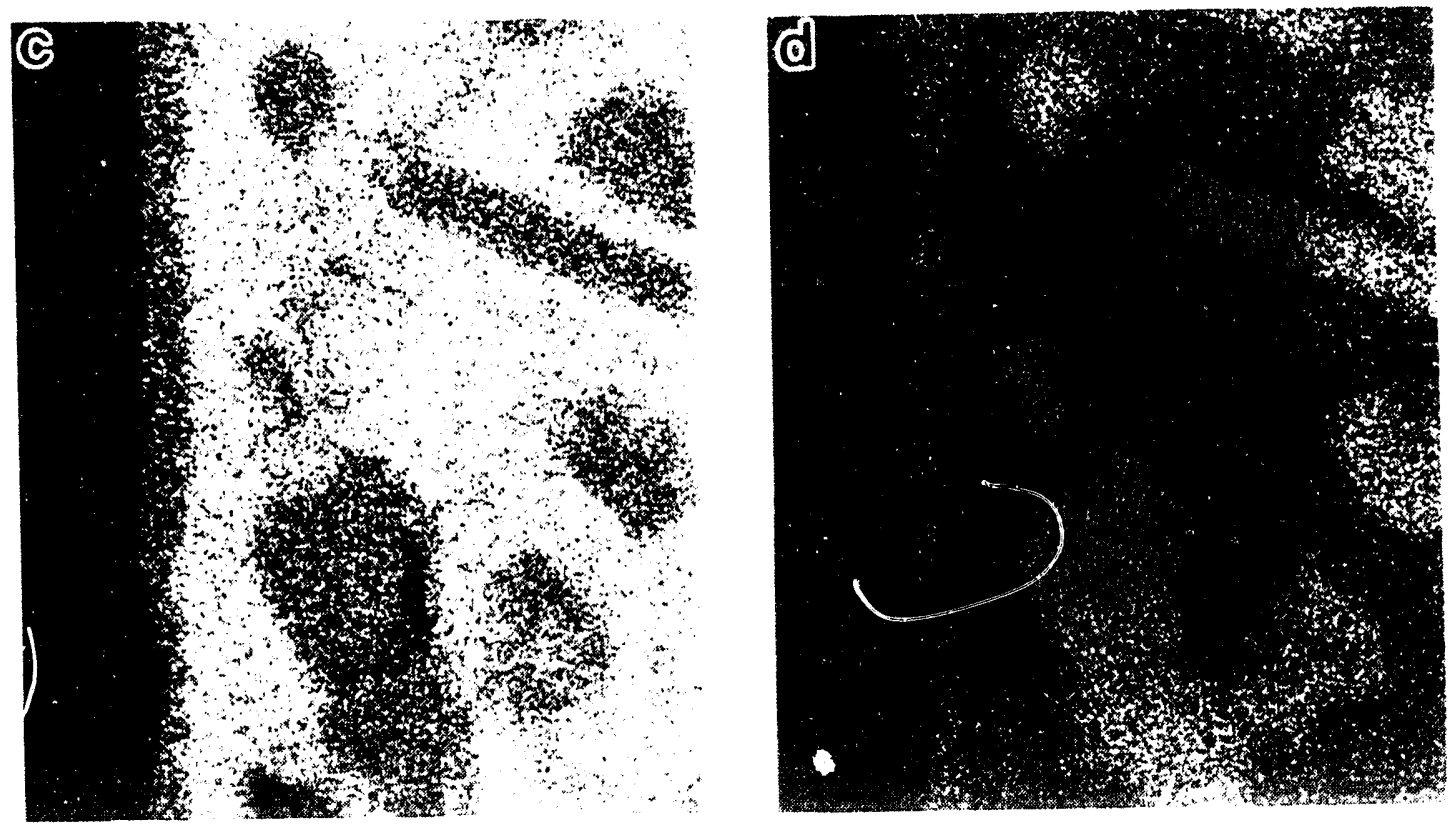

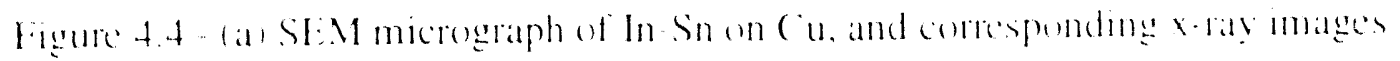

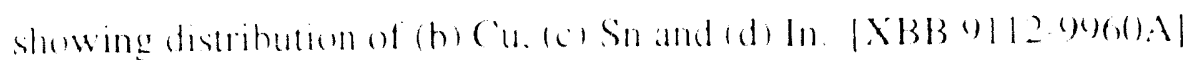



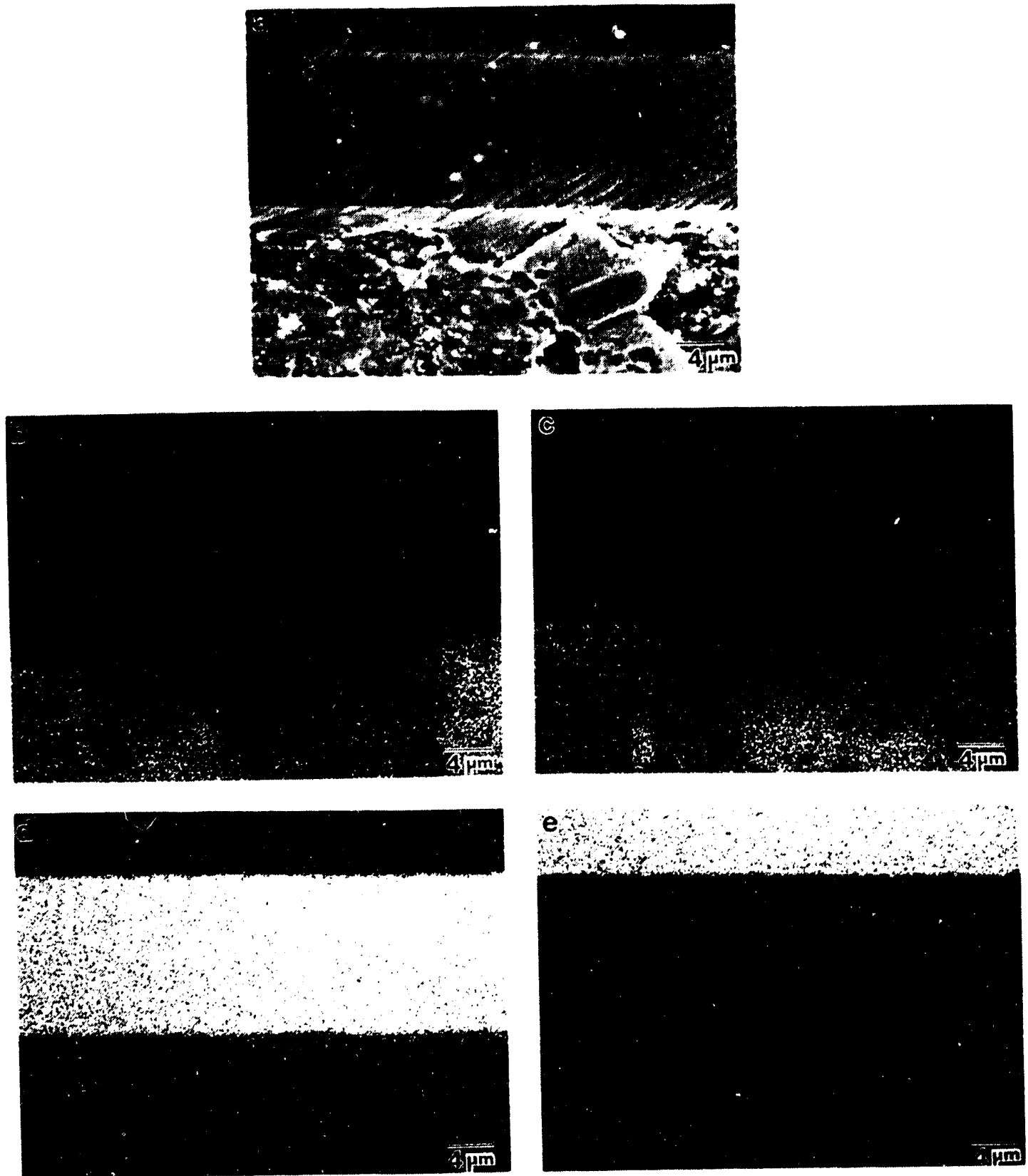

Figure 4.5 - (a) SEM micrograph of $\mathrm{In}-\mathrm{Sn}$ on $\mathrm{Ni}$, and corresponding x-ray images showing distribution of (b) In, (c) Sn, (d) Ni and (e) Cu. [XBB 9311-7270] 


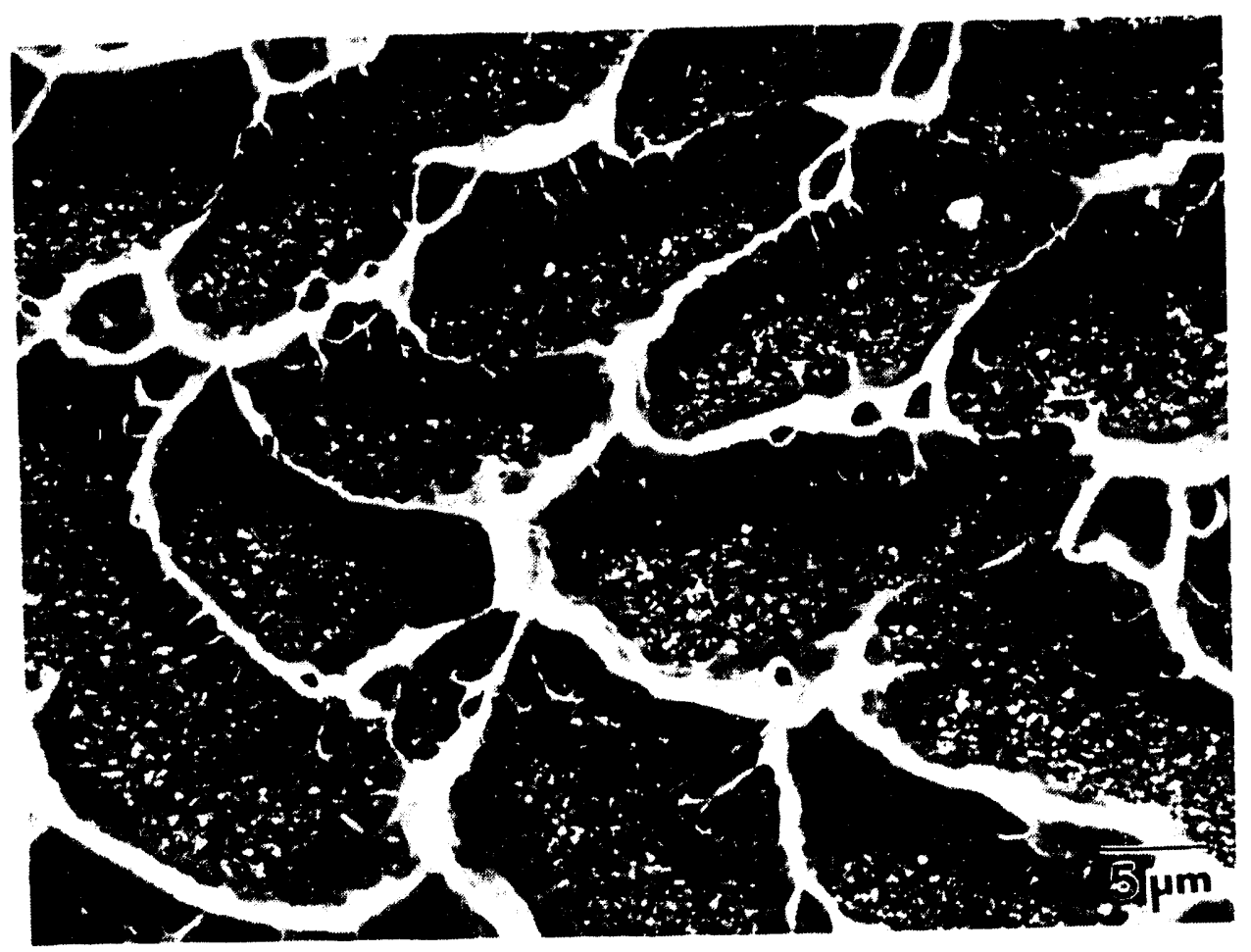

Figure 4.6 - SEM micrograph of fracture surface of In-Sn on Ni. Raised regions are the $\beta$ phase of the eutectic, and pockets between them are Ni-In-Sn intermetallics. [XBB 9311-7269] 

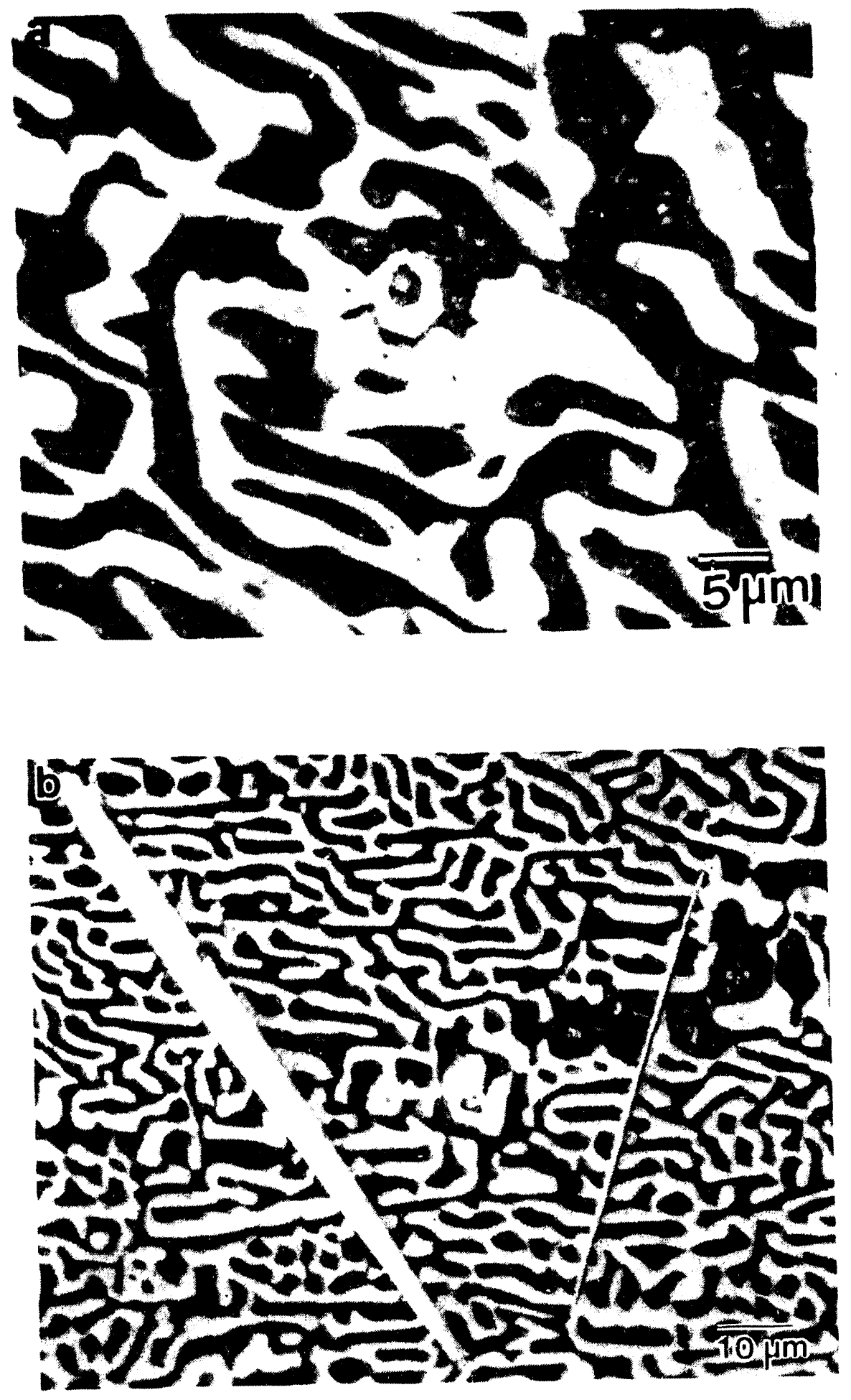

Figure 4.7 - SEM micrographs of $\mathrm{Cu}_{6} \mathrm{Sn}_{5}$ intermetallics within Bi-Sn eutectic, (a) sectioned crosswise, showing hexagonal morphology, and (b) sectioned lengthwise. [XBB 9311-7263] 

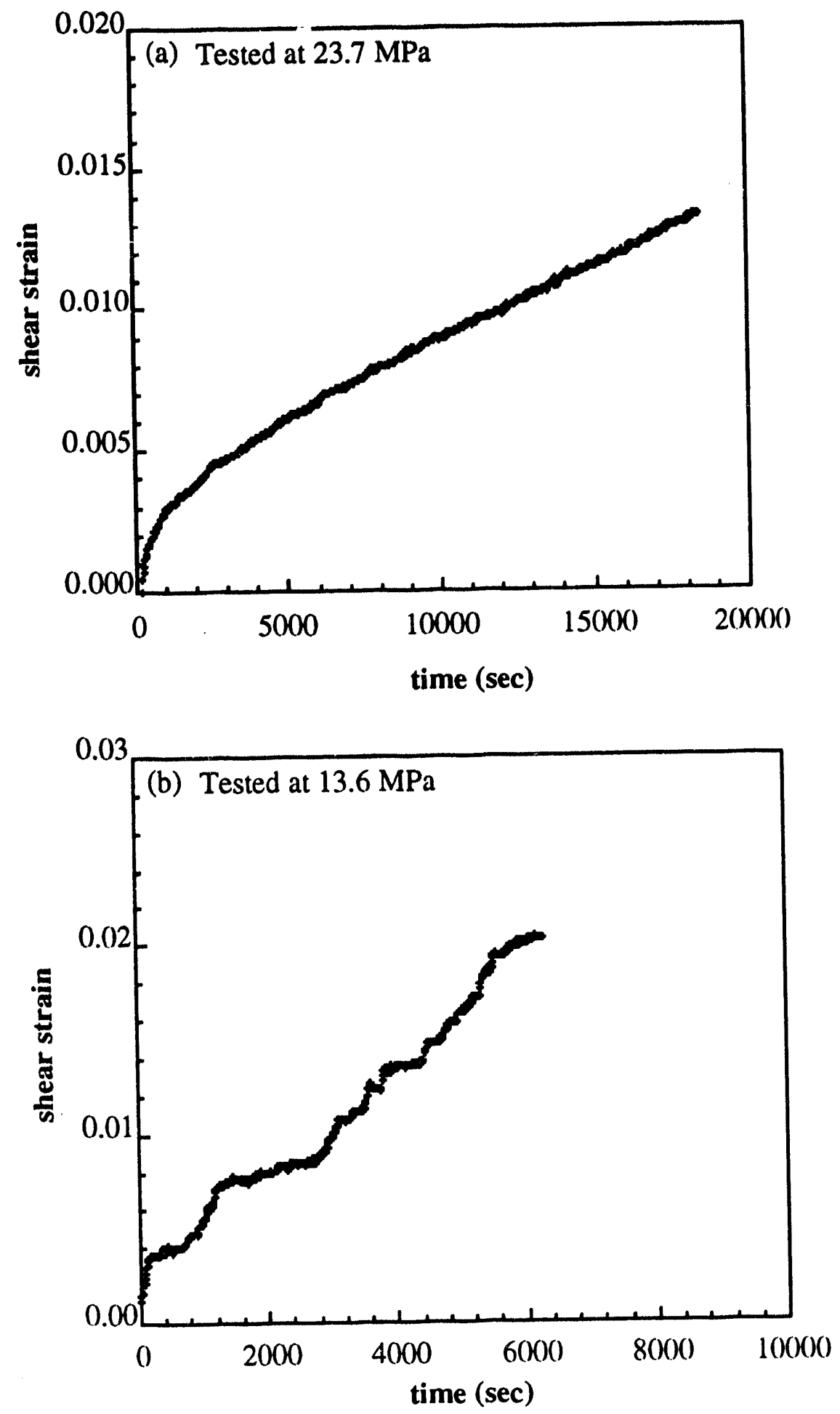

Figure 4.8 - Typical creep curves for Bi-Sn at (a) $20{ }^{\circ} \mathrm{C}$ and (b) $65^{\circ} \mathrm{C}$, showing primary and steady-state creep regions. 


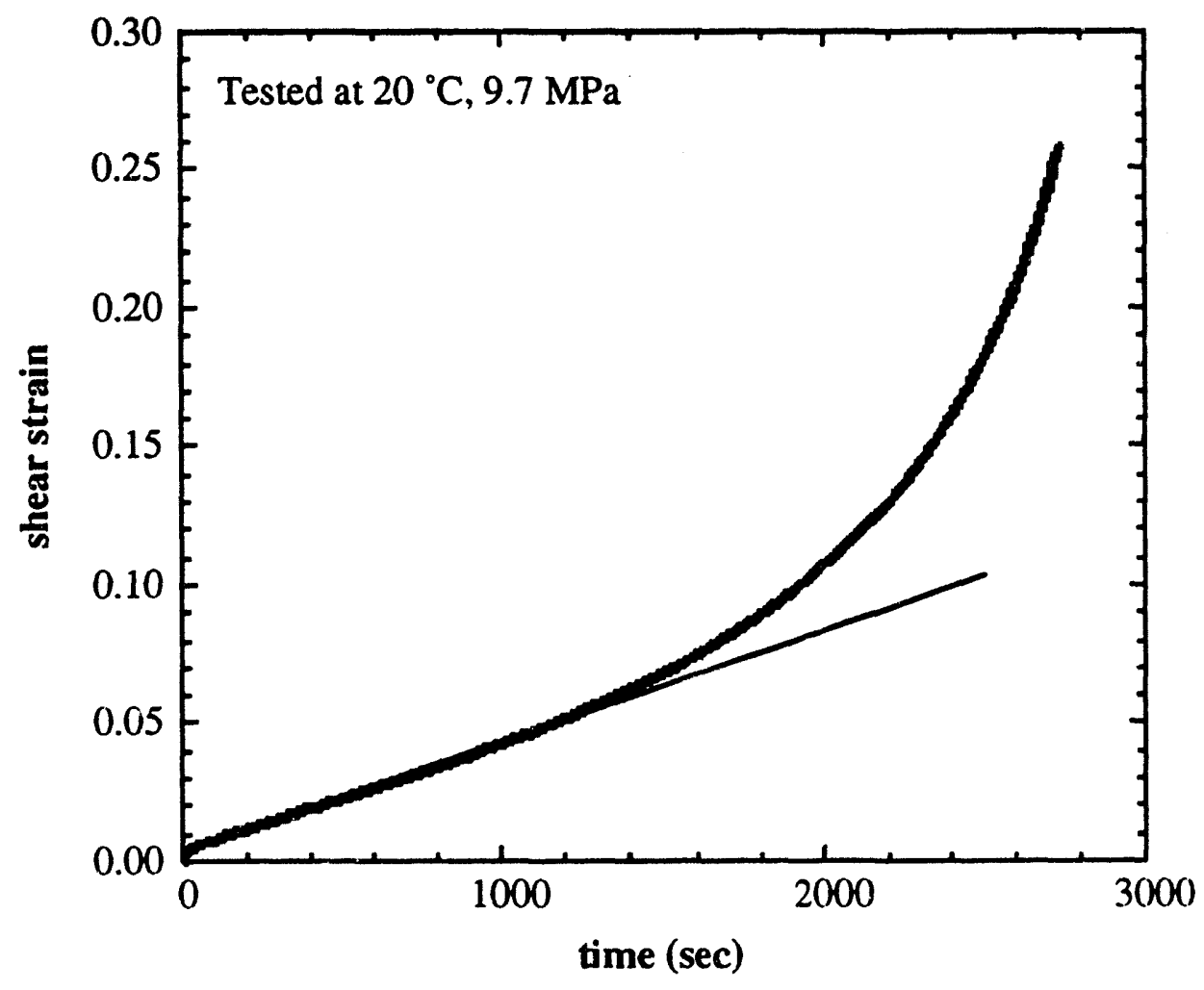

Figure 4.9 - Typical creep curve for In-Sn, showing all three creep regions. The straight line is drawn to indicate the extent of steady-state creep. 

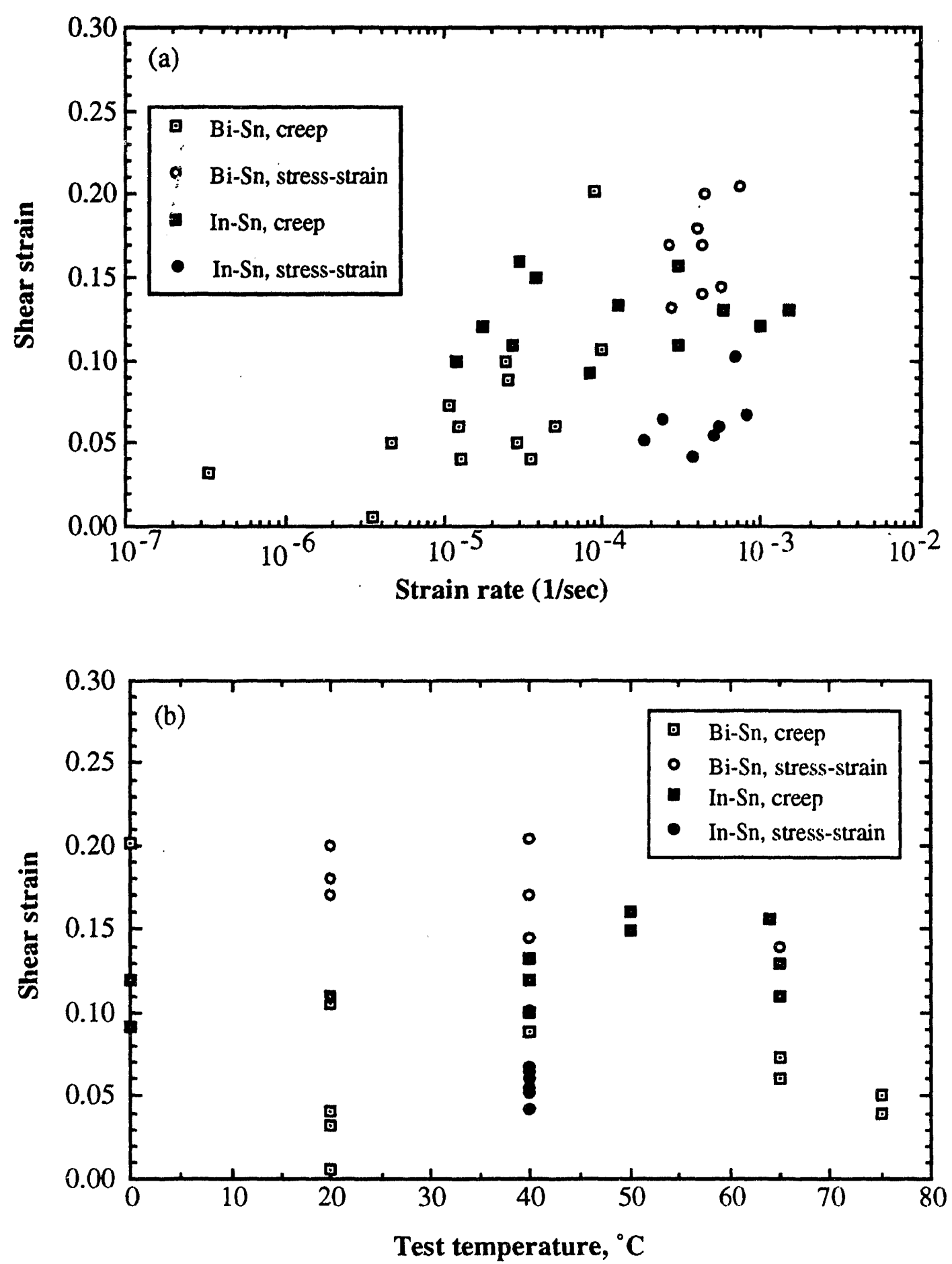

Figure 4.10 - Strain to tertiary creep (creep data) or strain to peak stress (stress-strain data) as a function of (a) strain rate and (b) test temperature. 

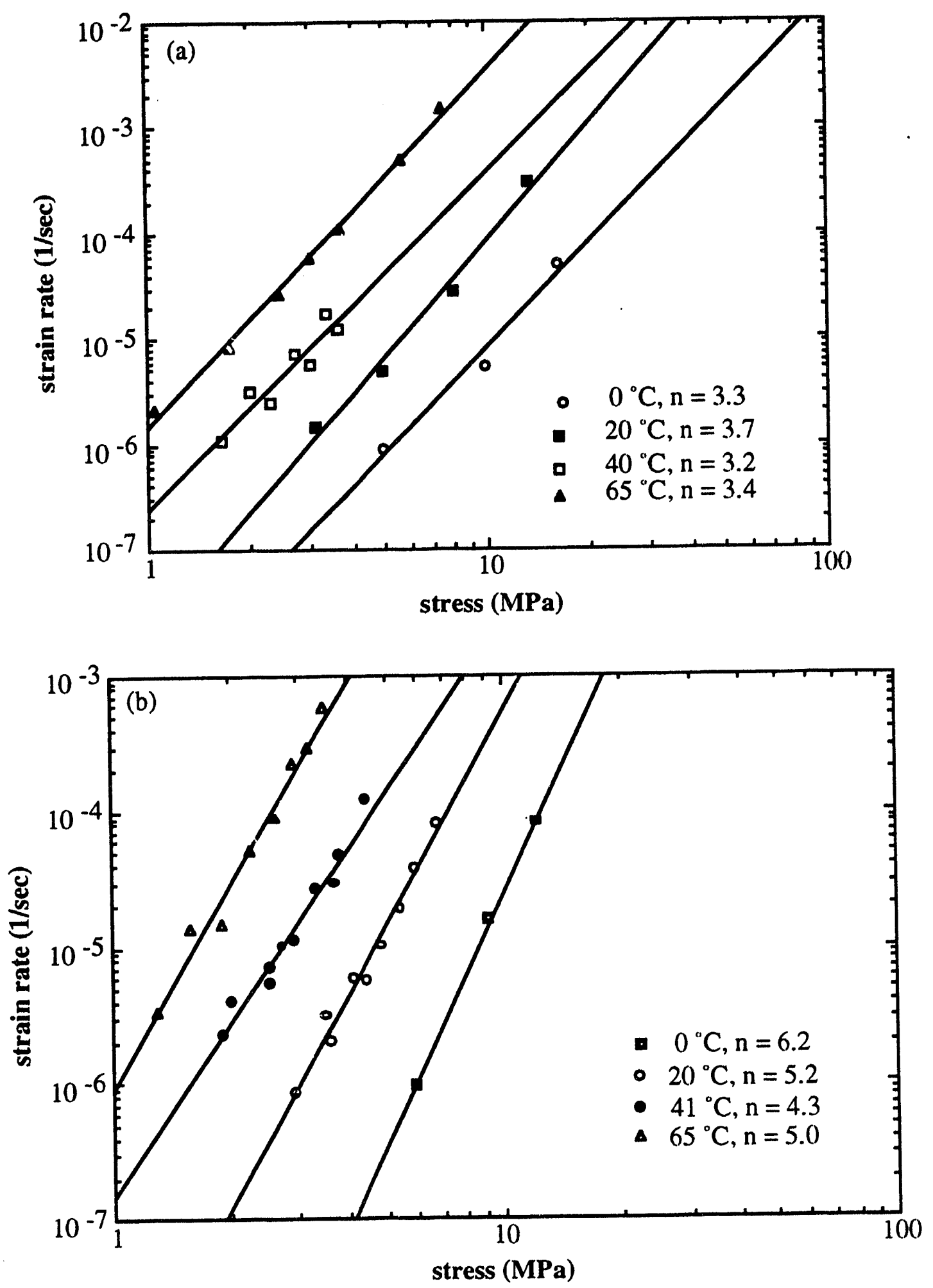

Figure 4.11 - Creep data at various temperatures for (a) In-Sn on $\mathrm{Cu}$ and (b) In-Sn on Ni. 


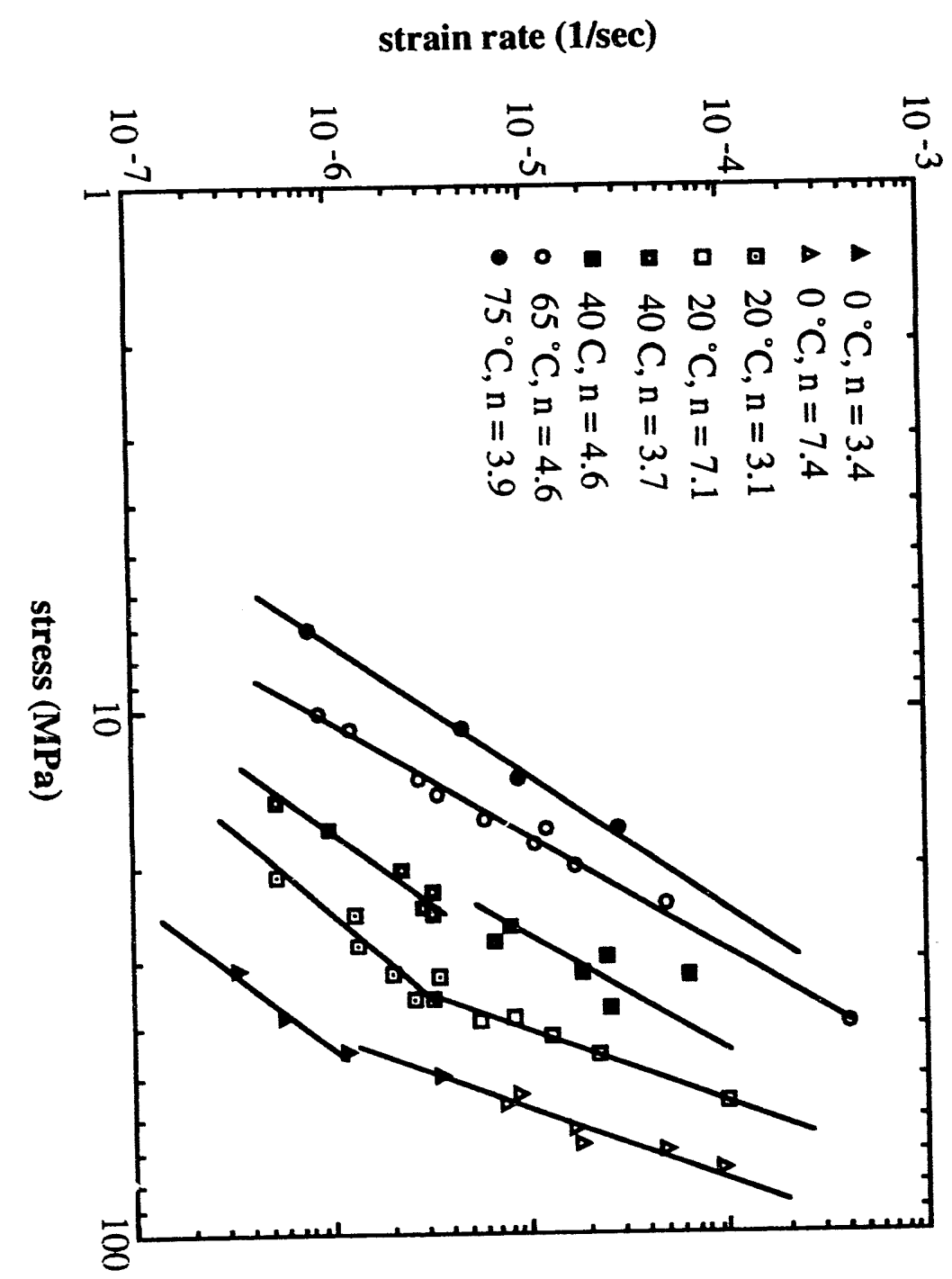




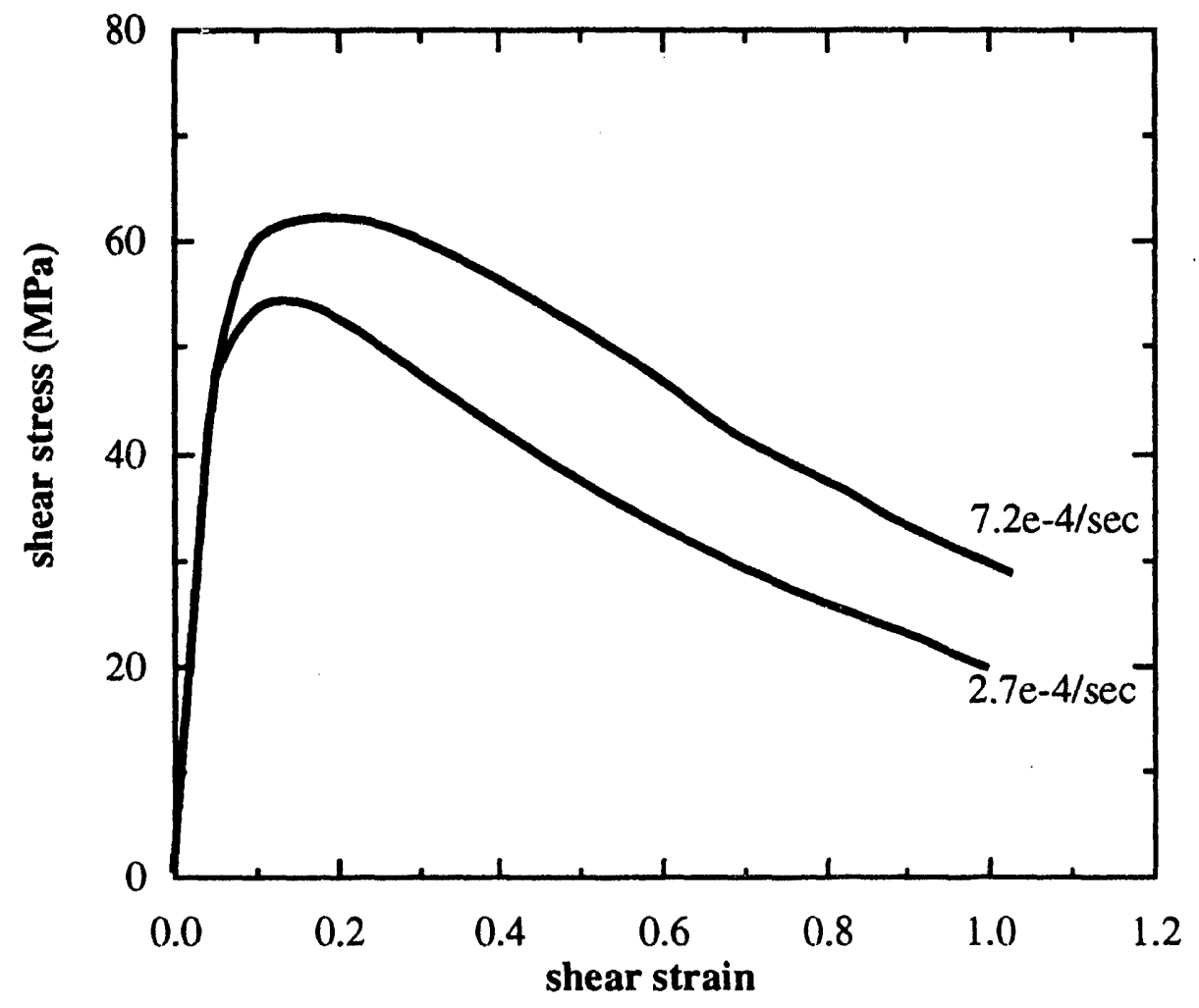

Figure 4.13 - Engineering stress-strain curves for Bi-Sn. Applied strain rates are shown on the plot. 


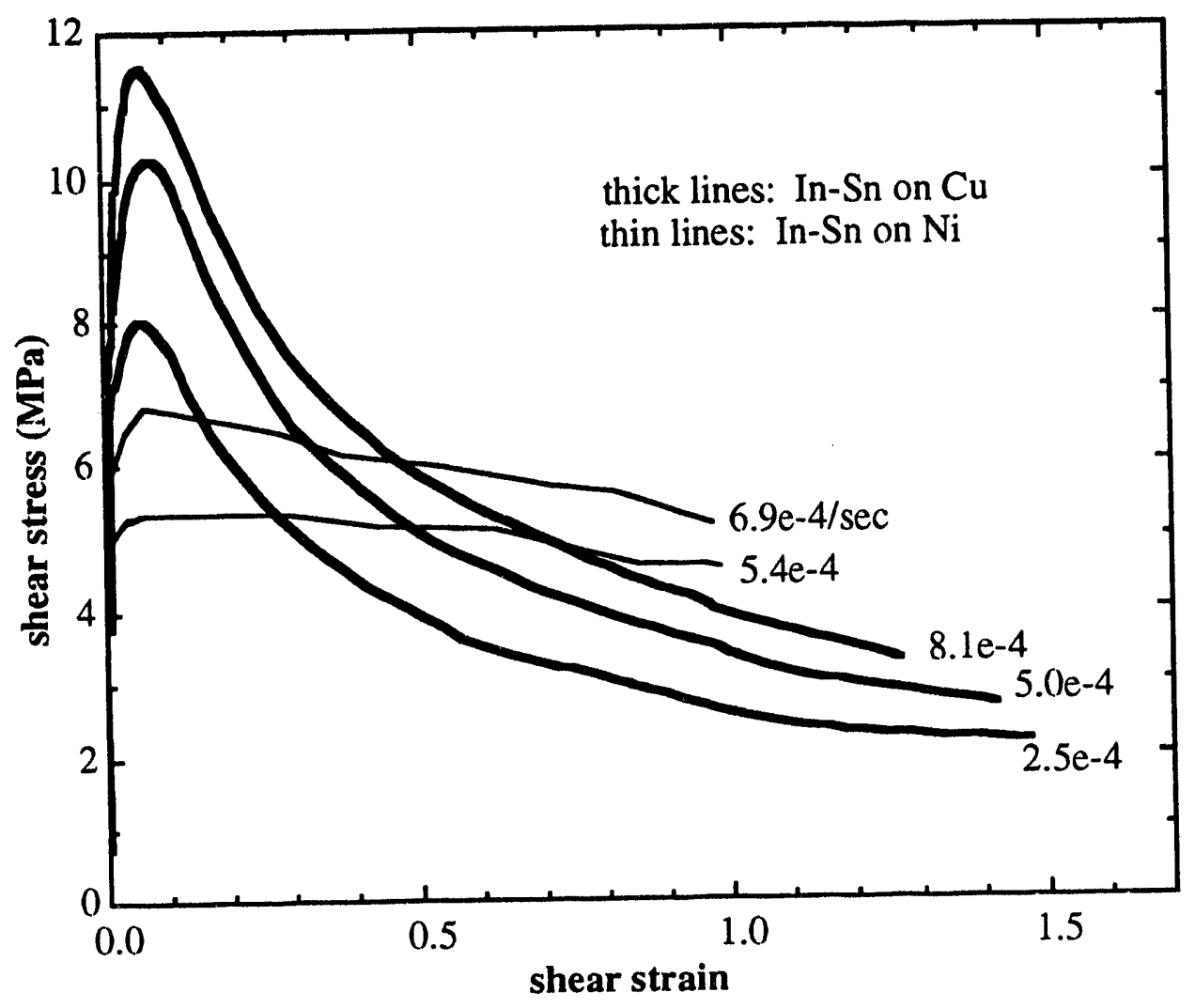

Figure 4.14 - Engineering stress-strain curves for $\mathrm{In}-\mathrm{Sn}$ on $\mathrm{Cu}$ and $\mathrm{In}-\mathrm{Sn}$ on Ni. Applied strain rates are shown on the plot. 

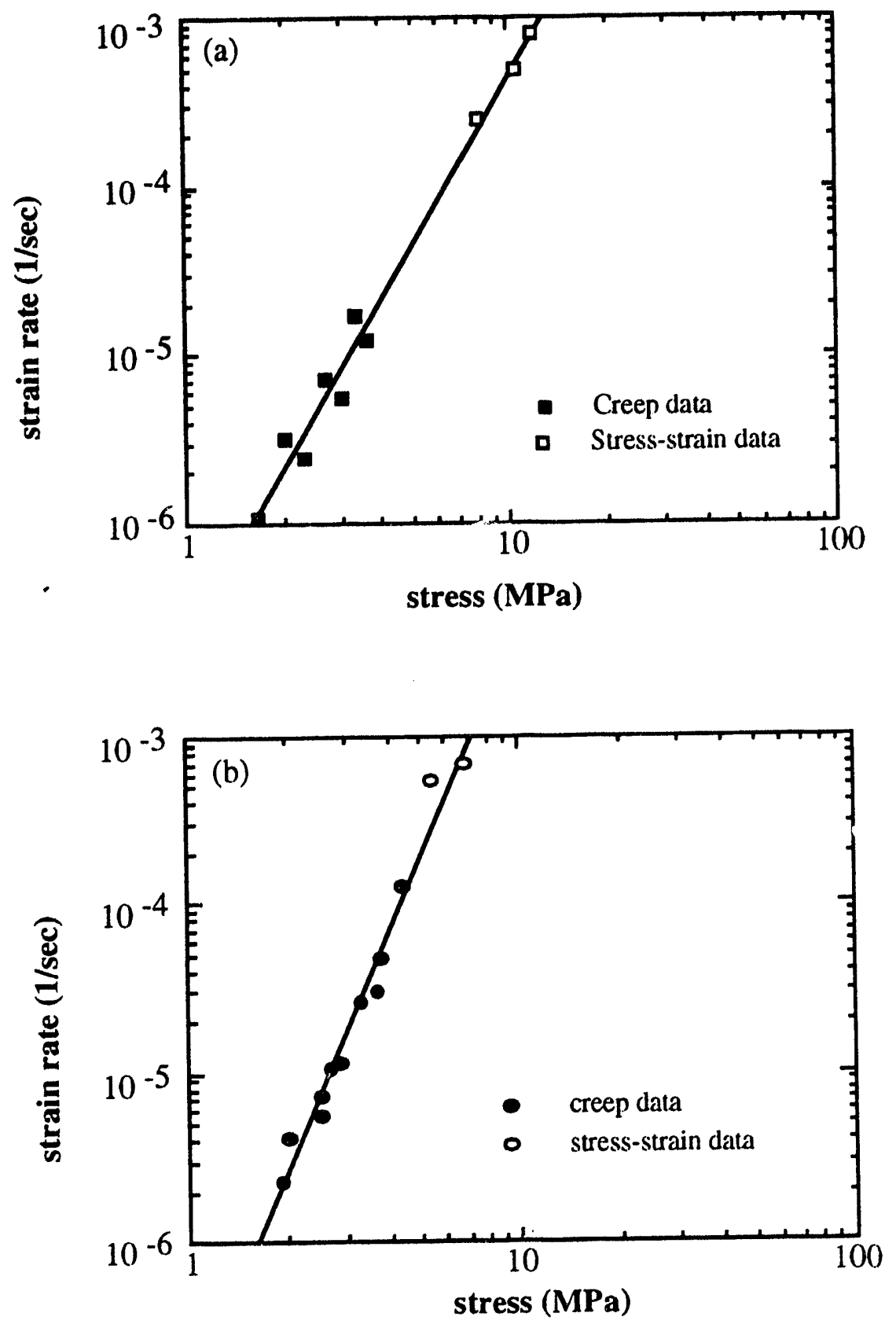

Figure 4.15 - Correlation between creep and stress-strain data for (a) In-Sn on $\mathrm{Cu}$ and (b) In-Sn on $\mathrm{Ni}$ at $40^{\circ} \mathrm{C}$. 


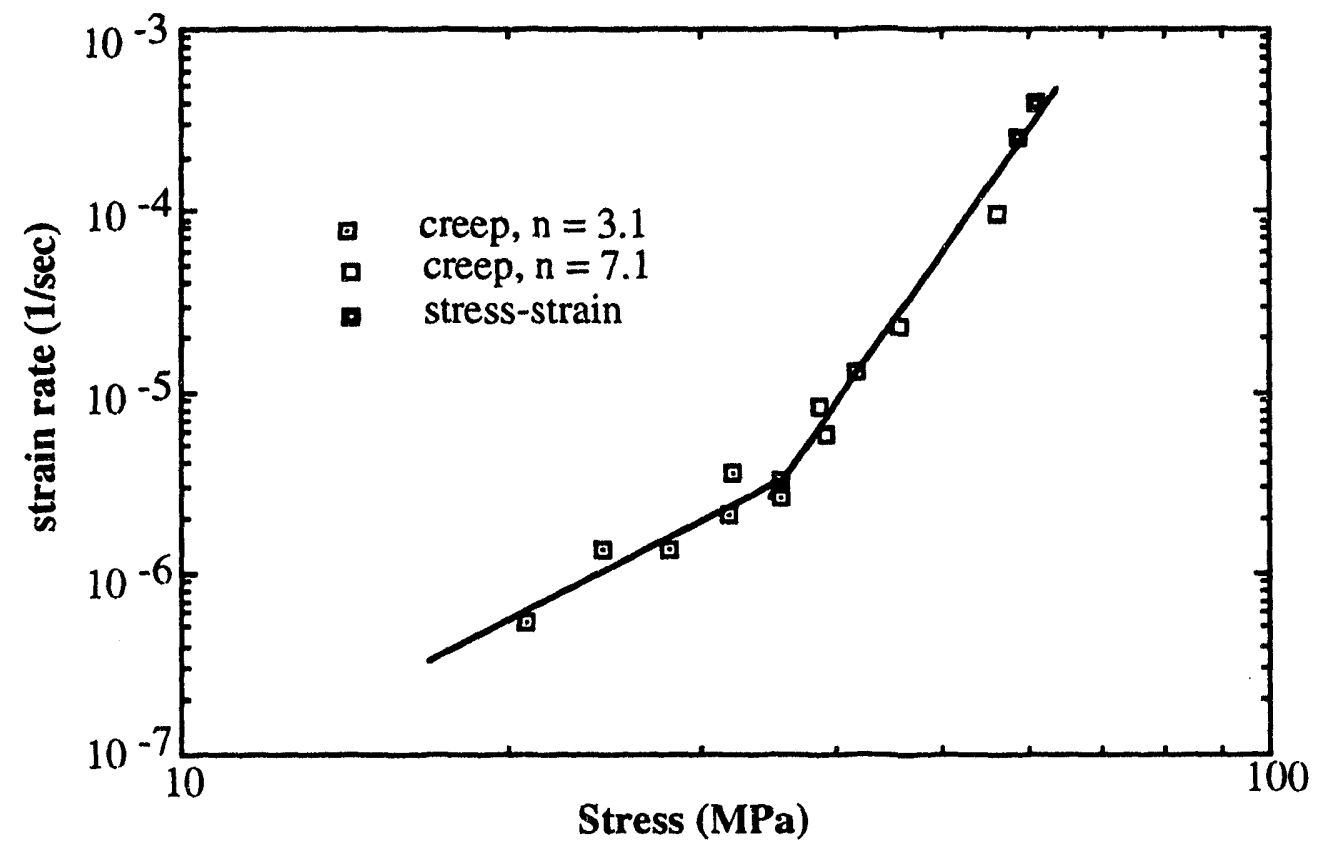

Figure 4.16 - Correlation between creep and stress-strain data for Bi-Sn at $20^{\circ} \mathrm{C}$. 


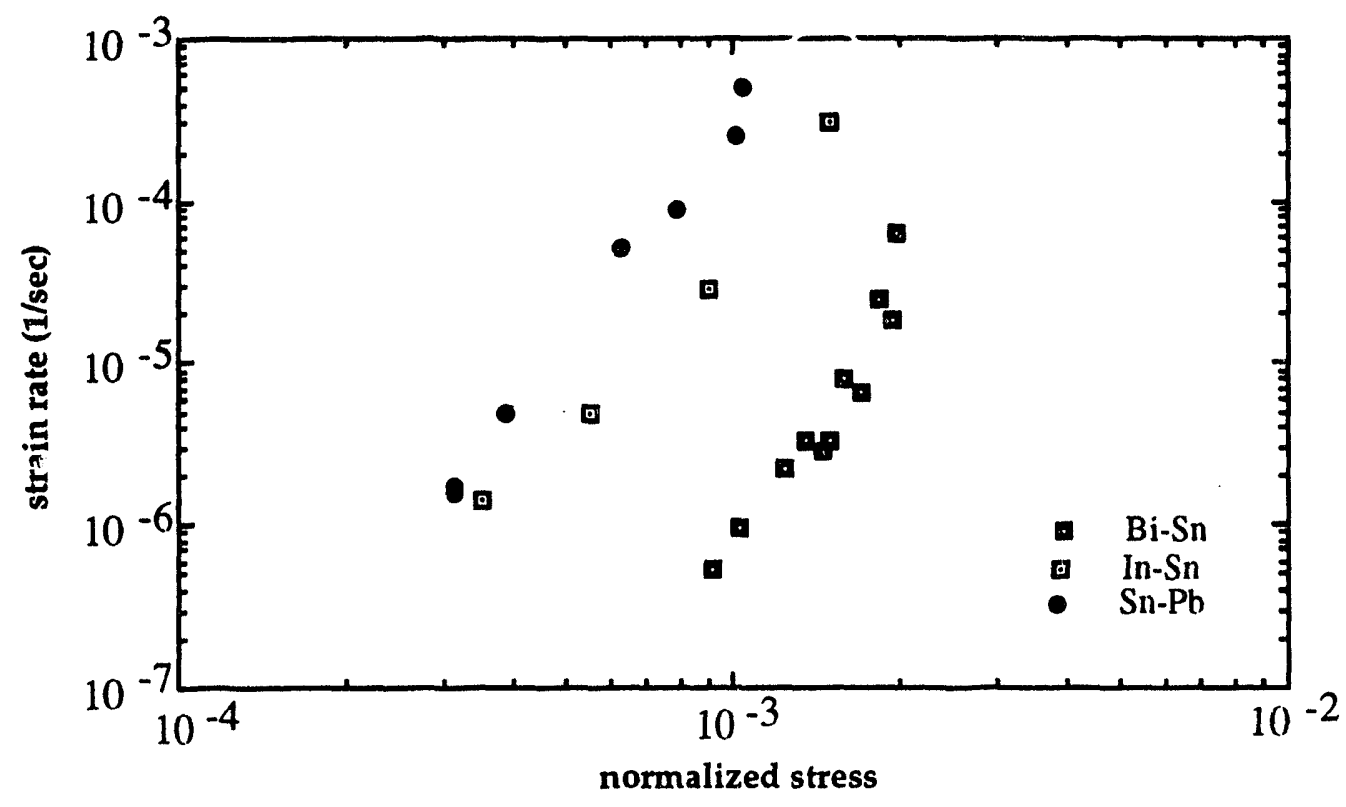

Figure 4.17 - Creep data at a homologous temperature of 0.75 , which corrseponds to $20^{\circ} \mathrm{C}$ for $\mathrm{In}-\mathrm{Sn}, 40^{\circ} \mathrm{C}$ for $\mathrm{Bi}-\mathrm{Sn}$ and $75^{\circ} \mathrm{C}$ for $\mathrm{Sn}-\mathrm{Pb}$. 

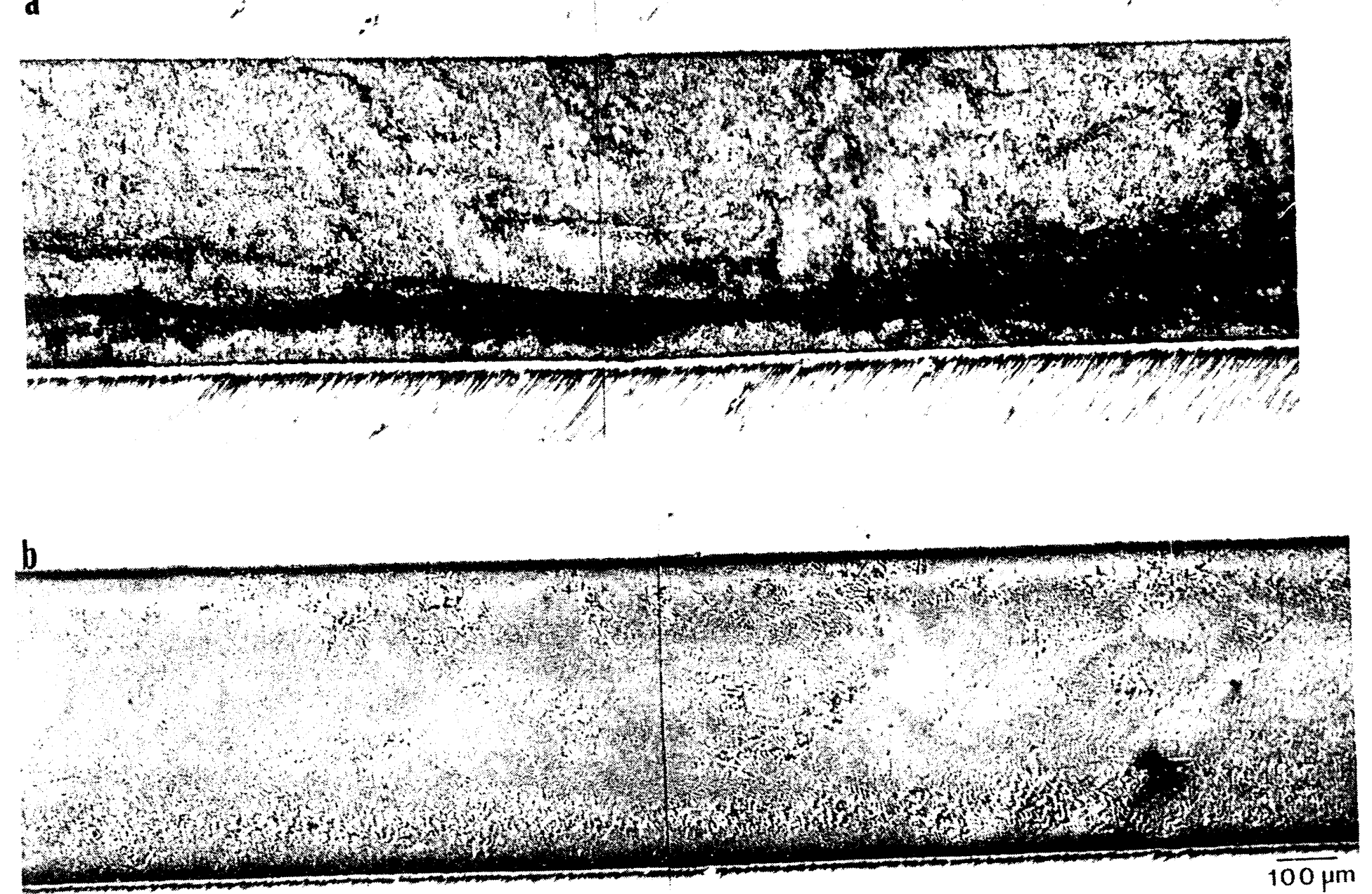

Figure 4.18 - Optical micrographs of creep-tested Bi-Sn sample, (a) as-tested, showing deformation concentrated in dark regions. and (b) after repolish to reveal microstructure. [XBB 923-19017 A] 

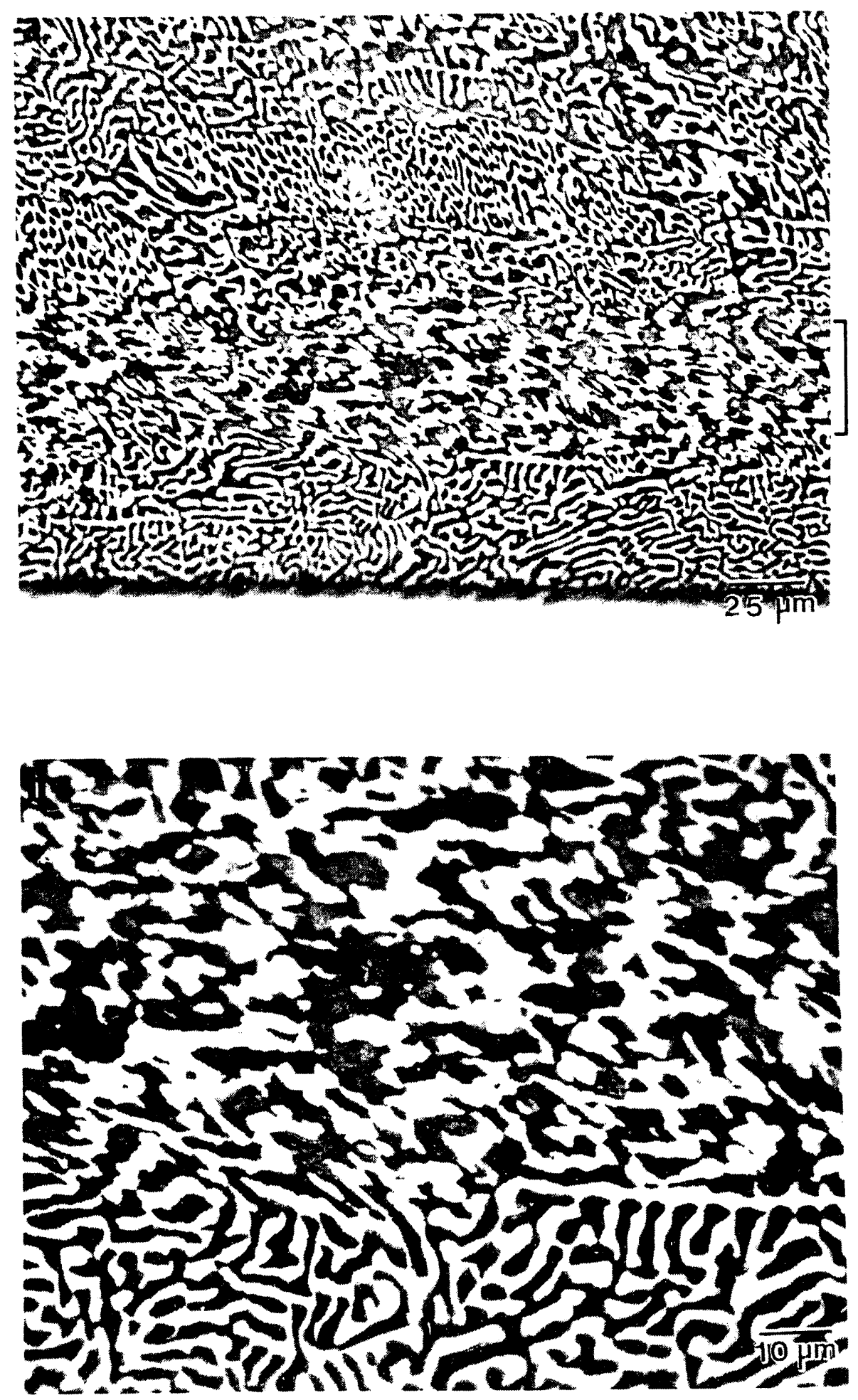

Figure 4.19 - Higher magnification micrographs of the repolished sample in Figure

4.18, showing the detail of the microstructural change. [XBB 923-1908A] 


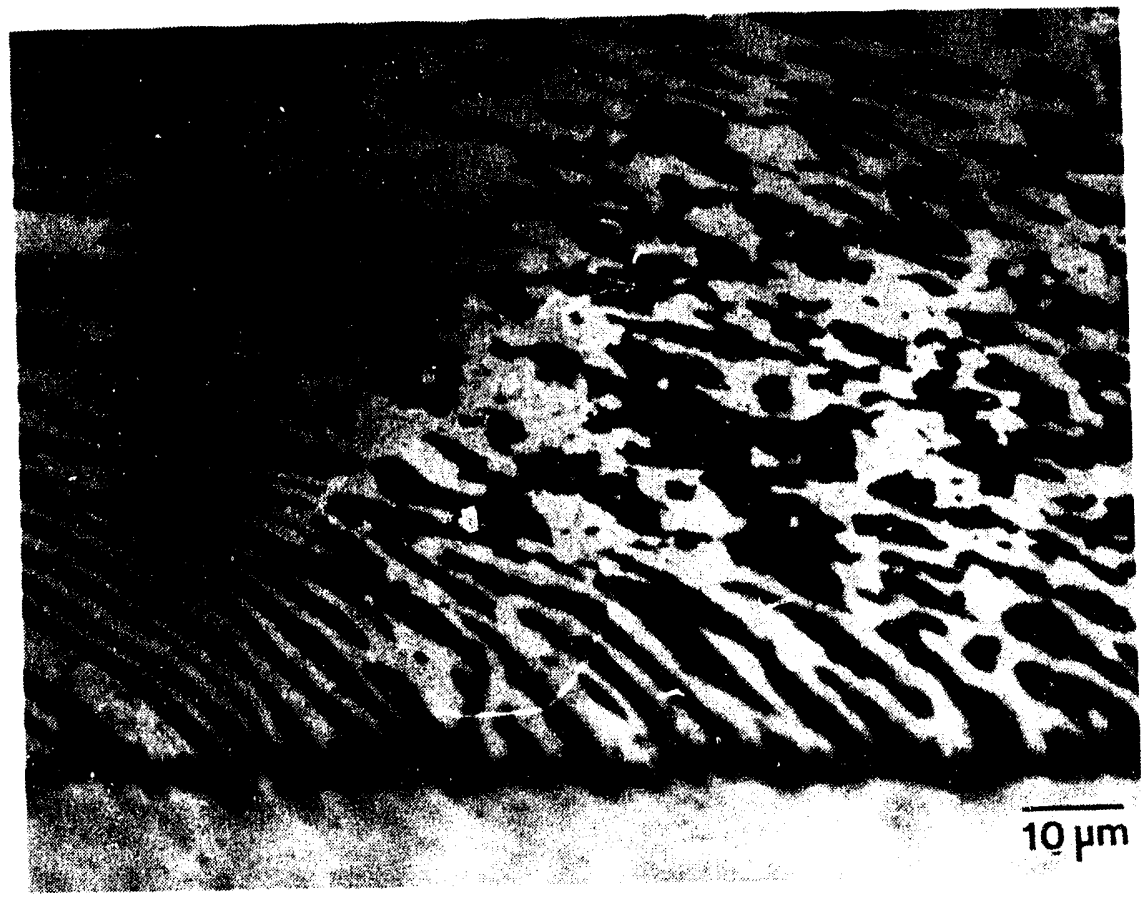

Figure 4.20-Optical micrograph of Bi-Sn sample tested at constant strain rate and repolished. [XBB 920-9580A] 


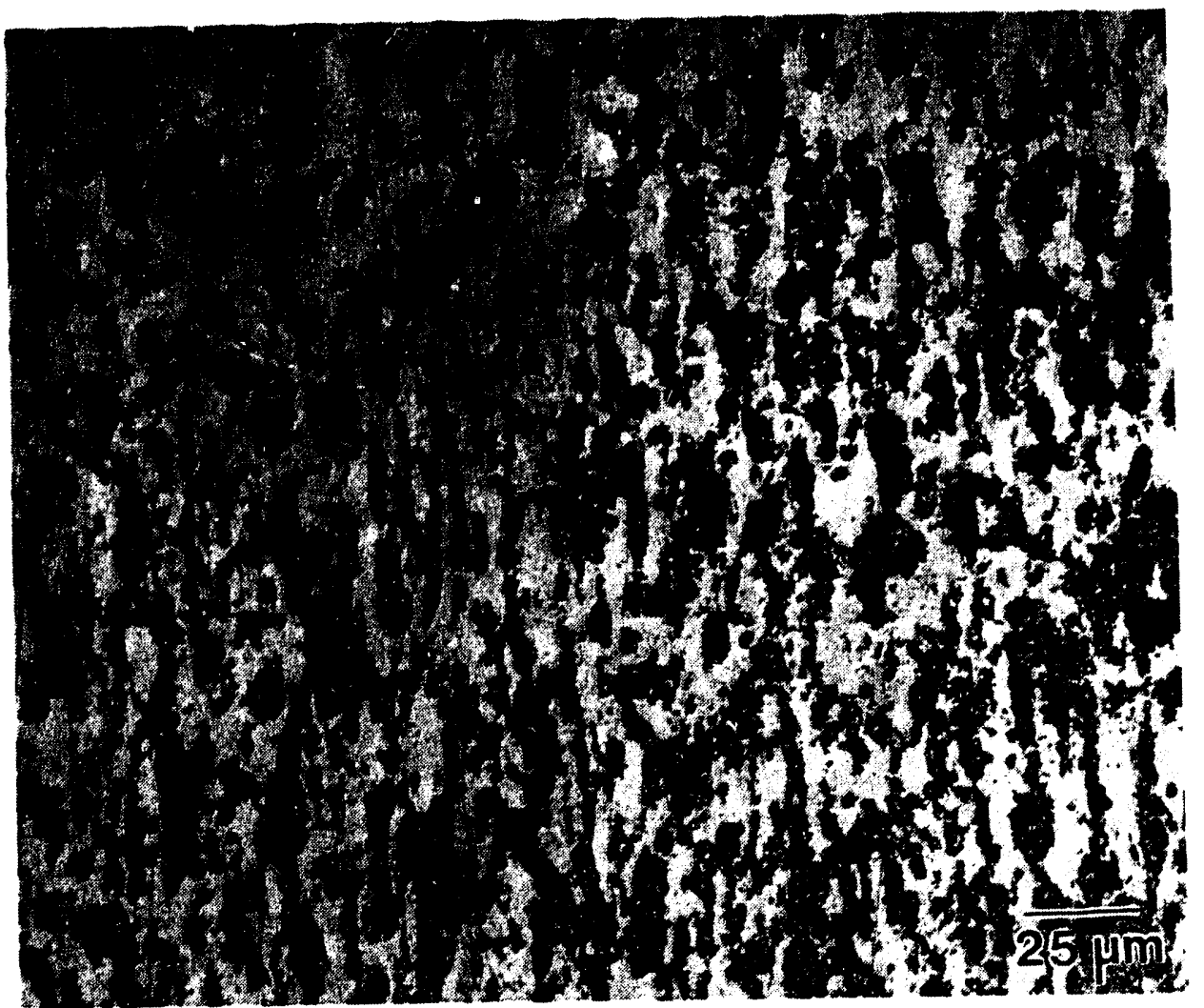

Figure 4.21 - Optical micrograph of deformed Bi-Sn bulk ingot. [XBB 9311-7268] 


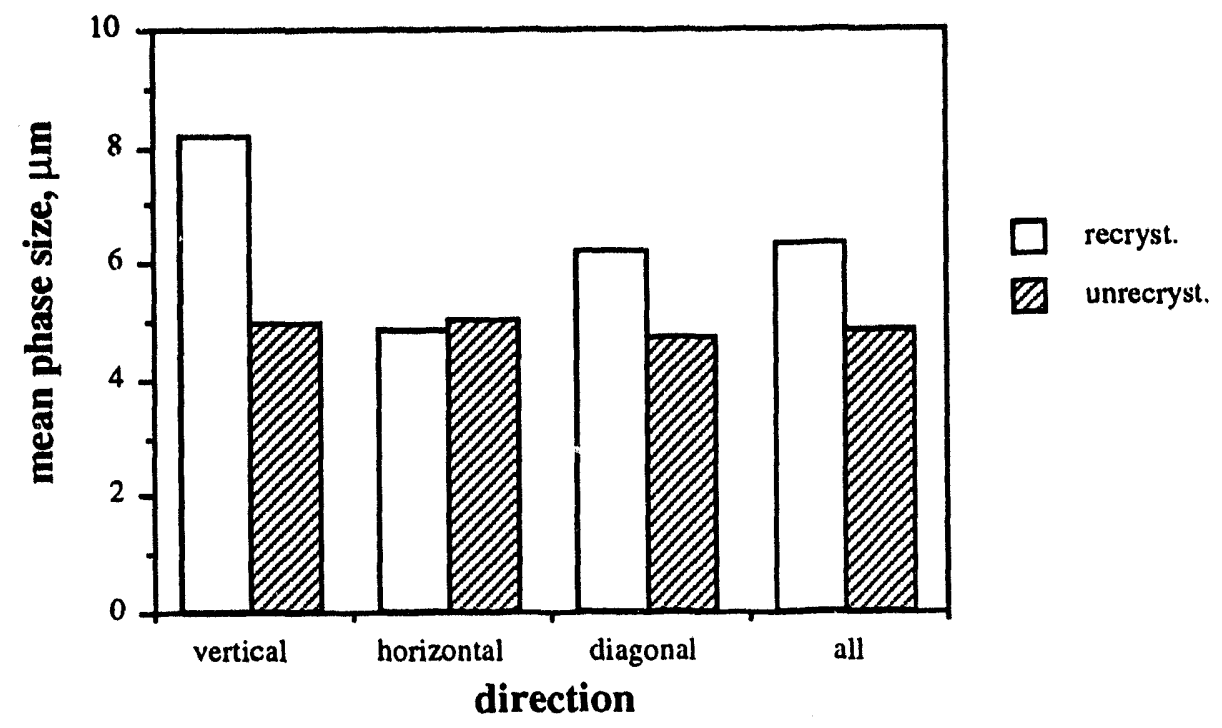

Figure 4.2z - Phase size in Bi-Sn ingot, comparing uncrystallized and recrystallized microstructures. The column "all" is an average of the other three columns. 


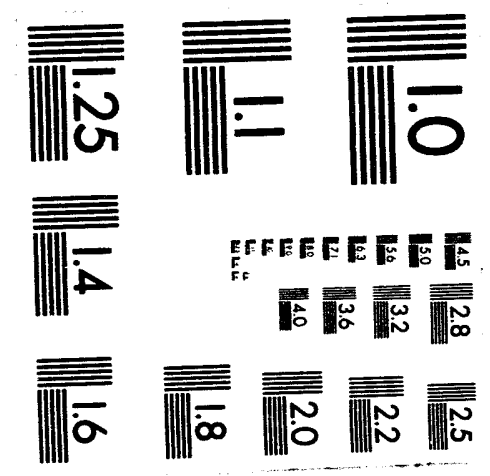



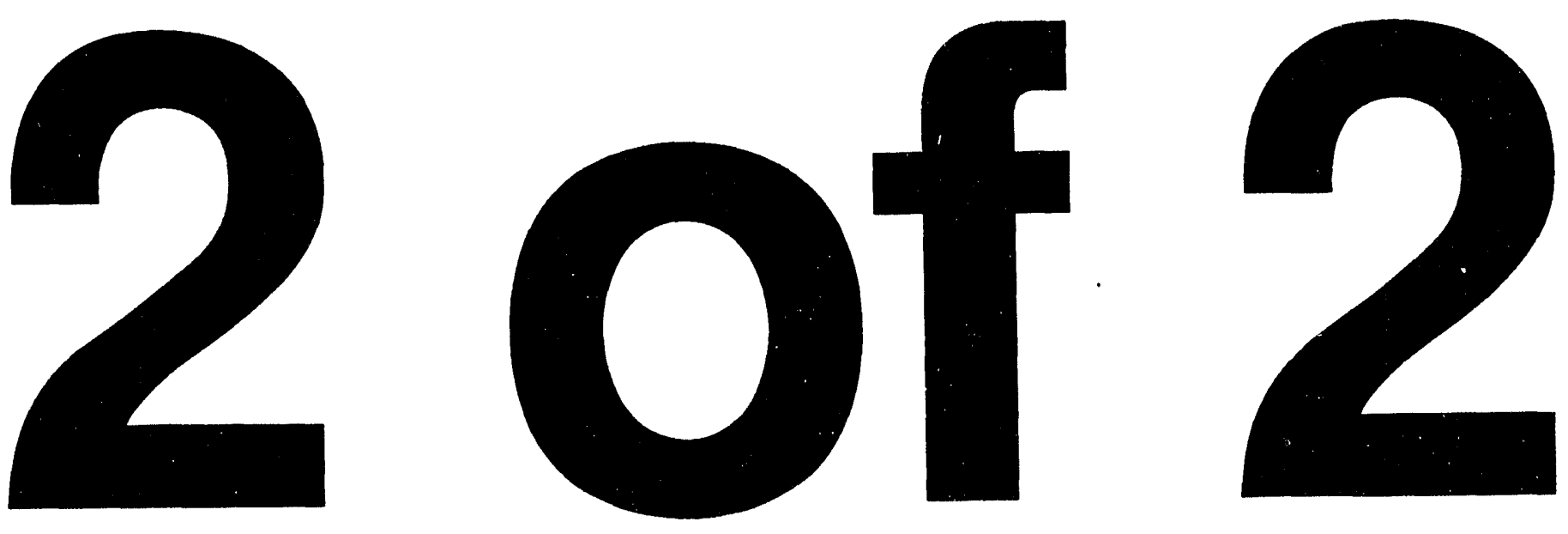

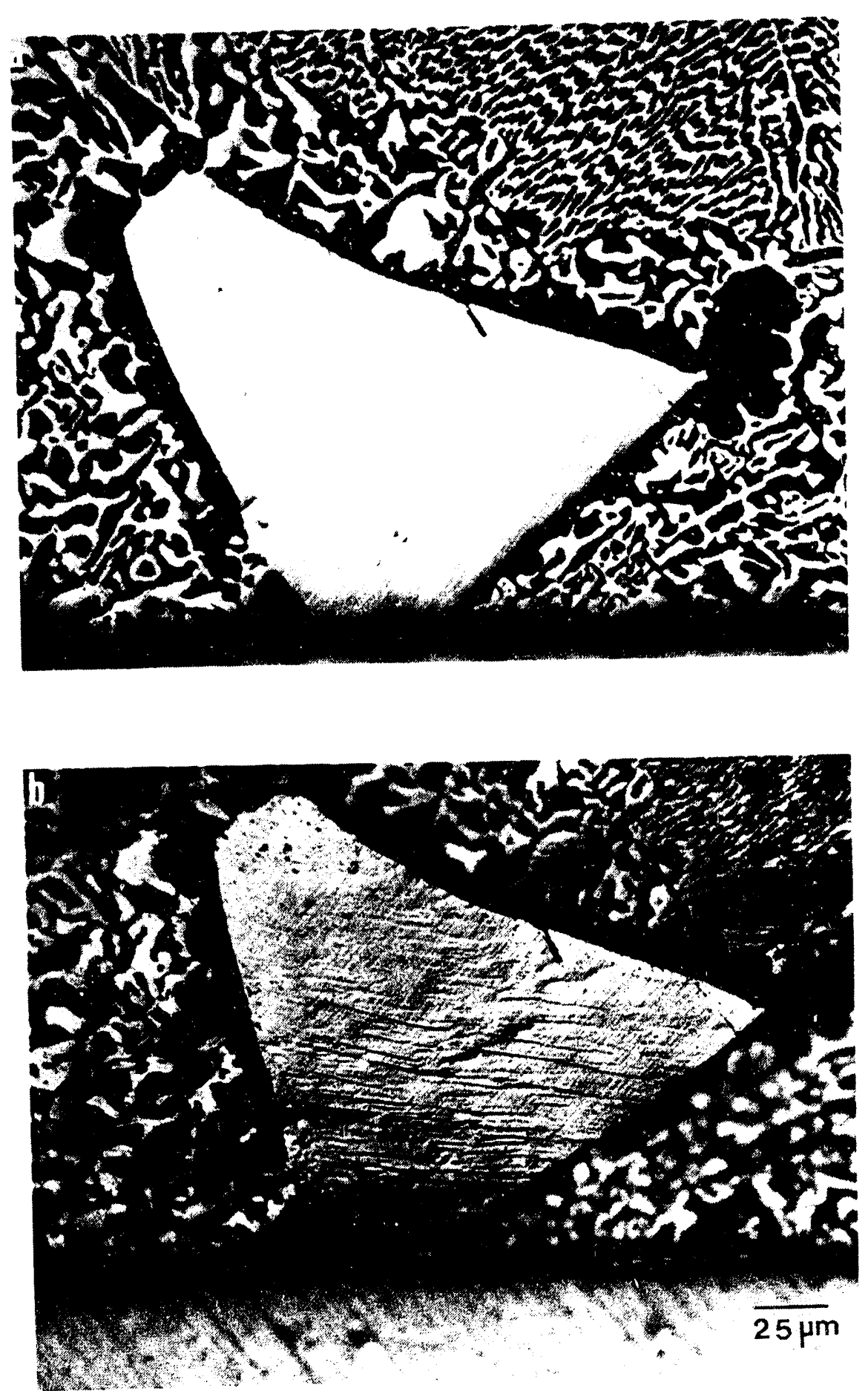

Figure 4.23 - Optical micrographs of Bi-Sn sample (a) untested and (b) tested, showing slip lines in large Bi particle. [XBB 920-9581A] 

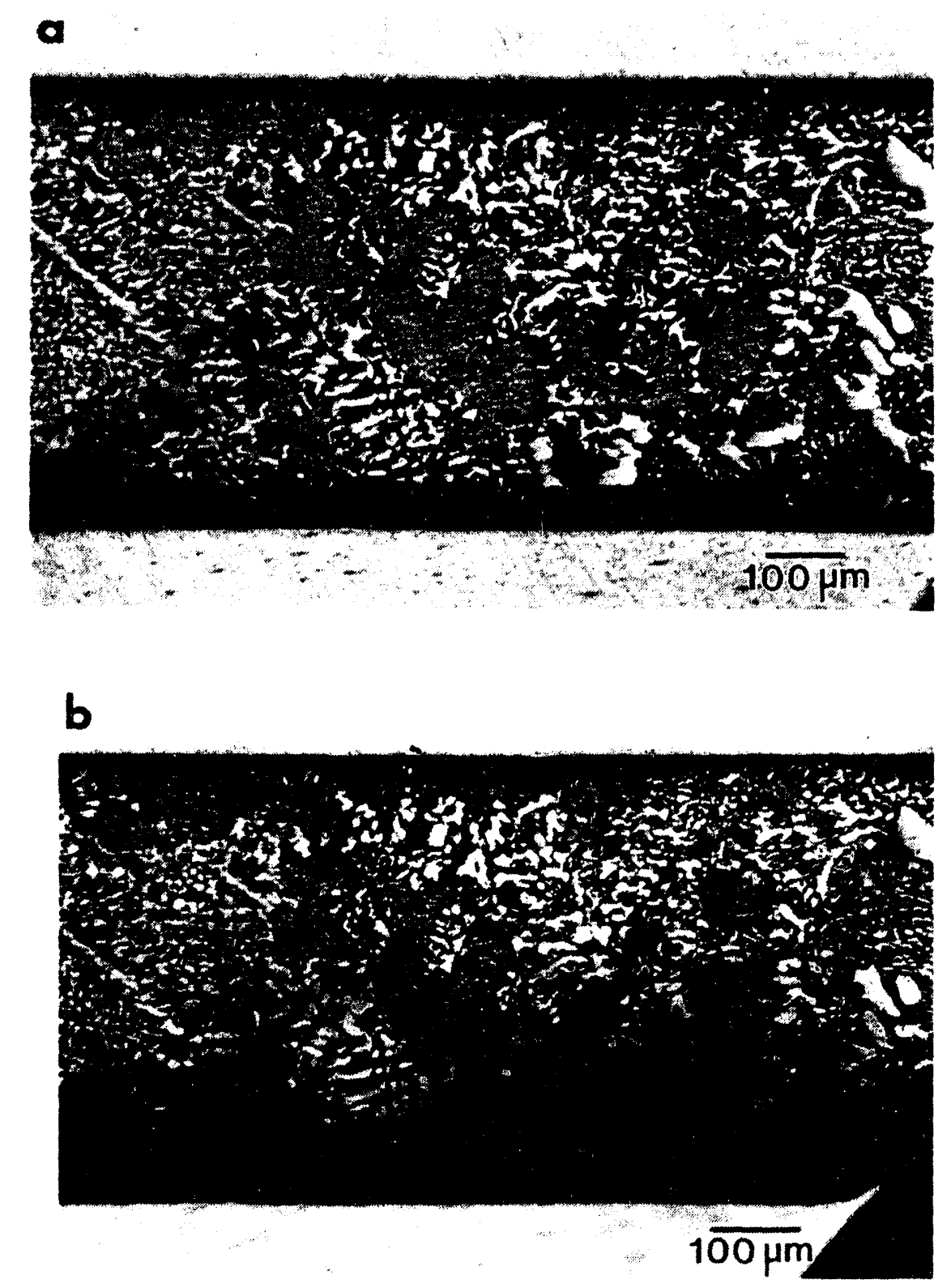

Figure 4.24 - Optical micrographs of In-Sn on Cu sample (a) before and (b) after testing. The dark regions show where deformation is concentrated. [XBB 938$5604 \mathrm{~A}]$ 


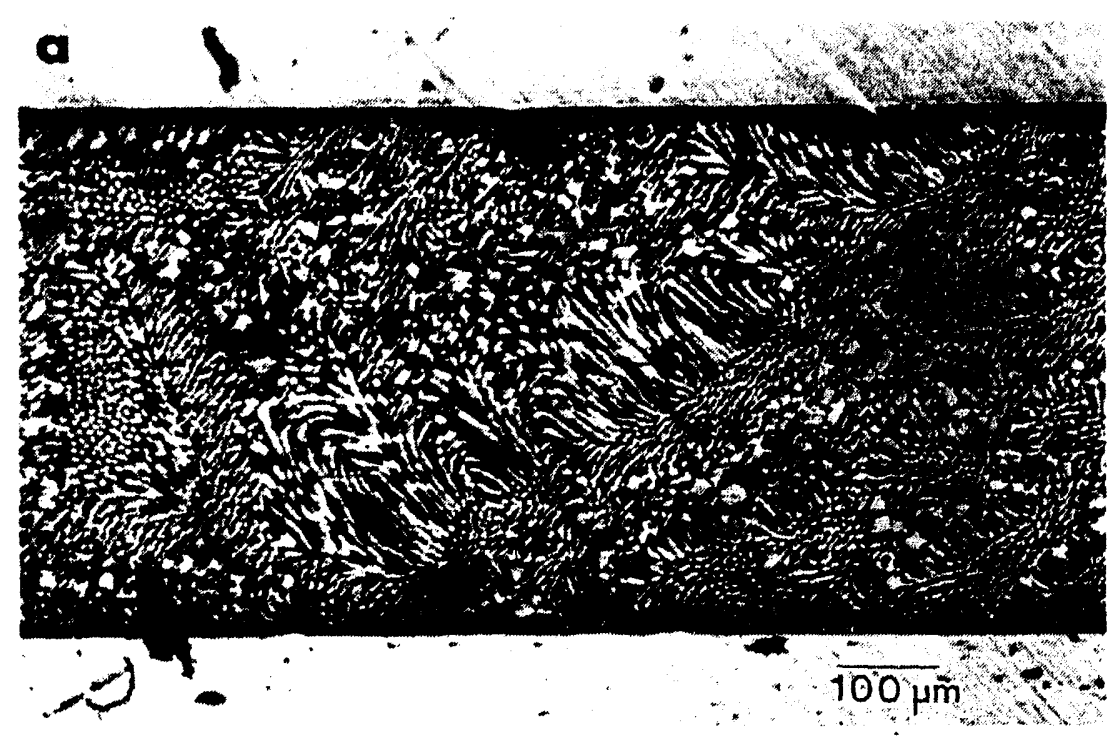

b

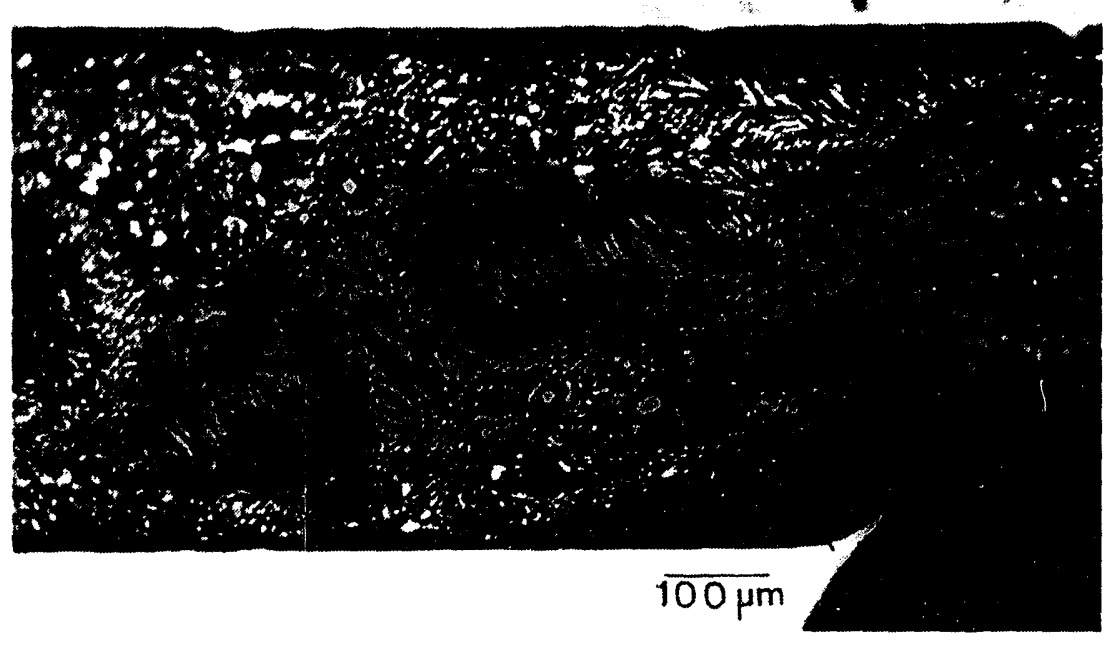

Figure 4.25 - Optical micrographs of In-Sn on Ni sample (a) before and (b) after testing. The dark regions show where deformation is concentrated. [XBB 939$5983 \mathrm{~A}]$ 


\section{[L9ZL-IIE6 ggX] 'səıensqnS !N (q) pue}

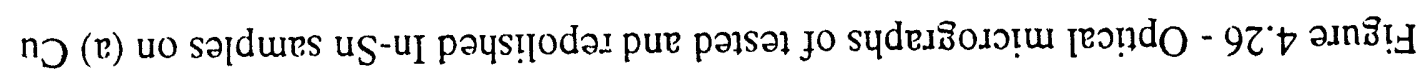

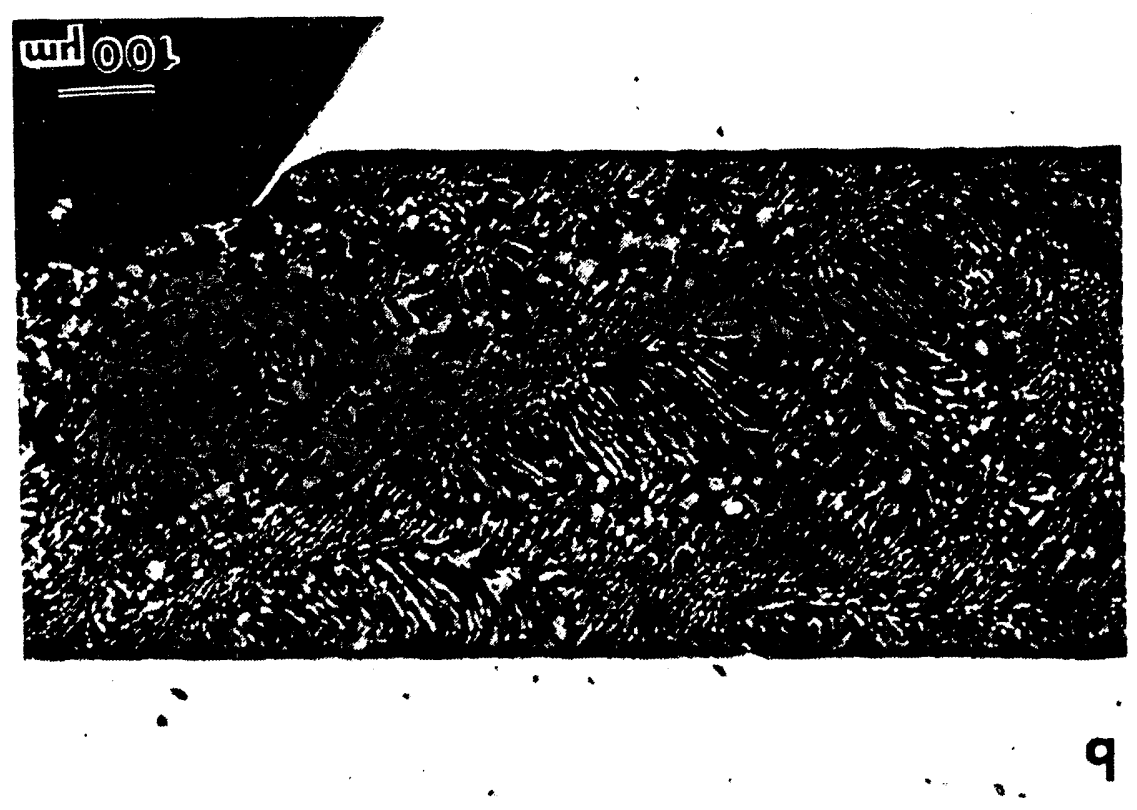

\section{wrt oOt}

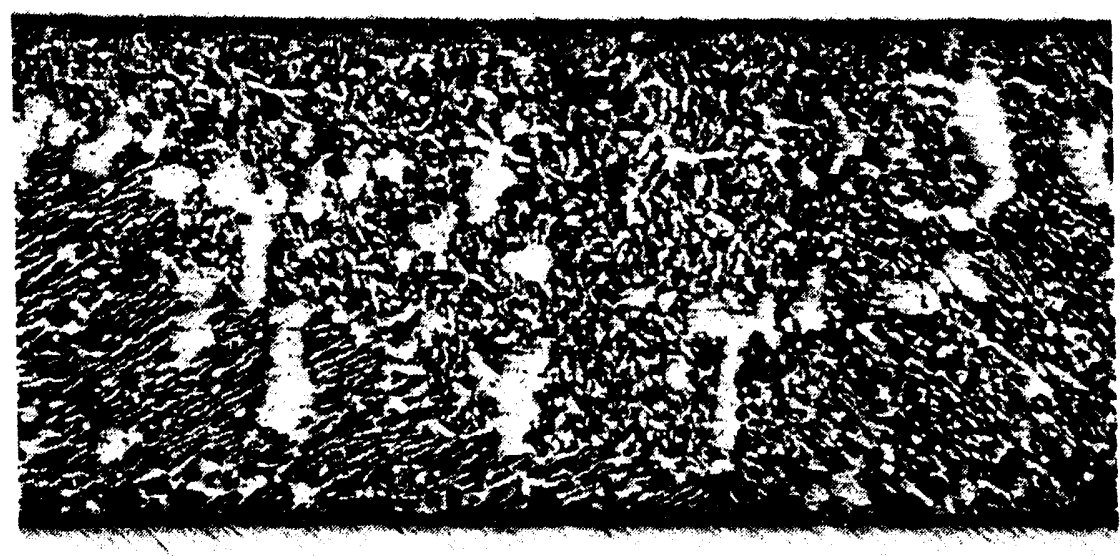

D 


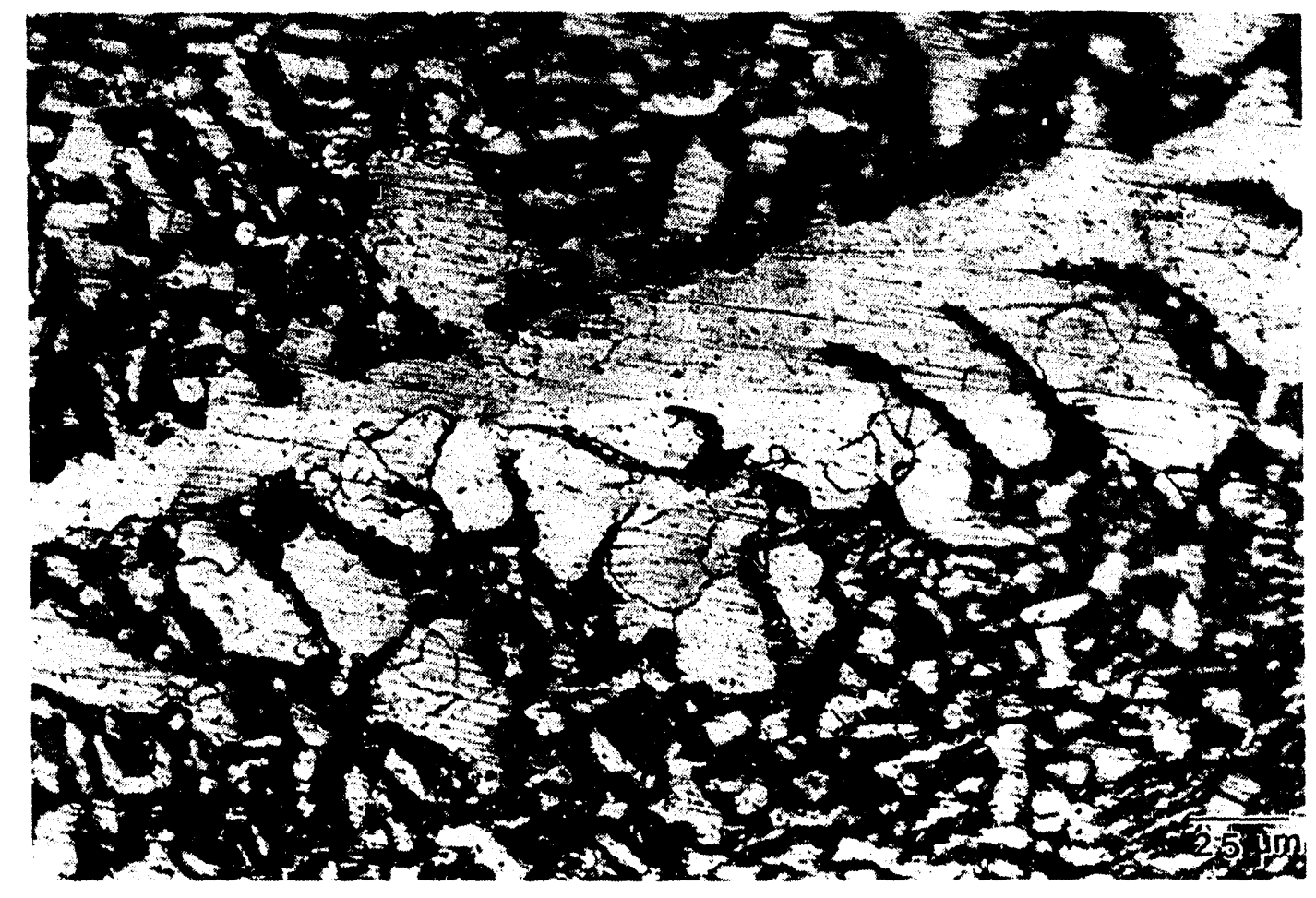

Figure 4.27 - Optical micrograph of $\gamma$ phase dendrite within tested In-Sn on Cu sample. The dark lines in the dendrite are assumed to be grain boundaries. [XBB 934-2400] 

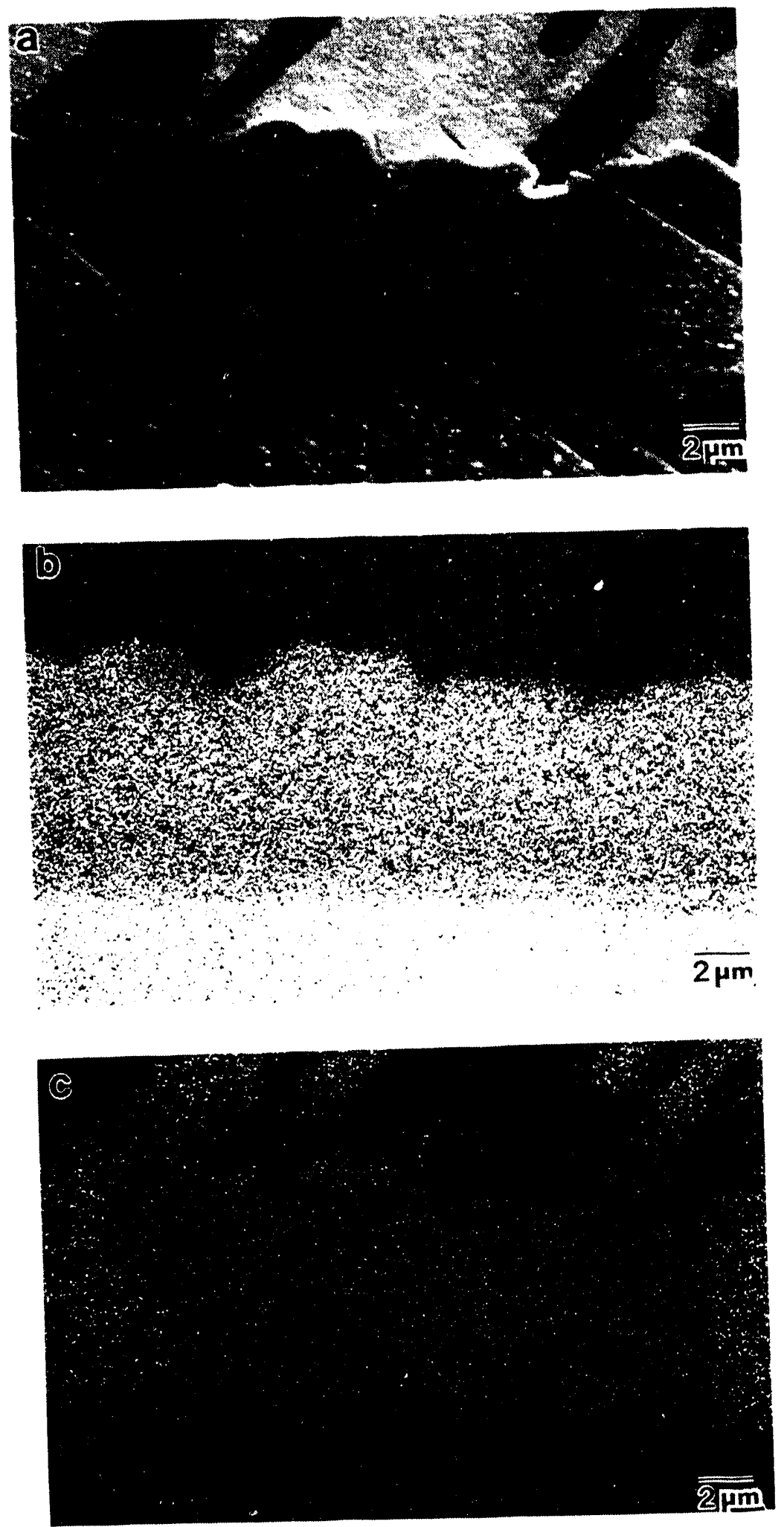

Figure 4.28 - SEM micrograph of Bi-Sn sample aged for 2 months at $1000^{\circ} \mathrm{C}$, and corresponding $\mathrm{X}$-ray images of (b) $\mathrm{Cu}$ and (c) Sn distribution. [XBB 9311-7266] 

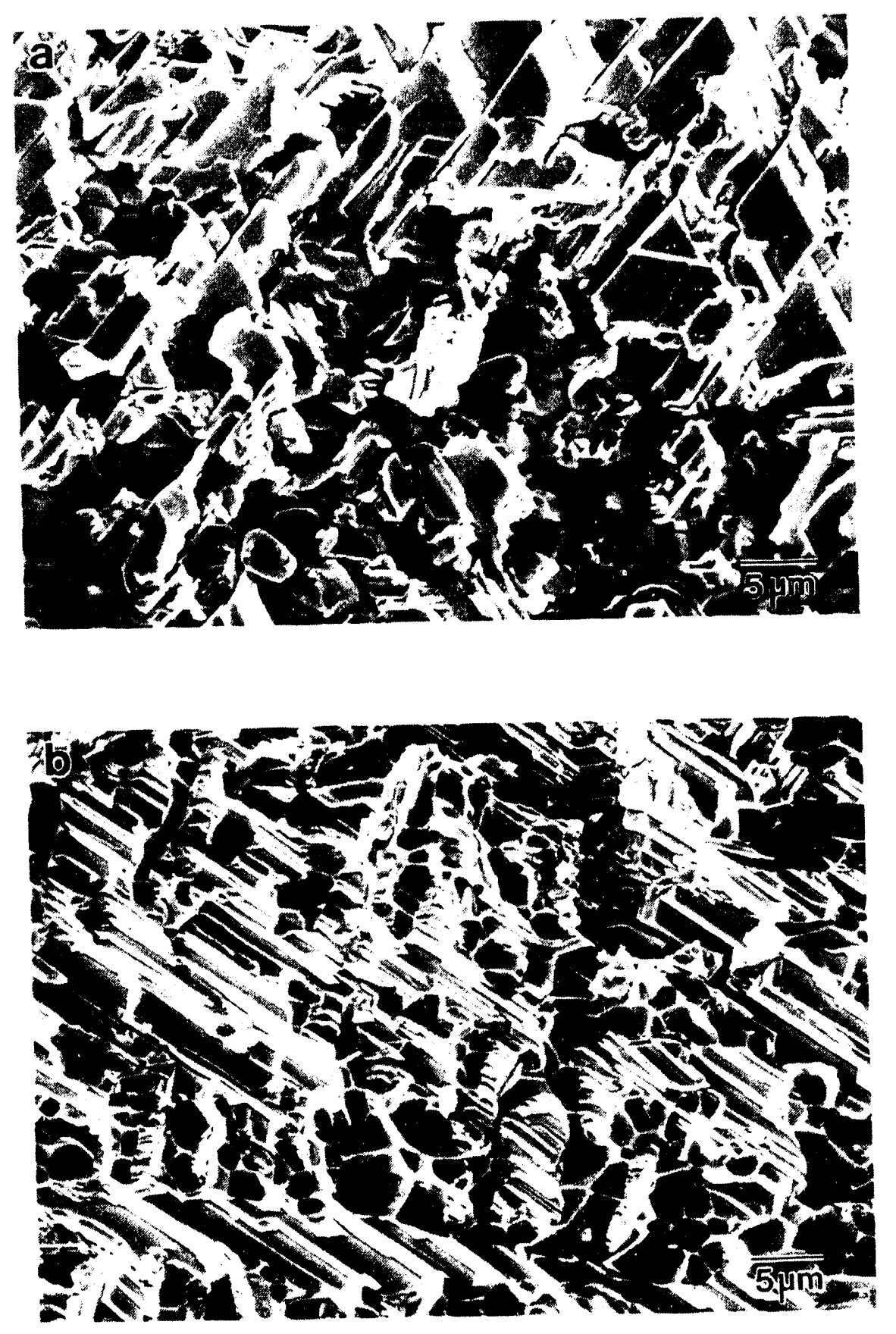

Figure 4.29 - SEM micrograph of fracture surfaces of Bi-Sn sample. (a) side 1, with Bi phase (faceted) and intermetallic particles, and (b) side 2, with Bi phase and dimples where intermetallic separated from surface. [XBB 9311-7265] 


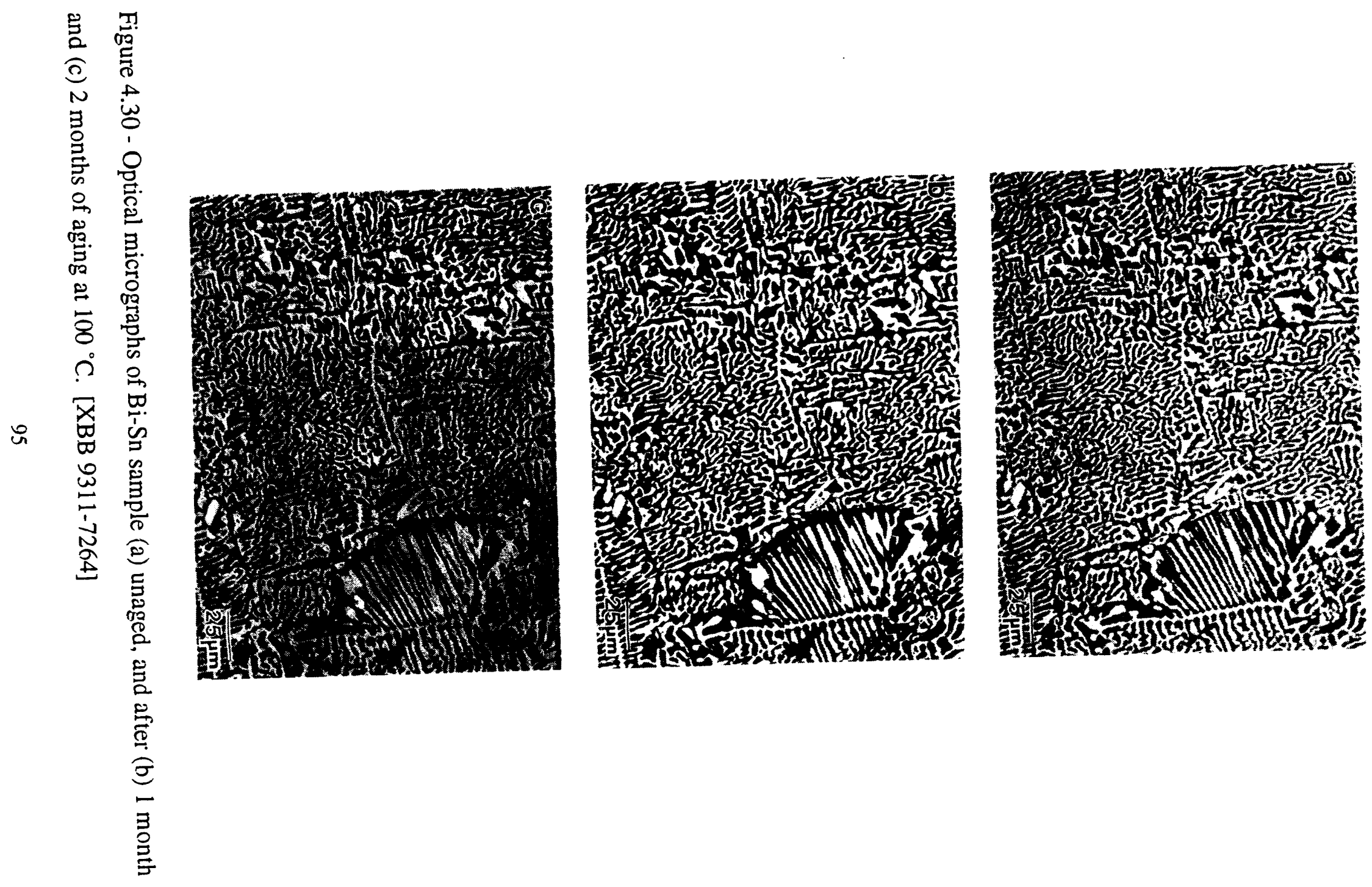




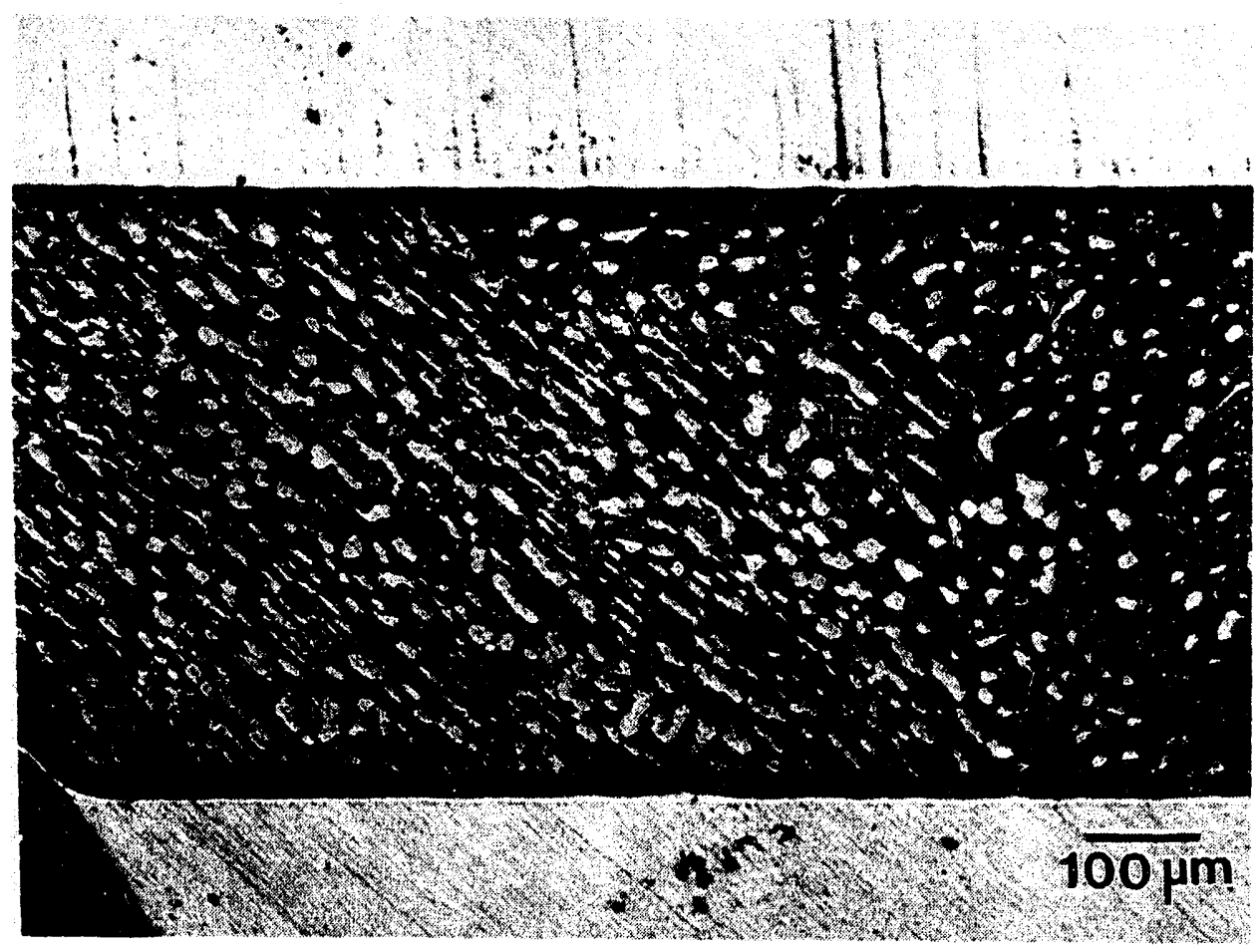

Figure 4.31 - Optical micrograph of In-Sn on Ni aged for 2 months at $811^{\circ} \mathrm{C}$. [XBB 938-5605] 


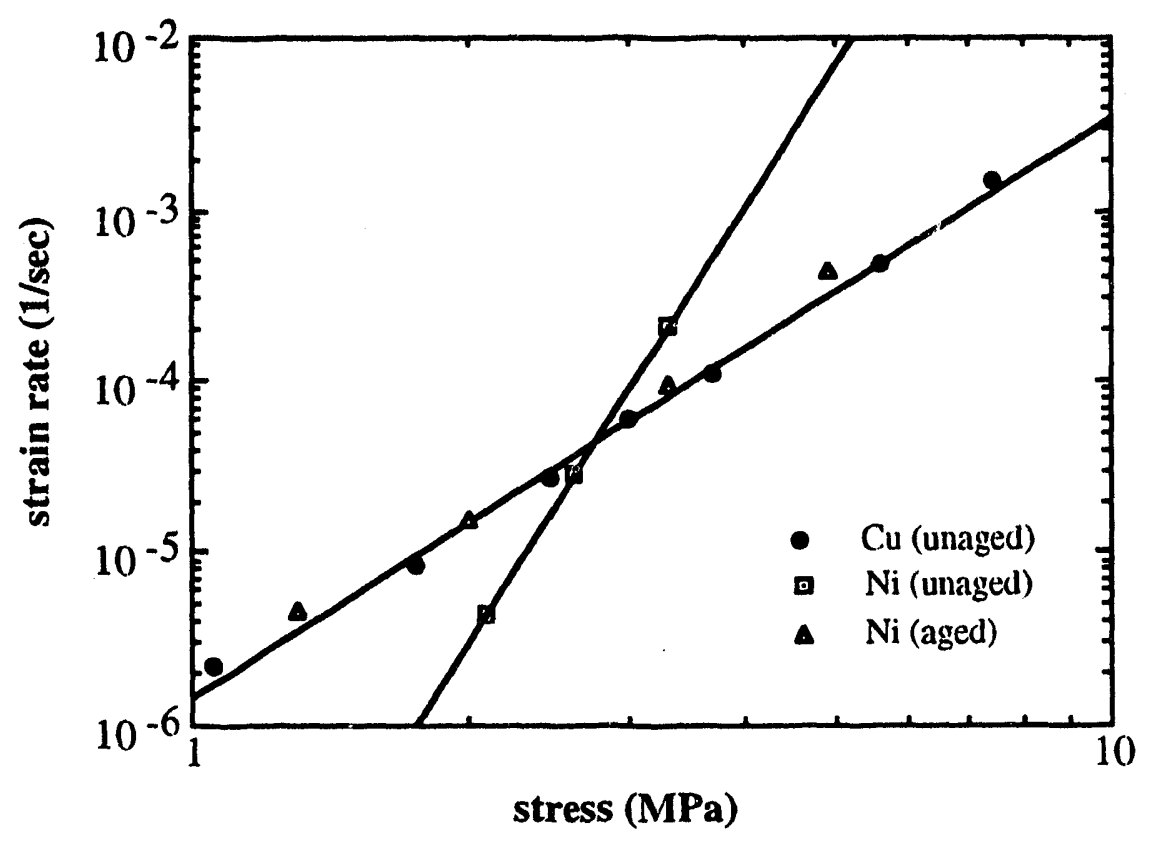

Figure 4.32 - Creep data at $65^{\circ} \mathrm{C}$ for unaged $\mathrm{In}-\mathrm{Sn}$ on $\mathrm{Cu}$, unaged $\mathrm{In}-\mathrm{Sn}$ on $\mathrm{Ni}$, and aged In-Sn on Ni. 


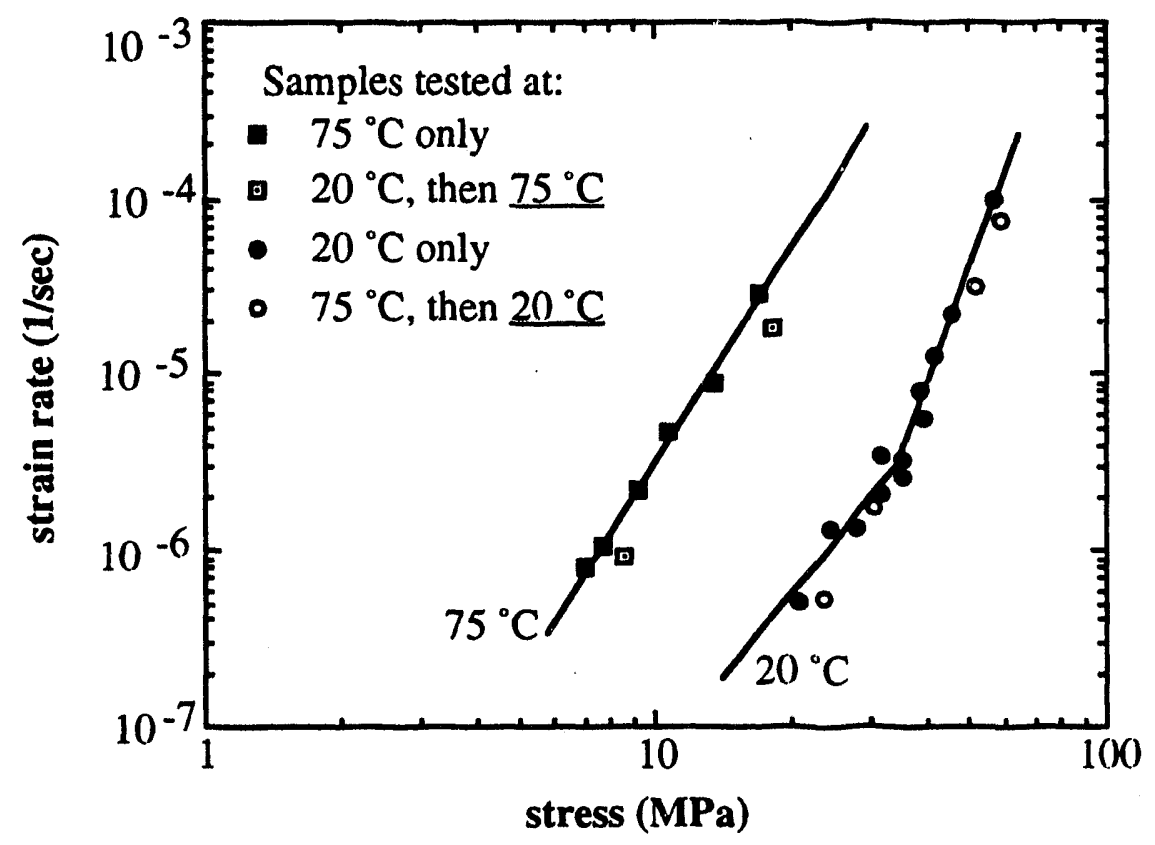

Figure 4.33 - Creep data for Bi-Sn. For samples tested at two temperatures, data plotted are from the temperatures underlined. 


\begin{tabular}{|c|c|c|}
\hline Alloy, region & n & Q.eV \\
\hline Bi-Sn, high T & 4.0 & 0.88 \\
\hline Bi-Sn, low T, low $\tau$ & 3.2 & 0.65 \\
\hline Bi-Sn, low T, high $\tau$ & 7.3 & 0.88 \\
\hline Bi-Sn, all data & 4.9 & 0.79 \\
\hline In-Sn/Cu, all data & 3.3 & 0.73 \\
\hline In-Sn/Ni, all data & 4.9 & 1.04 \\
\hline $\mathrm{Sn}-\mathrm{Pb}^{*}$ & 5.5 & 0.92 \\
\hline
\end{tabular}

Table 4.1. Calculated activation energies and stress exponents for Bi-Sn and In-Sn 


\begin{tabular}{lcccc} 
Strain rate & Stress. $\mathrm{MPa}$ & $\mathrm{T} .{ }^{\circ} \mathrm{C}$ & Strain. \% & Recrystallized? \\
\hline $1.09 \times 10^{-5}$ & 18.2 & 65 & 9 & no \\
$1.29 \times 10^{-5}$ & 42.0 & 20 & 13 & no \\
$4.72 \times 10^{-6}$ & 10.8 & 75 & 16 & no \\
$4.2 \times 10^{-4}$ & 39.6 & 65 & 18 & no \\
$4.98 \times 10^{-5}$ & 23.5 & 65 & 19 & no \\
$2.44 \times 10^{-5}$ & 29.8 & 40 & 24 & no \\
$3.33 \times 10^{-7}$ & 18.7 & 20 & 27 & yes \\
$4.11 \times 10^{-6}$ & 35.6 & 20 & 44 & yes \\
$4.0 \times 10^{-4}$ & 60.7 & 20 & 80 & yes \\
$4.2 \times 10^{-4}$ & 50.6 & 40 & 100 & yes \\
$2.6 \times 10^{-4}$ & 58.8 & 20 & 147 & yes
\end{tabular}

Table 5.1 Total strain versus recrystallization of $\mathrm{Bi}-\mathrm{Sn}$ 

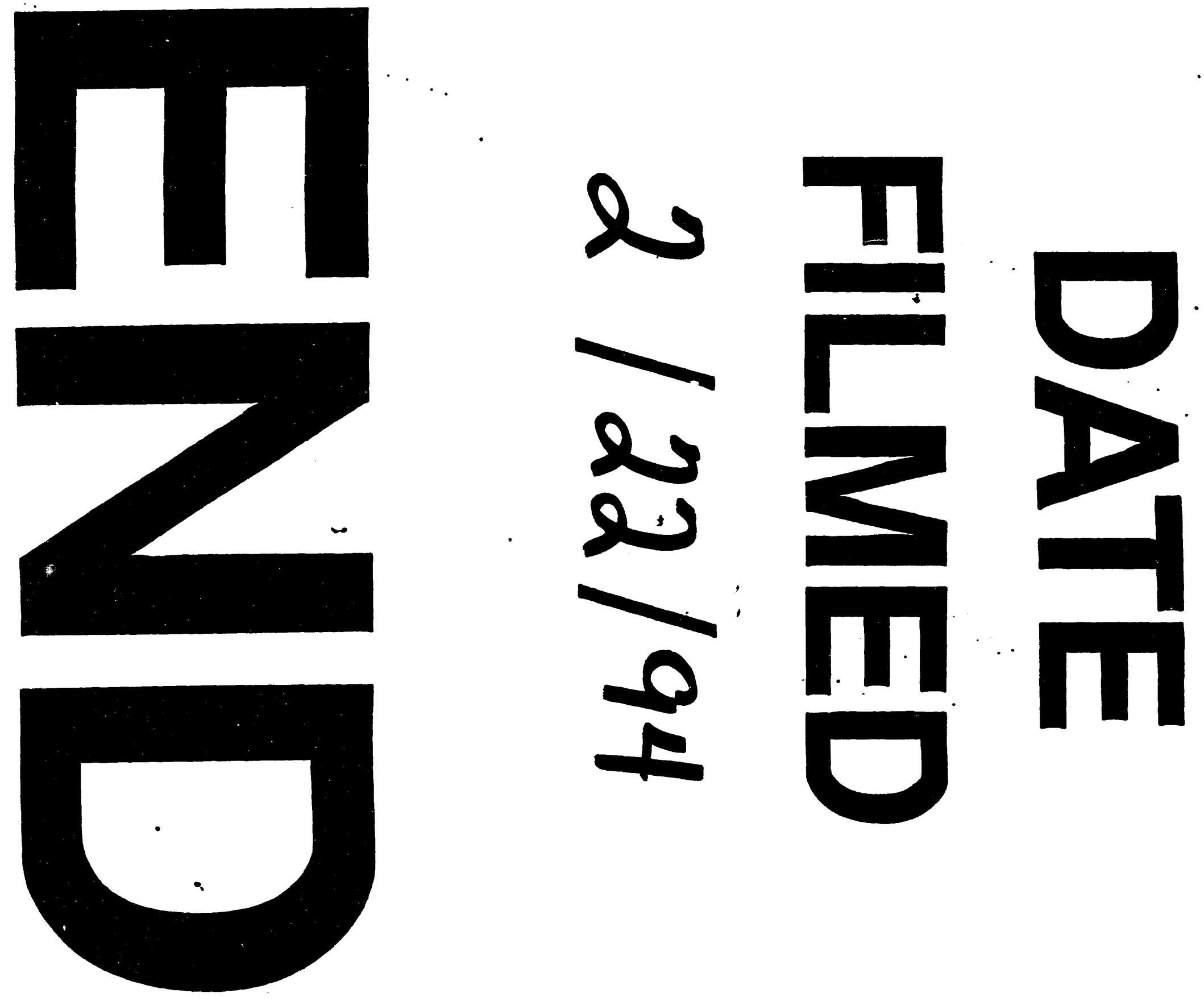


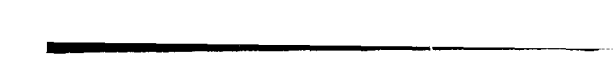

.

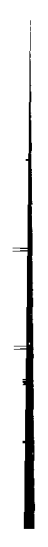

